\title{
Kiára Mendonça
}

Engenheiro Agrônomo

Plantas apícolas e caracterização físico-química e polínica de mel produzido por Apis mellifera L. em área de cerrado do município de Itirapina/SP

Orientador:

Prof. Dr. LUIS CARLOS MARCHINI

Dissertação apresentada para obtenção do título de Mestre em

Ciências. Área de concentração: Entomologia

Piracicaba

2005 


\section{Dados Internacionais de Catalogação na Publicação (CIP)}

DIVISÃO DE BIBLIOTECA E DOCUMENTAÇÃO - ESALQ/USP

\section{Mendonça, Kiára}

Plantas apícolas e caracterização físico-quimica e polínica de mel produzido por Apis mellifera L. em área de cerrado do município de Itirapina/SP / Kiára Mendonça. - Piracicaba, 2005.

84 p. : il.

Dissertação (Mestrado) - - Escola Superior de Agricultura Luiz de Queiroz, 2005.

1. Abelha 2. Cerrado 3. Mel 4. Pólen 5. Planta melifera I. Título

CDD 638.1

Permitha aropla totalou parcial destedocumento desde que citada a fonte-- o autor" 
Aos meus pais, Paulo e Regina, e à minha irmã, Aluanna, pelo apoio, amor e dedicação em todas as etapas de minha vida. 


\section{Agradecimentos}

À Escola Superior de Agricultura "Luiz de Queiroz" ESALQ/USP, pelo apoio concedido por meio de sua estrutura, em especial ao Departamento de Entomologia, Fitopatologia e Zoologia Agrícola, pela oportunidade de realização do curso.

Ao Prof. Dr. Luís Carlos Marchini pela orientação, amizade, confiança e, principalmente, apoio concedido em todos os momentos.

Aos demais professores do curso de pós-graduação em Entomologia, pelos ensinamentos transmitidos.

À Dra. Augusta Carolina de C. C. Moreti pela amizade, atenção, disposição e colaboração, principalmente nas análises polínicas.

À Dra. Ortrud Monika Barth da FIOCRUZ pelo auxílio nas análises polínicas.

À Dra. Denise Zancheta e à todos os funcionários da Estação Experimental de Itirapina/SP, Divisão de Florestas e Estações Experimentais do Instituto Florestal, pela atenção e auxílio.

Ao Prof. Dr. Vinícius Castro Souza do Laboratório de Sistemática Vegetal da ESALQ/USP pela identificação das espécies vegetais.

Aos companheiros e amigos do Laboratório de Insetos Úteis: Bruno, Daniela, Geni, Gustavo, Márcia, Vagner, Vitor, Kogu, Nona e Precoce, pela colaboração, auxílio, apoio nas análises, sugestões e amizade.

Aos colegas, amigos e funcionários do Setor de Entomologia, pelo convívio, amizade e simpatia. Especialmente ao colega Gilberto pelo auxilio na elaboração do "abstract", e às amigas, Maria Fernanda e Moréia, pela disposição e por sempre estarem ao meu lado. 
Aos meus familiares, especialmente aos meus avós Paulo e Léa, às minhas tias Juliana, Anna e Beth, e à minha prima Nani, pelo incentivo, apoio e carinho.

Às irmãs de coração da República Kza Verde, especialmente às companheiras de ano: BicuDoce, Di-Lúvio, Noturna e Voazã, pela amizade sincera e momentos de alegria.

Aos amigos: Pioio, Fulano, Gorgonzola, Flávia, Uau, Ana Gabriela, Claudia, Melissa e Wyratan, pelo companheirismo, atenção e amizade.

Aos amigos, que mesmo longe, sempre estiveram dispostos em apoiar-me: Matinê, Marocas, Santo, Zaga, Karina, Xafariz, Malufinho, Fekal, Lâmina e Neston.

Às bibliotecárias da ESALQ pela colaboração nas pesquisas e correção das referências bibliográficas.

À Fundação de Amparo à Pesquisa do Estado de São Paulo (FAPESP), pelo apoio ao projeto e bolsa concedida; e ao acessor responsável, pela atenção, correções e sugestões valiosas despendidas a esta pesquisa. 


\section{SUMÁRIO}

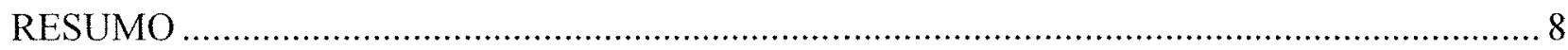

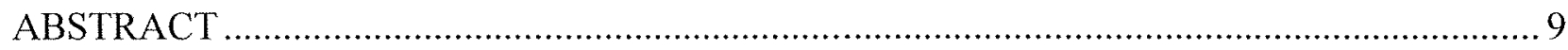

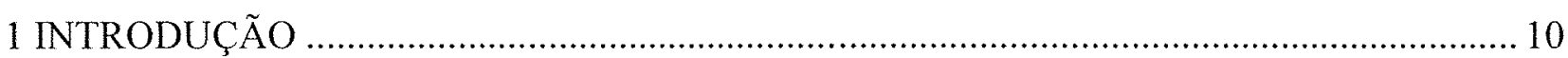

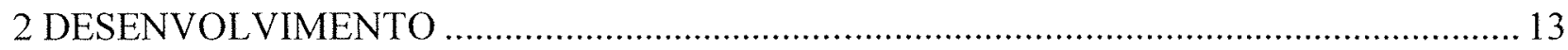

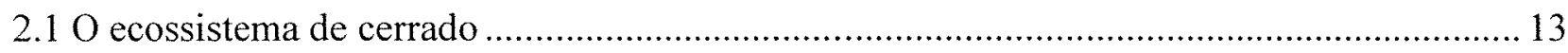

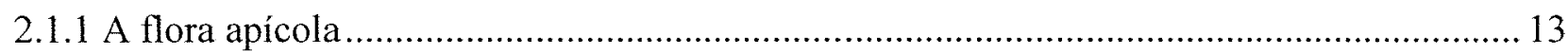

2.1.2 Clima

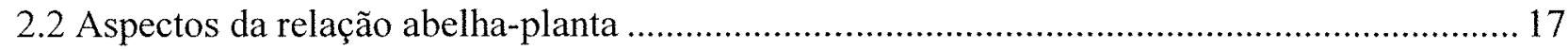

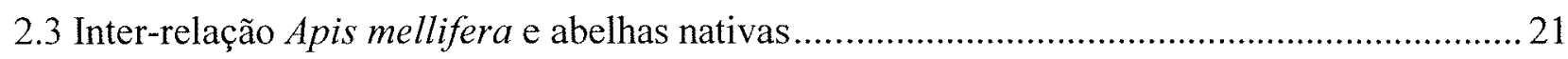

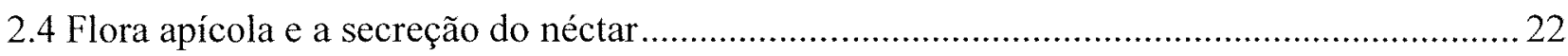

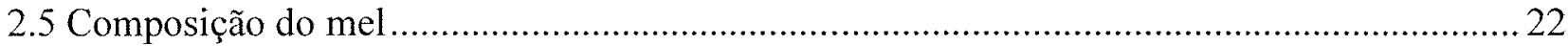

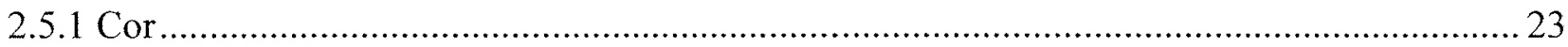

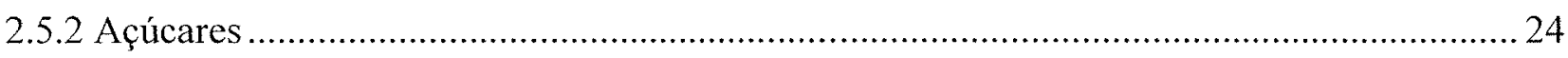

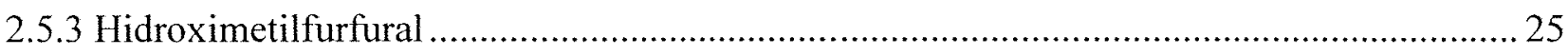

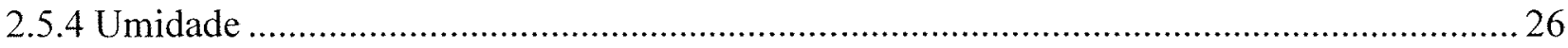

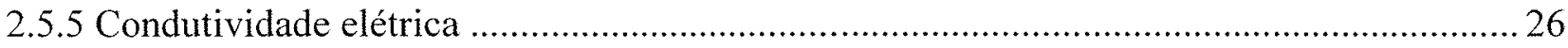

$2.5 .6 \mathrm{pH}$

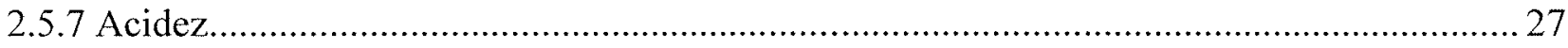

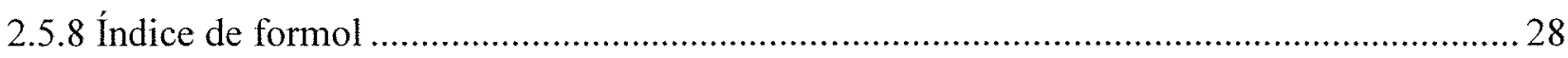

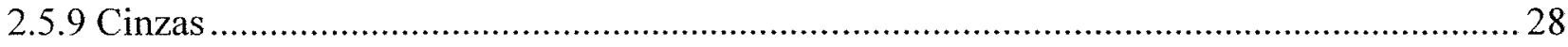

2.5.10 Proteína

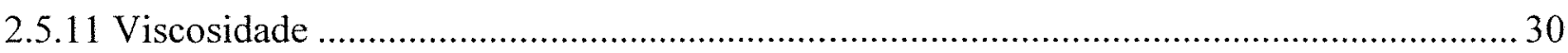

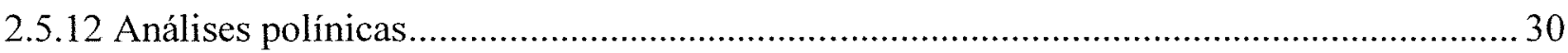

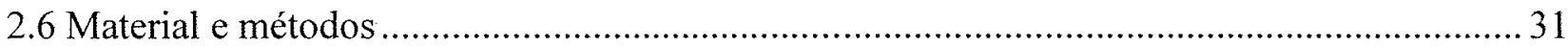

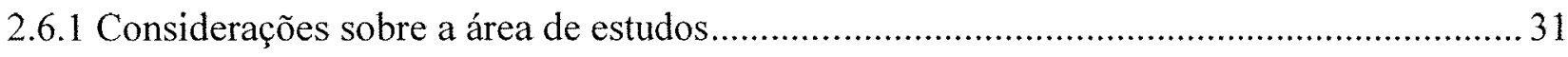

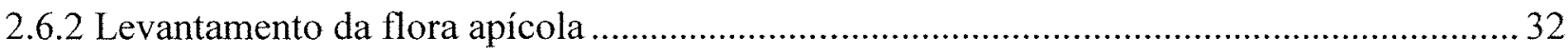

2.6.3 As colônias de $A$. mellifera utilizadas no estudo..................................................................... 33

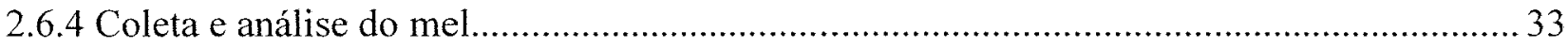

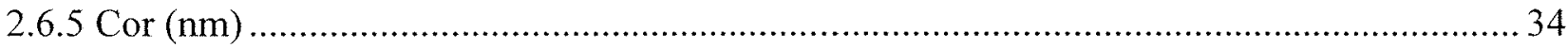

2.6.6 Açúcares redutores totais (AT), açúcares redutores (AR) e sacarose aparente (\%).............. 34

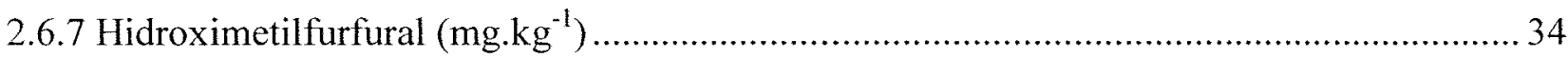




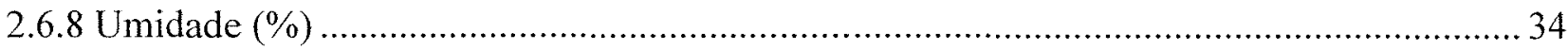

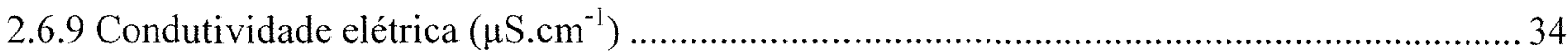

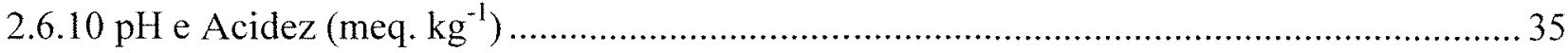

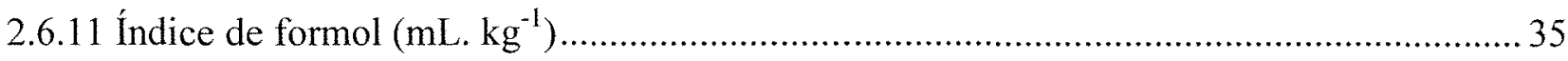

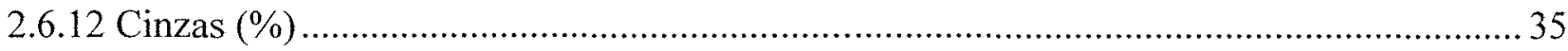

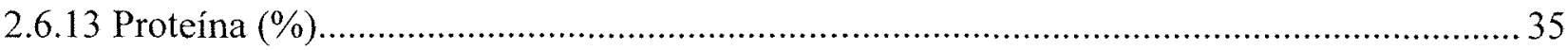

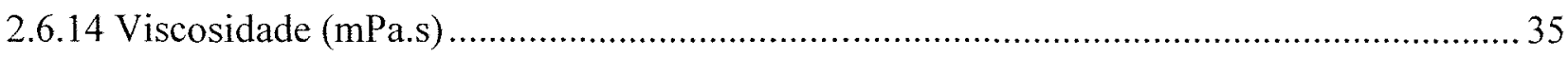

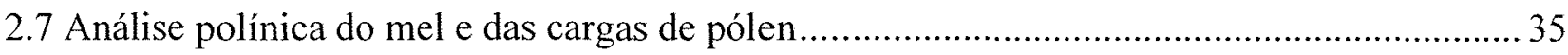

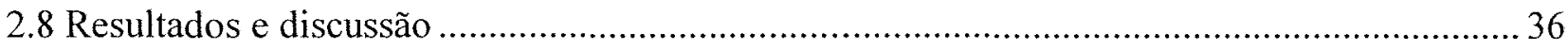

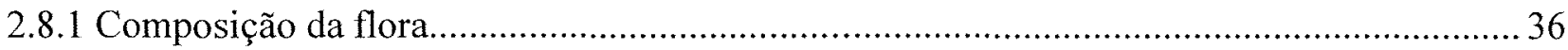

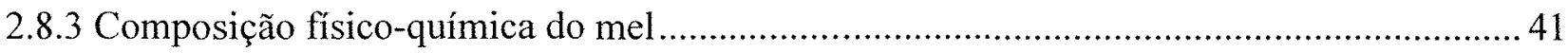

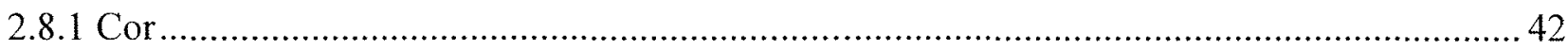

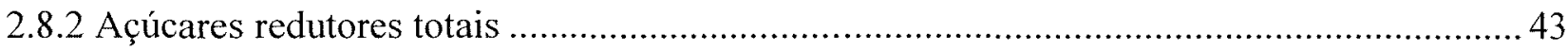

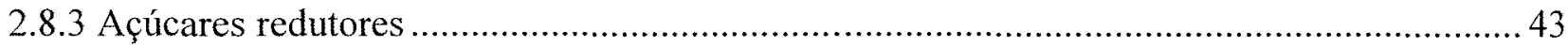

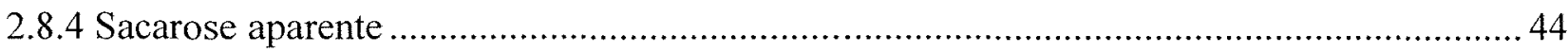

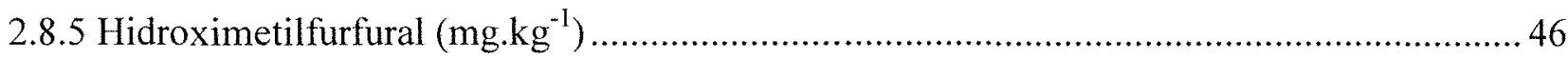

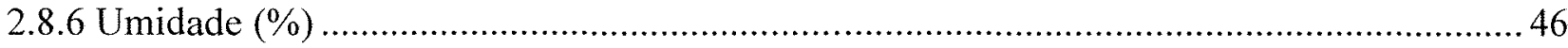

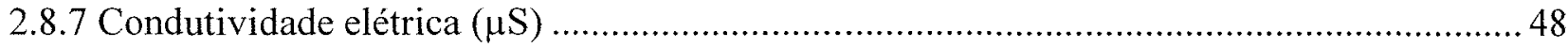

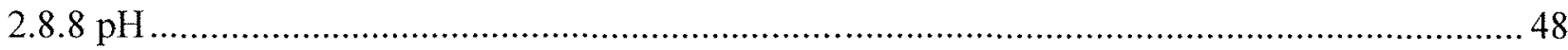

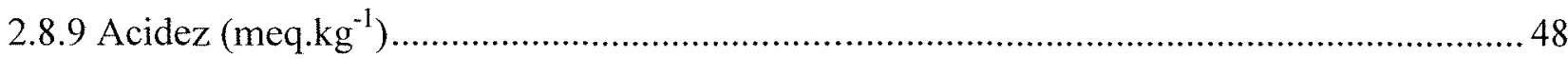

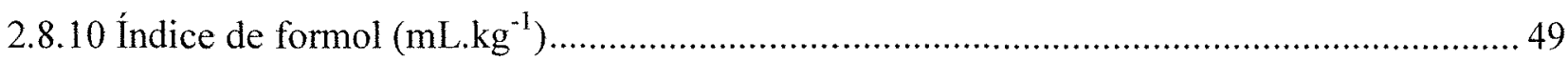

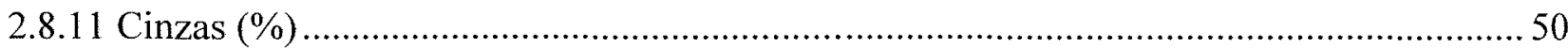

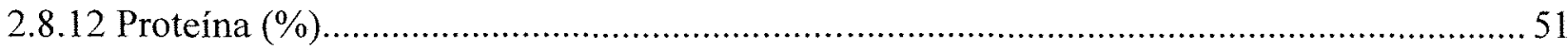

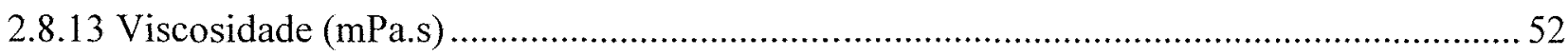

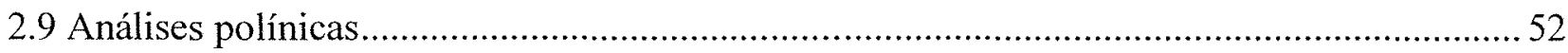

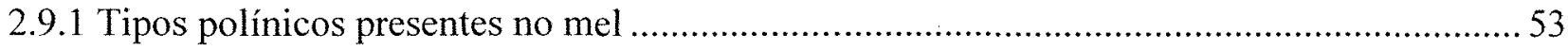

2.9.2 Tipos polínicos presentes nas cargas de pólen ............................................................... 55

3 CONCLUSÕES

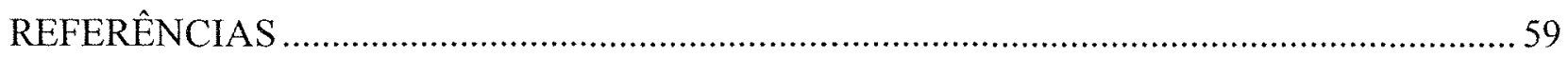

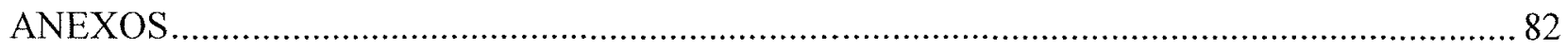




\section{RESUMO}

\section{Plantas apícolas e caracterização físico-química e polínica de mel produzido por Apis mellifera L. em área de cerrado do município de Itirapina/SP}

O presente trabalho teve como objetivos conhecer a composição da flora apícola de uma área de cerrado da Estação Experimental de Itirapina, unidade da Divisão de Florestas e Estações Experimentais do Instituto Florestal, no município de Itirapina/SP (22 $14^{\prime} \mathrm{S}$ e $\left.47^{\circ} 49^{\prime} \mathrm{W}\right)$, determinar as características físico-químicas e polínicas do mel produzido e identificar o pólen coletado por Apis mellifera no local. Essas informações contribuem para o conhecimento do potencial de exploração da apicultura em áreas remanescentes de cerrado, como alternativa para o desenvolvimento auto-sustentável, promovendo a preservação destes ambientes. As plantas em florescimento foram coletadas quinzenalmente de dezembro/2004 a novembro/2005, ao longo de uma trilha com $3 \mathrm{~km}$ de extensão. As amostras de pólen foram coletadas quinzenalmente de dezembro/2004 a novembro/2005, e as amostras de mel foram coletadas mensalmente durante o mesmo período, em cinco colméias de $A$. mellifera instaladas na mesma área. A flora apícola foi representada por 233 indivíduos pertencentes a 79 espécies, 57 gêneros e 33 famílias. Pelas análises polínicas dos méis foram considerados como espécies vegetais dominantes Eucaliptus sp (Myrtaceae) e Citrus sp. (Rutaceae). Já para as amostras do pólen coletado pelas A. mellifera foram considerados dominantes os polens de Eucaliptus sp (Myrtaceae), tipo Myrcia (Myrtaceae), tipo Poaceae (Poaceae) e Citrus sp. (Rutaceae). A maioria das médias dos parâmetros físico-químicos das amostras de méis encontra-se dentro dos limites estabelecidos pela legislação vigente, entretanto, verifica-se que o valor médio de açúcares redutores de $22,2 \%$ das amostras encontra-se abaixo do valor estabelecido pela norma, enquanto que o valor médio do teor de cinzas de $44,4 \%$ das amostras encontra-se acima do valor estabelecido.

Palavras-chave: Apis mellifera, mel, pólen, caracterização, flora apícola. 


\section{ABSTRACT \\ Apicultural plants and physiochemical and pollen characterization of honey produced by Apis mellifera $\mathrm{L}$. in the savannah area in the municipal district of Itirapina/SP}

The present work had as objective to study the composition of the honey flora in a savannah area at the Experimental Station of Itirapina, Division of Forests unit and the Experimental Stations of the Forestry Institute, in the municipal district of Itirapina/SP $\left(22^{\circ} 14^{\prime} \mathrm{S}\right.$ and $47^{\circ} 49^{\prime} \mathrm{W}$ ), to determine the physiochemical and pollen characteristics of the honey and to identify the pollen collected by Apis mellifera in the area. That information contributes to the knowledge of the exploitation potential of beekeeping in the remaining areas of the savannah as an alternative for self-sustained development, promoting the preservation of these environments. Flowering plants were collected fortnightly from December/2004 to November/2005, along a three-kilometer trail. The pollen samples were collected fortnightly from December/2004 to November/2005, and the honey samples were collected monthly during the same period, from five beehives of $A$. mellifera located in the same area. The honey flora was represented by 233 individuals belonging to 79 species, 57 genres and 33 families. For the pollen analyses of the honeys, Eucaliptus sp (Myrtaceae) e Citrus sp. (Rutaceae) were considered dominant species. For the pollen samples collected by A. mellifera, the pollen of Eucaliptus sp (Myrtaceae), tipo Myrcia (Myrtaceae), tipo Poaceae (Poaceae) e Citrus sp. (Rutaceae). were considered dominant. Most of the means of the physiochemical parameters of the honey samples are within the established limits by current legislation; however, it is noticeable that the sugar reducers mean value in $22,2 \%$ of the samples is below the established value by law, while the mean value for ash levels in $44,4 \%$ of the samples is above the established value.

Keywords: Apis mellifera, honey, pollen, characterization, honey flora. 


\section{INTRODUÇÃO}

A riqueza em plantas e animais tem um valor incalculável como patrimônio natural e é o resultado da evolução ocorrida em um determinado espaço de tempo cujas condições não mais serão repetidas (TILMAN, 1996). Apesar disso, a redução da diversidade devido à simplificação dos ecossistemas e/ou por introdução de produtos tóxicos é o efeito direto, ou indireto, mais importante e irreversível das atividades humanas ao longo do século XX. Esses ecossistemas, embora não percam necessariamente a produção em biomassa, normalmente reduzem sua diversidade praticamente em todas as ocasiões (DOUROJEANNI, 1990; HALFFTER; EZCURRA, 1996).

A fisionomia vegetal mais representativa do país depois da floresta Amazônica é o cerrado, uma formação xeromórfica que ocupa atualmente 2 milhões de $\mathrm{km}^{2}$ do território brasileiro. Considerado ponto crítico para a preservação da biodiversidade, este ecossistema encontra-se muito fragmentado e degradado pelo avanço das cidades, da agricultura e da pecuária. Em São Paulo ocupa apenas $1 \%$ da área do Estado $\left(248,8 \mathrm{mil} \mathrm{km}^{2}\right.$ ), do qual já cobriu $14 \%$, e só $18 \%$ do que resta é protegido por 32 unidades de conservação e de reserva legal (FIORI; FIORAVANTI, 2001).

As estratégias que contemplam a conservação de ecossistemas tropicais, como o cerrado, agregam aspectos econômicos e sociais concretos, tais como: manutenção e regularização dos mananciais hídricos que abastecem as grandes cidades, conservação da diversidade existente para uso futuro (especialmente na indústria farmacêutica) e exploração imediata ou atual dos recursos florestais múltiplos (mel, madeira, plantas ornamentais e medicinais, frutíferas, caça controlada, etc.). Entretanto, a conservação destes ecossistemas envolve necessariamente alternativas de uso que permitam retorno econômico (GODOY; BAWA, 1993; GODOY; LUBOWSKI; MARKANDAYA, 1993). Alternativas que propõem a obtenção de produtos que possam ser repostos pelo próprio ecossistema, num ciclo definido, podem possibilitar renda aos proprietários da terra e, ao mesmo tempo, manter o equilíbrio desejado destes ecossistemas (REIS; MARIOT, 1999).

Pela sua natureza, a apicultura é uma atividade conservadora das espécies, sendo uma das poucas atividades agropecuárias que preenche todos os requisitos do tripé da autosustentabilidade: o econômico, porque gera renda para o agricultor; o social, porque ocupa 
mão-de-obra familiar no campo e o ecológico, porque não se desmata para criar abelhas (ALCOFORADO-FILHO, 1998).

Nestes ecossistemas naturais as abelhas desempenham papel importante na manutenção das comunidades de plantas e animais, por serem eficientes polinizadores de muitas espécies de angiospermas que, por sua vez, são responsáveis pela produção de alimentos utilizados por aves e mamíferos. As abelhas Apis mellifera L. são elementos importantíssimos tanto para o homem como para o meio ambiente, pelos produtos de valor comercial fornecidos (mel, própolis, cera e geléia real), seja pela sua ação na polinização, contribuindo para o aumento da produção de frutos e sementes de diversos vegetais de interesse agroflorestal (FREE, 1993; WIESE, 1985).

Segundo Wiese (1985) a apicultura é uma das atividades mais antigas e importantes do mundo, prestando grande contribuição ao homem por meio da produção do mel, da geléia real, da própolis, da apitoxina, da cera e do pólen e à agricultura, por meio da polinização.

A flora é o mais importante fator de progresso de uma exploração apícola, devendo o apicultor ter conhecimentos relativos às essências principais do lugar e épocas de florescimento (BARROS, 1965).

O Brasil tem um potencial apícola bastante grande, o que o diferencia dos demais países que, normalmente, colhem mel uma única vez por ano, pois a flora brasileira é bastante diversificada, devido à extensão territorial e variabilidade climática do país, sendo possível produzir o ano todo (MARCHINI; SODRÉ; MORETI, 2004).

No Brasil a flora é rica e variada, todavia, pouco se conhece do ponto de vista apícola. Freitas (1991) cita vários estudos realizados, principalmente, em zonas temperadas referentes à flora apícola, mesmo assim a bibliografia de plantas melíferas ainda é bastante incompleta pois fundamenta-se em dados empíricos e resultados de trabalhos conduzidos na Europa e Américas Central e do Norte.

A exploração apícola está intimamente ligada às plantas, pois o néctar e o pólen produzidos pelas plantas apícolas são os alimentos essenciais para a vida das abelhas (FREITAS, 1996). Portanto, a localização do apiário é um dos fatores importantes para o sucesso da apicultura.

A apicultura tem estreita relação com o desenvolvimento da flora de uma região, quer pela participação direta da abelha por meio da polinização, quer pela ação do homem procurando melhorar as condições apícolas e favorecendo, deste modo, o ambiente (SCHEREN, 1983). 
Nesse contexto, a identificação das espécies vegetais visitadas pelas abelhas assume grande importância, por indicar aos apicultores fontes adequadas e de abundante suprimento de néctar e pólen, principalmente, considerando-se que a apicultura no Brasil visa o maior aproveitamento das riquezas que a vegetação natural oferece (ALCOFORADO-FILHO, 1993; FREITAS, 1991).

Devido ao interesse pela apicultura no Estado de São Paulo e a escassez de informações sobre o potencial de exploração da atividade apícola na vegetação de cerrado, pesquisas nessas áreas fazem-se necessárias para possibilitar estratégias futuras de utilização racional da flora apícola e de conservação destes ecossistemas.

Este trabalho tem como objetivos conhecer a composição da flora apícola de uma área de cerrado do município de Itirapina, Estado de São Paulo, além da determinação das características físico-químicas e polínicas do mel produzido e polínicas do pólen coletado por $A$. mellifera no local, contribuindo para o conhecimento do potencial de exploração da apicultura em áreas remanescentes de cerrado. 


\section{DESENVOLVIMENTO}

\subsection{0 ecossistema de cerrado}

O cerrado representa $22 \%$ do território nacional, ou cerca de 2 milhões de $\mathrm{km}^{2}$, abrange os Estados de Mato Grosso, Mato Grosso do Sul, Rondônia, Goiás, Tocantins, Maranhão, Piauí, Bahia, Minas Gerais, São Paulo e o Distrito Federal. A diversidade de climas, solos e topografia existentes nessa extensa região resulta no bioma denominado cerrado - um mosaico de diferentes tipos de vegetação, reflexo de sua heterogeneidade espacial (EMBRAPA/CPAC, 1987).

O cerrado, propriamente dito (cerrado "sensu strictu"), tem vegetação herbácea e árvores esparsas. O chamado cerradão é a forma florestal, enquanto que no campo sujo e no campo cerrado predomina a vegetação herbácea (rasteira), com capim e outras plantas pequenas (COUTINHO, 1978).

A flora existente nesse complexo fitofisionômico é uma das mais ricas do Brasil e talvez do mundo. São cerca de 6.000 espécies de fanerógamas nativas, além de algumas centenas de espécies introduzidas de alguma forma pelo homem (PEREIRA, 1994).

No cerrado há uma diversidade de plantas apícolas que também oferecem frutos comestíveis saborosos e dentre as diversas frutíferas, a família Myrtaceae é uma das mais bem representadas, englobando 3.000 espécies (NILSSON, 1984).

Silveira (1989) afirma que se tem elevado a necessidade de estudos que visam a preservação das abelhas nas áreas de cerrado, pois são de grande importância para a manutenção dos ecossistemas, visto que essas áreas apresentam elevado grau de destruição, decorrente do rápido e devastador processo de ocupação humana nos últimos anos.

\subsubsection{A flora apícola}

Os fatores determinantes para eficiência da atividade apícola, em uma região, são: qualidade das abelhas, das colméias utilizadas e do pasto apícola (FREITAS, 1996).

A flora apícola é definida como o conjunto de espécies vegetais que as abelhas $A$. mellifera utilizam como fonte de néctar e/ou pólen, para sua sobrevivência e produção de mel (PEREIRA, 1990). Segundo Moreti (1998) acrescentando-se água, também de vital importância, tem-se o 
pasto apícola. A expressão pasto apícola engloba a somatória dos recursos naturais ou não, disponíveis para as abelhas num dado local, sendo que a qualidade e a quantidade do pasto são uns dos principais fatores que limitam a produção apícola (NOGUEIRA-COUTO; COUTO, 2002).

As principais condições para uma planta ser considerada apícola, de acordo com Castro (1994) são: abundância na região, florescer copiosamente e de preferência por um período prolongado e possuir néctar e/ou pólen acessíveis às abelhas. Nogueira-Couto e Couto (2002) firmam que, numa determinada região, uma planta é considerada apícola se for abundante, atrativa e com produção de pólen e/ou néctar interessante, pela quantidade e qualidade produzida e se tiver período longo de florescimento. Qualquer colméia só irá desenvolver todo seu potencial produtivo se houver disponibilidade de pasto apícola, em quantidade adequada

As abelhas realizam a visita às flores para suprirem suas necessidades nutricionais, tendo basicamente como única fonte de alimento o pólen e o néctar encontrado nas flores. Sendo o pólen a fonte concentrada de proteína e o néctar fornecedor de energia, contendo sacarose, frutose e glicose. A disponibilidade de alimento afeta o peso das larvas, pupas e adultos recémemergidos, sendo as floradas e o conhecimento das épocas de ocorrência das mesmas, de grande importância, para o desenvolvimento e produção da colônia (MORETI, 1998).

Segundo Silveira (1983) a flora apícola é a fonte direta de matéria-prima para todos os produtos da colônia, com exceção da geléia real e da cera. Entretanto, para a elaboração das mesmas, a abelha depende dos alimentos fornecidos pela flora, pois por meio da digestão do pólen que as abelhas nutrizes produzem a geléia real e do consumo de mel ou néctar de que as operárias necessitam para a produção de cera.

Segundo Moreti (1998) a maioria das plantas são produtoras de pólen e néctar, sendo raras as que fornecem apenas pólen ou as que produzem apenas néctar. Ainda segundo esta autora as plantas apícolas podem ser divididas em três grupos: plantas nectaríferas, que fornecem exclusivamente néctar às abelhas; plantas poliníferas, que fornecem exclusivamente pólen às abelhas; e plantas nectarífero-poliníferas, que fornecem tanto néctar como pólen às abelhas. No grupo das plantas nectaríferas podem ser considerados dois sub-grupos: o das plantas que apresentam nectários florais (98\% da plantas); e das plantas que apresentam nectários extraflorais ( $2 \%$ das plantas). 
Quanto à produtividade, as plantas apícolas podem ser classificadas como: flora apícola principal (constituída pelas plantas de maior fluxo nectarífero, normalmente forma pastos densos, com floradas prolongadas); flora apícola secundária ou flora de manutenção (plantas cujos recursos promovem apenas a manutenção da colônia); flora apícola terciária (florada eventual, quando bem representadas); flora apícola quaternária (culturas, nas quais o maior interesse é a polinização) (MORETI, 1998).

A quantidade e qualidade de pólen e/ou néctar produzidos pelas flores úteis podem variar tanto entre espécies de plantas, quanto dentro da mesma espécie. Em algumas regiões as plantas produzem néctar abundante, podendo as colônias coletar $5 \mathrm{~kg}$ ou mais de néctar diariamente, e produzir anualmente mais de $200 \mathrm{~kg}$ de mel, enquanto em outras regiões, as colônias devem ser alimentadas com xarope de açúcar, por mais de um ano para sobreviver. Embora as colônias possam responder com grande flexibilidade à condições tão variáveis, o potencial das colônias coletarem alimento está limitado pela produção de néctar e pólen nas plantas (WINSTON, 2003).

Segundo Hein et al. (1986) uma planta pode ser apícola em um ano, numa determinada localidade e não ser em outro, pois a intensidade floral e o período de florescimento variam de acordo com as condições climáticas. Por isso, a produção de pólen e/ou néctar vai ser diferente nos vários períodos e regiões.

A flora apícola ideal à apicultura seria aquela que fornecesse grande quantidade de néctar e pólen às abelhas durante todo o ano, possibilitando às colônias manter o desenvolvimento constante e que o apicultor possa também, coletar mel de boa qualidade regularmente. Entretanto, o potencial apícola difere de região para região, e em uma mesma região, a produção concentrase em determinados períodos, devido à produção de néctar e, em menor escala, à de pólen, ser, influenciada por fatores internos e externos à planta, tais como: radiação solar, temperatura e umidade do ar, umidade do solo, altitude, chuvas e fertilidade do solo (ALCOFORADO-FILHO, 1996).

Locais que apresentam vegetação com diferentes floradas, em diferentes períodos do ano, são os mais adequados para a apicultura fixxa. Em locais com monocultura não se produz alimento para as abelhas o ano todo. A exploração do pasto apícola de monocultura só se justifica na atividade comercial, na qual o apicultor realiza a apicultura migratória, que consiste em levar as colônias para pomares ou culturas em floração, transferindo-as para outro ponto assim que termina a florada (DE CICCO, 2003). 
A melhor pastagem para as abelhas é constituída por pastos sujos e áreas de preservação, nas quais devido à diversidade de plantas silvestres ocorre florescimento o ano todo (FREITAS, 1996).

O mel oriundo de uma área de mata varia em sua composição, odor e cor de acordo com a época do ano, sendo caracterizado como "silvestre" (MAIA; OLIVEIRA; ITAGIBA, 1994).

Sabe-se, no entanto, por meio dos poucos levantamentos feitos nas áreas de cerrado e da prática dos apicultores, que são numerosas as espécies vegetais que exercem atração sobre as abelhas e podem entrar na geração de excedentes de mel nas colméias ou pelo menos ajudar na sua manutenção. Já observou-se que algumas espécies propiciam mel de características inigualáveis (PEREIRA, 1990).

De acordo com Almeida (1996) existem mais de 60 espécies de plantas com potencial melífero nas diferentes fisionomias do cerrado, verificando-se floração de janeiro a dezembro, sendo que as floradas atingem o pico no final da época seca.

Em trabalho feito na bacia do rio São Bartolomeu/DF, Pereira (1990) verificou que de um total de 1600 espécies levantadas, 220 foram visitadas pela $A$. mellifera, sendo a maior parte também de porte arbóreo, ocorrendo nas matas. Alguns exemplos: Anadenanthera macrocarpa (angico do cerrado), Luehea divaricata (açoita cavalo), Acacia polyphylla (monjoleiro), Inga sp. (ingá), Vernonia polyanthes (assa-peixe) e Cupania vernalis (camboatá).

Mateus (1998) em levantamento feito no cerrado da Estação Ecológica de Jataí (Luiz Antônio, SP) encontrou um total de 137 espécies vegetais visitadas por abelhas, sendo 36 utilizadas como recursos por $A$. mellifera.

Almeida (2002) em duas áreas de cerrado do município de Pirassununga/SP constatou um total de 74 espécies de plantas visitadas por abelhas, sendo que as $A$. mellifera utilizaram como recurso para produção de mel 29 destas plantas e como recurso polínico 41 espécies.

\subsubsection{Clima}

O clima do cerrado é do tipo tropical estacional, com precipitação média anual de $1500 \mathrm{~mm}$ de chuva. Mais de $90 \%$ da precipitação ocorre de outubro a março, demarcando duas estações climáticas distintas: a chuvosa e a seca. Aproximadamente $86 \%$ do cerrado recebe entre $1000 \mathrm{~mm}$ 
e $2000 \mathrm{~mm}$ de chuva por ano, que coloca este bioma numa posição intermediária entre a Floresta Amazônica e a Caatinga em termos pluviométricos.

Durante a estação seca, a umidade relativa é baixa e a evaporação alta, sendo que a precipitação pode ser zero em alguns meses. Em $67 \%$ do cerrado, a estação seca prolonga-se por cinco ou seis meses. Esta duração, no entanto, pode variar na medida em que regiões de cerrado sofrem influência de outros biomas, como a Amazônia ou a caatinga. Em termos agronômicos, considera-se seco o mês no qual a precipitação seja inferior a $60 \mathrm{~mm}$, uma vez que tal quantidade de chuva é insuficiente para manter um campo de cultura (DIAS, 1992).

A precipitação durante o período chuvoso pode ser irregular, havendo dias de chuva intensa (em Planaltina, no Distrito Federal, registrou-se $135 \mathrm{~mm}$ de chuva em um único dia em dezembro de 1989) intercalados com períodos curtos de estiagem. Tais períodos são conhecidos por "veranicos" e podem ser danosos ao crescimento de algumas plantas (DIAS, 1992).

Encontram-se no cerrado duas temperaturas médias distintas. Em sua parte sul, onde há influência de massas polares de ar e altitudes mais pronunciadas, a média é de $22^{\circ} \mathrm{C}$. Na porção norte, onde as altitudes são menores e há maior influência das condições climáticas equatoriais, a temperatura média é de $27^{\circ} \mathrm{C}$ (DIAS, 1992).

\subsection{Aspectos da relação abelha-planta}

Segundo Morgado (2000) o Brasil apresenta características físicas que determinam domínios climato-botânicos que favorecem a riqueza de insetos, principalmente de abelhas, devido à sua grande extensão territorial e localização geográfica.

Segundo Simpson e Neff (1981), o néctar é a substância mais importante na atração das abelhas pelas plantas, embora os óleos utilizados na composição de alimentos, as ceras e resinas utilizadas na construção de ninhos, também sejam eficientes na atratividade da flor.

Bawa (1983) observou que os padrões de florescimento são variáveis e apresentam implicações em muitos aspectos da organização e estrutura das comunidades. Essas variações aparentemente são moldadas por um conjunto de pressões seletivas, como a competição interespecífica por polinizadores, a disponibilidade de polinizadores, a seleção contra o fluxo gênico interespecífico e a natureza das recompensas florais oferecidas. 
As características das flores visitadas pelas abelhas são muito variadas, mas, geralmente, possuem coloração brilhante ou refletem o ultravioleta, são aromáticas e fornecem quantidades moderadas de néctar (PROCTOR; YEO; LACK, 1996).

A eficiência polinizadora de qualquer visitante floral está intimamente relacionada com a biologia floral da planta e o comportamento do animal. Durante milhões de anos as flores desenvolveram mecanismos como pétalas coloridas, odores e recompensas de néctar, pólen, essências e óleos para atraírem interessados e obterem polinização (FREITAS, 1998).

A atratividade de uma florada pode ser influenciada pela quantidade do pólen produzido, a concentração e abundância das flores, o número de insetos competidores, a distância entre a florada e o ninho e a preferência inata da espécie. Entretanto, esses fatores ainda estão sujeitos a variações como o tamanho da flor, a umidade relativa do ar, a umidade do solo, a temperatura, a altitude, as horas do dia e a duração do dia (BAWA, 1983; CASTRO, 1994).

A maioria da flora encontrada em muitas comunidades depende das abelhas para efetuar a polinização, como várias espécies de Caesalpiniaceae e Fabaceae. Para representantes das famílias Bignoniaceae, Lamiaceae e Scrophulariaceae a ausência das abelhas poderia causar o desaparecimento dessas plantas nas áreas onde normalmente são encontradas (SIMPSON; NEFF, 1993).

As abelhas constituem os agentes polinizadores mais adaptados a visita às flores das Angiospermas. Suas relações baseiam-se em um sistema de dependência recíproca, no qual as plantas fornecem o alimento para as abelhas, principalmente, pólen e néctar e, em troca, recebem os benefícios da transferência de pólen (KEVAN; BAKER, 1983; PROCTOR; YEO; LACK, 1996).

Entre todos os possiveis agentes polinizadores das plantas, as abelhas destacam-se por sua dependência em visitar flores para obterem seus alimentos, pólen e néctar, enquanto a maioria dos outros polinizadores potenciais só visita as flores para satisfazerem suas necessidades imediatas e quase sempre não as tem como suas única fontes de alimento. As abelhas, de um modo geral, alimentam-se quase que exclusivamente de pólen e néctar e precisam visitar grandes quantidades de flores diariamente para satisfazerem suas necessidades individuais, das crias e/ou da colônia. Esse trabalho incansável de visitação às flores faz das abelhas os principais agentes polinizadores das plantas (CORBET; WILLIAMS; OSBORNE, 1991; FREE, 1993). 
Os insetos ocupam lugar de destaque nos processos de polinização e dentre estes, os himenópteros, em especial as abelhas, são os mais estudados e conhecidos vetores de pólen (BERTIN, 1989; CREPET, 1983; PERCIVAL, 1965). As abelhas, incluindo as espécies solitárias e sociais, são os visitantes florais mais freqüentes (LAROCA; ALMEIDA, 1985), Constituindose nos mais importantes polinizadores de plantas entomófilas tropicais (NOGUEIRA-NETO, 1997; ROUBIK, 1989; SILVEIRA; MELO; ALMEIDA, 2002).

O processo de polinização constitui uma das mais fortes ligações entre plantas e animais. O fluxo gênico entre membros de uma população vegetal depende do raio de alcance do polinizador, distribuição espacial da planta e da sua biologia floral (BARTH, 1991).

Como em outros tipos de vegetação tropical, as abelhas representam os principais polinizadores de plantas do cerrado, constituindo o grupo mais importante, tendo sido observadas como polinizadoras de 60 a $75 \%$ das espécies estudadas por Silberbauer-Gottsberger e Gottsberger (1988).

Segundo Araújo (1984); Martinho (1990); Scheren (1977) e Silva (1985) dentre todos os benefícios produzidos pelas abelhas como o mel, cera, própolis e geléia real, sem dúvida a polinização é o mais importante para o homem.

As abelhas exercem grande importância nos ecossistemas terrestres, devido à sua alta especialização na coleta de pólen, néctar e resinas, sendo excelentes polinizadores, indispensáveis à sobrevivência das angiospermas (BAWA, 1990; BAWA et al., 1985; ENDRESS, 1994).

Segundo Souza et al. (1993), cerca de 225000 espécies da flora correspondem às angiospermas, sendo 2/3 dependente das abelhas para polinização.

As abelhas necessitam tanto de pólen quanto de néctar para o seu desenvolvimento. Somente após terem satisfeitas suas exigências, e havendo disponibilidade, elas irão estocar alimentos que poderão ser utilizados pelo homem. Quanto mais abundantes forem as floradas e quanto mais próximas as colméias estiverem delas, maior a produção (NOGUEIRA-COUTO; COUTO, 2002).

Vansell e Griggs (1952) afirmam que as abelhas podem contribuir com mais de $80 \%$ da polinização nas culturas agrícolas. Nos ecossistemas tropicais proporção semelhante foi observada por Andena; Bego e Mechi (2002). Na natureza esse processo de polinização é muito vantajoso, no sentido de aumentar a probabilidade de manutenção ou alcance de um alto grau de variabilidade em vigor da espécie (CAMARGO, 1972). 
Proctor; Yeo e Lack (1996) ressaltaram a importância da polinização cruzada para a maioria das espécies existentes nas florestas tropicais, visto que em muitos casos as plantas são incapazes de realizar a autopolinização. A contribuição dos animais para a realização desta tarefa é bastante grande (BAWA, 1990; ENDRESS, 1994)

Segundo Nogueira-Couto e Couto (1996) muitos pesquisadores consideram a polinização como a grande e principal contribuição de uma colônia de A. mellifera. À medida que a agricultura vai se desenvolvendo com o aprimoramento das técnicas de cultivo, de fertilização e irrigação do solo e de utilização de sementes selecionadas, a polinização pode se tornar um fator limitante na produção agrícola dos países tropicais. Somado a isso, a população de insetos nativos, responsável pela polinização de muitas espécies vegetais, tem se reduzido drasticamente devido ao desmatamento, queimadas e uso de pesticidas, aumentando a dependência de polinizadores com ampla distribuição geográfica e eficiência, como as abelhas Apis.

Segundo Nogueira (1984) as abelhas apresentam maior eficiência entre os agentes polinizadores, o que garante boa qualidade dos frutos e sementes produzidos.

As características de um bom polinizador são totalmente preenchidas pelas abelhas $A$. mellifera: visitam um grande número de flores de plantas de uma mesma espécie, carregam em seus pêlos ramificados numerosos grãos de pólen, ocorrem em grande número na natureza sendo que sua vida social favorece o controle da quantidade de abelhas em um determinado local, não destroem as flores e coletam em grande quantidade, não só para seu sustento imediato como para o armazenamento. Quanto à primeira característica, é interessante mencionar que essa fidelidade de um indivíduo em particular poderia se constituir num problema, pela existência de pólen deficiente em certos aminoácidos, se não houvesse em $A$. mellifera um estoque de grãos de pólen coletados de diferentes fontes nos favos (NOGUEIRA-COUTO; COUTO, 1996).

As características biológicas das abelhas (colônias perenes, grandes populações, área de forrageamento extensa, elevada capacidade de orientação e comunicação) conferem-lhe grande habilidade competitiva, de modo que, juntamente com as abelhas eussociais, sem ferrão (meliponíneos), A. mellifera integra um grupo de fundamental importância na estruturação das comunidades de abelhas tropicais (ROUBIK, 1989). 


\subsection{Inter-relação Apis mellifera e abelhas nativas}

Segundo Begon; Harper e Townsend (1996) a competição é definida como o uso de um recurso por um indivíduo, reduzindo a sua disponibilidade a outros indivíduos. Sendo assim, a competição é um dos mais importantes mecanismos pelos quais as atividades dos indivíduos afetam o bem estar dos outros, tanto se tratando de competição intra-específica como interespecífica.

De acordo com Nogueira-Couto (1998) a inter-relação entre as abelhas nativas brasileiras e as $A$. mellifera africanizadas necessita de maiores estudos. Ocorre divergência entre os autores quanto a interferência entre elas durante a coleta. Roubik $(1978,1983)$ não observou agressão entre elas em suas pesquisas, enquanto Meneses-Pedro e Camargo (1991) observaram diferenças nos horários de visita e na preferência floral entre diferentes espécies de abelhas. Por outro lado, trabalhos desenvolvidos em Jaboticabal, SP, mostraram um comportamento agressivo da Trigona com relação às demais abelhas, durante a atividade de forrageio (NOGUEIRA-COUTO, 1998).

É comum entre os meliponicultores atribuir às abelhas africanizadas a redução de seu número de colônias, seja por meio de invasões, seja pela redução dos recursos tróficos. Porém, Lorenzon (1996) avaliando a competição entre as abelhas africanizadas (A. mellifera) e jandaíras (Melipona subnitida), na região semi-árida de São João do Cariri, PB, registrou a produção de mel de ambas as espécies por três anos, além de não observar qualquer tentativa de invasão das africanizadas sobre os meliponíneos, mesmo em período de escassez. Para a pesquisadora ficou evidente que as abelhas jandaíras são mais seletivas que as africanizadas e que as preferências dos recursos são próprios.

A competição inter e intra-específica assim como as flutuações ambientais aumentam a eficiência de exploração e ampliam a gama de recursos utilizados. As abelhas africanizadas podem buscar outras fontes de recurso ou utilizar horários diferentes de coleta, além de seu raio de atuação bem maior que o das abelhas nativas, para evitar a competição (CORTOPASSILAURINO, 1982). 


\subsection{Flora apícola e a secreção do néctar}

O valor de uma planta apícola é medido pela concentração de açúcares em seu néctar, podendo apresentar grandes variações (2 a 77\%) e pela quantidade de néctar secretado. O néctar mais concentrado é preferido pelas abelhas, pois elas gastam menos tempo e tem menos trabalho para desidratá-lo, transformando-o em mel (WIESE, 1982).

Segundo Barros (1965) há uma infinidade de plantas que produzem néctar em elevada quantidade e, no entanto, as abelhas não visitam. Isso ocorre devido à procura das plantas pelas abelhas se basear em fatores como a elevada concentração de açúcar do néctar; a preferência por néctar com melhor aroma e sabor para elas; a possibilidade de acesso aos nectários, alguns são fechados ou protegidos por tecidos quaisquer, impossibilitando que a abelha sugue o néctar e a escassez de alimento, pois na falta de néctar de elevada atração para as abelhas, elas recorrerão aos inferiores.

\subsection{Composição do mel}

O mel é resultado da desidratação e transformação do néctar das plantas pelas abelhas. A quantidade de mel que pode ser obtida de uma determinada planta varia com os fatores que influenciam a produção e a concentração de néctar e, ainda, com a concentração e proporções de seus carboidratos, com a quantidade de flores da área e com o número de dias em que as flores estão secretando néctar (CRANE, 1975).

Entende-se por mel a substância doce produzida pelas abelhas a partir do néctar das flores ou de exsudações de outras partes vivas das plantas ou presentes nelas (BRASIL, 2000).

As características do mel como sabor, aroma, coloração, densidade e propensão à cristalização, variam de acordo com a flora do local, pois estão relacionadas aos componentes presentes no néctar das diversas flores, assim como à proporção em que estão presentes.

A composição do mel depende, basicamente, da composição do néctar de cada espécie vegetal produtora, conferindo-lhe características específicas enquanto que as condições climáticas e o manejo do apicultor têm influência menor (WHITE, 1978). 
As características físico-químicas e polinícas do mel ainda são relativamente pouco conhecidas, principalmente, nas regiões tropicais onde existe elevada diversidade de flora apícola associada às taxas elevadas de umidade e temperatura (SODRÉ, 2000).

Os casos de adulterações de mel são comuns, por ser um produto natural de fornecimento limitado, o que gera desconfiança dos consumidores tradicionais, criando barreiras para ampliação do seu consumo (AZEREDO; AZEREDO; DAMASCENO, 1999).

Segundo Pereira et al. (1983) não é possível avaliar a qualidade e integridade do mel apenas pelas características organolépticas, sendo que alguns parâmetros físico-químicos são constantes dentro de uma faixa nos méis naturais, permitindo a detecção de fraudes.

É de fundamental importância a caracterização dos méis visando a criação de padrões, segundo os fatores edafo-climáticos e florísticos das regiões, estabelecendo critérios comparativos nas análises, e controlando possíveis fraudes desse produto (CRANE, 1990).

Os trabalhos de análises físico-químicas de méis visam comparar os resultados obtidos com padrões ditados por órgãos oficiais internacionais, ou com os estabelecidos pelo próprio país, deixando claro não só uma preocupação com a qualidade do mel produzido internamente, como também, torna possível a fiscalização de méis importados com relação a sua alteração (MARCHINI, 2001).

\subsubsection{Cor}

A cor é uma das características do mel que mais influencia na preferência do consumidor, que, na maioria das vezes, escolhe o produto apenas pela aparência. Tal é a relevância deste parâmetro que o International Trade Forum (1977) considerou a cor como uma das características do mel que tem particular importância no mercado internacional.

A cor do mel representa um dos principais entraves para os países produtores que almejam conquistar o mercado internacional (YEBOAH-GYAN; MARFO, 1998). De acordo com os padrões estabelecidos, há uma preferência por méis claros (CRANE, 1975; ITC, 1977).

A cor do mel está correlacionada com a sua origem floral, processamento e armazenamento, fatores climáticos durante o fluxo do néctar e a temperatura na qual o mel amadurece na colméia (SEEMANN; NEIRA, 1988).

Segundo Bath e Singh (1999) a proporção de frutose, glicose, conteúdo de nitrogênio e aminoácidos livres, a reação de substâncias polifenólicas como sais de ferro, o conteúdo de 
minerais e a instabilidade da frutose em solução ácida, são fatores que determinam a velocidade do escurecimento do mel.

Pode ocorrer escurecimento do mel devido ao tempo de armazenamento do mesmo, paralelamente a isso, também podem ocorrer alterações nas propriedades organolépticas, influenciando na qualidade e aromas originais (AUBERT; GONNET, 1983).

Alguns autores analisando méis de diferentes origens florais, observaram que méis escuros apresentavam maiores concentrações de minerais quando comparados com méis claros (CAMPOS, 1998; PETROV, 1970; WHITE, 1961; YEBOAH-GYAN; MARFO, 1998).

Os autores Almeida (2002); Arruda (2003); Azeredo; Azeredo e Dasmaceno (1999); Baldi Coronel; Dall'ogllio e Lezcano (1993); Campos (1998); Carvalho et al. (1998, 2000); Gomez et al. (1993); Marchini e Moreti (2001); Pamplona (1989); Persano-Oddo et al. (1995); SerraBonvehí e Granados-Tarrés (1993); Sodré (2000, 2005); Uñates et al. (1999) e Vieira (2005) analisaram a cor de méis de diferentes origens e obtiveram uma predominância da cor clara sobre a escura.

\subsubsection{Açúcares}

Segundo Gil (1986) os açúcares constituem a maior porcentagem no mel, variando a proporção de acordo com a origem do néctar floral.

Os açúcares encontrados no mel são: glicose, frutose, sacarose, maltose, isomaltose, eilose, questose, melezitose, rafinose, dextrantiose, 4-glicosildextrantriose e um oligossacarídeo. Estes açúcares influenciam na viscosidade, higroscopicidade, granulação e valor energético dos méis (WHITE, 1979).

Os monossacarídeos frutose e glicose, açúcares redutores, capazes de reduzir íons cobre em solução alcalina (NAUTA, 1983), são predominantes no mel (VIDAL; FREGOSI, 1984), representam em torno de 85 a 95\% dos carboidratos, sendo que a proporção média de frutose é de $39,3 \%$, enquanto que a de glicose é de 32,9\% (DURAN et al., 1996; SEEMANN; NEIRA, 1988; WHITE, 1979).

A glicose, devido a sua pouca solubilidade, determina a tendência da cristalização do mel, já a frutose, possibilita a doçura devido a sua alta higroscopicidade, enquanto que, méis com altas 
taxas de frutose podem permancer líquidos por longos períodos ou nunca cristalizarem (DURAN et al., 1996; SEEMANN; NEIRA, 1988; WHITE, 1979).

O dissacarídeo sacarose, não redutor, é passível de hidrólise por meio de ácidos diluídos ou enzimas (invertase), resultando em monossacarídeos (frutose e glicose). Representa em média de 2 a $3 \%$ dos carboidratos, e valores superiores indicam um mel verde ou adulterado (VIDAL; FREGOSI, 1984).

Os valores de açúcares redutores não devem ser inferiores a $65 \%$, enquanto que os de sacarose não devem ultrapassar 6\% (BRASIL, 2000).

Dentre diversos trabalhos realizados no Brasil e no exterior os menores e maiores valores observados para açúcares redutores totais em mel foram 62,27\% (AMIN; SAFWAT; EL-IRAKI, 1999) e 91,90\% (VIEIRA, 2005), para açúcares redutores foram 48,00\% (MESALLAN; ELSHAARAWY, 1987) e 88,39\% (SODRÉ, 2005) e para sacarose foram 0,00\% (VIT-OLIVER; MARTORELI; PALACIOS, 1994) e 27,40\% (KOMATSU; MARCHINI; MORETI, 2002).

\subsubsection{Hidroximetilfurfural}

O hidroximetilfurfural (HMF) é formado pela reação de certos açúcares em presença de ácidos. O seu conteúdo pode aumentar com a elevação da temperatura, com armazenamento do mel, adição de açúcar invertido, podendo ser afetado ainda pela acidez, pH, água e minerais no mel (SALINAS; ESOINOSA-MANSILLA; BERZAS-VEVADO, 1991; SEEMANN; NEIRA, 1988; WHITE, 1976).

Conforme Veríssimo (1988) o HMF é um indicador de qualidade do mel, visto que, quando elevado indica uma queda no seu valor nutritivo, pela destruição, por meio de aquecimento, de algumas vitaminas e enzimas que são termolábeis. Outro fator relacionado com aumento desse componente no mel é o tempo de armazenamento (CORNEJO, 1988).

Nos países subtropicais os méis podem apresentar altos teores de HMF sem que tenham sido superaquecidos ou adulterados, isso devido às altas temperaturas (WHITE, 1992).

Os padrões internacionais do "Codex Alimentarius Commission (1969)", definem que méis que apresentam valores superiores a $40 \mathrm{mg} \cdot \mathrm{kg}^{-1}$ (escala internacional) ultrapassam o máximo permitido estando, portanto, acima dos padrões de qualidade. No Brasil, considerando o clima tropical, este valor foi estendido para 60 $\mathrm{mg}^{\mathrm{kg}} \mathrm{kg}^{-1}$ (BRASIL, 2000). 
O valor mínimo para este parâmetro foi $0 \mathrm{mg}_{\mathrm{kg}}{ }^{-1}$ encontrado por Thrasyvoulou e Manikis (1995) para méis da Grécia, e Soria et al. (2004), em méis da Espanha, já o valor máximo foi $471 \mathrm{mg} . \mathrm{kg}^{-}$encontrado por Mendes et al. (1998) para méis de Portugal.

\subsubsection{Umidade}

$\mathrm{Na}$ composição do mel a água constitui o segundo componente em quantidade, geralmente variando de 15 a $21 \%$, dependendo do clima, origem floral e colheita antes da completa desidratação. Normalmente o mel maduro tem menos de $18,5 \%$ de água. O conteúdo de água no mel é, sem dúvida, uma das características mais importantes, por influenciar na sua viscosidade, peso específico, maturidade, cristalização, sabor, conservação e palatabilidade, conforme Seemann e Neira (1988).

Sodré (2005) relata que a umidade do mel pode ser alterada após a sua retirada da colméia, em função das condições de armazenamento após a extração.

Segundo White (1978) os microorganismos osmofílicos (tolerantes ao açúcar), presentes nos corpos das abelhas, no néctar, no solo, nas áreas de extração e armazenamento podem provocar fermentação no mel quando o teor de água for muito elevado.

Níveis elevados de umidade provocam a fermentação do mel devido à presença de leveduras que são tolerantes ao açúcar. A fermentação é evitada em condições de alto conteúdo total de açúcar associado a um baixo teor de água (CRANE, 1987).

Os valores mínimo e máximo encontrados para este parâmetro foram $12,9 \%$ para méis argentinos (UNÃTES et al., 1999) e 27,2\% para méis do nordeste do Brasil (PAMPLONA, 1989).

\subsubsection{Condutividade elétrica}

A condutividade elétrica pode ser utilizada como método suplementar na determinação da origem botânica do mel (AGANIN, 1971). É um parâmetro usado para determinar a origem do mel, se é néctar ou melato, ou ainda se o produto está adulterado (CRANE, 1987). 
A condutividade elétrica tem correlação com o conteúdo de cinzas, $\mathrm{pH}$, acidez, sais minerais, além da proteína e outras substâncias presentes no mel (BOGDANOV, 1999; BOGDANOV et al., 2001; CRANE, 1990; STEFANINI, 1984).

Crecente e Latorre (1993) constataram o menor valor para a condutividade elétrica $(66 \mu \mathrm{S})$ em méis espanhóis. Já Vieira (2005) encontrou o maior valor $(4836 \mu \mathrm{S})$ para méis de área de cerrado do estado do Mato Grosso do Sul.

\section{$2.5 .6 \mathrm{pH}$}

$\mathrm{O}$ pH determinado nas análises do mel refere-se aos íons hidrogênio presentes na solução e pode influenciar na formação de outros componentes, como na velocidade de produção do HMF (VIDAL; FREGOSI, 1984).

Todos os méis são ácidos e o pH é influenciado pela origem botânica, pela concentração de diferentes ácidos e pelo cálcio, sódio, potássio e outros constituintes das cinzas (SEEMAN; NEIRA, 1988; FRÍAS; HARDISSON, 1992).

O menor valor para pH $(2,3)$ foi encontrado por Flechtmann et al. (1963) e Marchini (2001) para méis do Estado de São Paulo, enquanto que o maior valor $(7,2)$ foi constatado por PersanoOddo et al. (1995) em méis italianos.

\subsubsection{Acidez}

A acidez é um importante componente do mel pois contribui para a sua estabilidade, frente ao desenvolvimento de microorganismos (CRANE, 1987; MARCHINI, 2001).

Os ácidos dos méis estão dissolvidos em solução aquosa e produzem íons de hidrogênio que promovem a sua acidez ativa, permitindo assim, indicar as condições de armazenamento e o processo de fermentação (CORNEJO, 1988).

Foram encontrados no mel os ácidos: acético, benzóico, butírico, cítrico, fenilacético, fórmico, glucônico, isovalérico, láctico, maléico, oxálico, propiônico, piroglutânico, succínico e valérico. $\mathrm{O}$ ácido glucônico em equilíbrio com a glucono-lactona, formado pela ação da glicose oxidase, é o principal deles (SEEMANN; NEIRA, 1988). 
Segundo Frias e Hardisson (1992) a ação de transformação é mais lenta em méis mais densos e é influenciada pela quantidade de ácidos obtidos no tempo que transcorre entre a coleta do néctar e o máximo do volume do néctar que é depositado nos favos.

De acordo com as normas estabelecidas são considerados dentro dos padrões méis com valores de acidez de até 50meq. $\mathrm{kg}^{-1}$ (BRASIL, 2000).

Persano-Oddo et al. (2004) analisando méis uniflorais europeus encontrou o menor valor (2,3meq. $\left.\mathrm{kg}^{-1}\right)$ para este parâmetro e Komatsu (1996) obteve o maior valor (75,5meq.kg) analisando méis silvestres do Estado de São Paulo.

\subsection{8 Índice de formol}

O índice de formol é importante no mel por representar, predominantemente, os compostos aminados, permitindo assim, avaliar o conteúdo em peptídios, proteínas e aminoácidos (TEMIZ,1983).

É um importante componente indicador de adulteração, pois quando muito baixo pode indicar a presença de produtos artificiais, enquanto excessivamente alto, mostra que as abelhas foram alimentadas com hidrolisado de proteínas (SIMAL; HUIDOBRO, 1984). Assim, o índice de formol pode ser utilizado para comprovar a autenticidade do mel (FRÍAS; HARDISSON, 1992).

Sodré et al. (2002) verificaram o menor $\left(1,67 \mathrm{~mL} \cdot \mathrm{kg}^{-1}\right)$ e o maior valor $\left(29 \mathrm{~mL} \cdot \mathrm{kg}^{-1}\right)$ para índice de formol em méis da região norte do Estado da Bahia.

\subsubsection{Cinzas}

O teor de cinzas expressa a riqueza do mel em minerais e constitui-se num parâmetro bastante utilizado nas determinações que visam verificar sua qualidade. Os sais minerais encontrados no mel podem ser modificados por fatores relativos às abelhas, ao apicultor, clima, solo e flora (LASCEVE; GONNET, 1974).

Segundo Bogdanov (1999) o conteúdo de cinzas no mel é um critério de qualidade e está relacionado com a sua origem botânica. Assim o mel de origem floral tem menos cinzas que o mel de "honeydew". 
Vermeulen e Pelerents (1965) relataram a possibilidade de modificações do espectro mineral do mel devido a uma quantidade maior do pólen, mel prensado ou colhido de favo com pólen.

Para Ortiz (1988) o conteúdo de cinzas está correlacionado com a cor do mel, pois quanto mais escuro é o mel mais cinzas ele contém.

White (1979) identificou no mel os seguintes minerais: potássio, cloro, enxofre, cálcio, sódio, fósforo, magnésio, sílica, silício, ferro, manganês e cobre.

Soria et al. (2004) constataram em méis espanhóis o menor valor $(0,003 \%)$ para cinzas, já o maior valor $(1,2 \%)$ foi encontrado por Thrasyvoulou e Manikis (1995) em méis da Grécia.

\subsubsection{Proteína}

Apesar do pouco conhecimento sobre as características do material protéico, a ocorrência de proteína em mel é utilizada na detecção de adulteração do produto comercial (CRANE, 1975), sendo encontradas em pequenas quantidades nos méis normais, provenientes mais das abelhas do que das plantas (CRANE, 1987).

As proteínas constituem uma importante fonte alimentar, que ao serem hidrolizadas fornecem os aminoácidos necessários ao organismo. Dentre os aminoácidos encontrados no mel, pode-se citar a lisina, alanina, arginina, cistina, glicina, histidina, isoleucina, metionina, fenilalanina, serina, treonina, triptofano, tirosina, valina e prolina, sendo este último considerado o de maior importância dentre eles (CRANE, 1975). De acordo com White e Rudyj (1978) dentre os aminoácidos encontrados no mel, a prolina é o que está presente em maior quantidade, representando cerca de $50-85 \%$ do total.

Archenti (1984) constatou o menor valor $(0,02 \%)$ para proteína em méis argentinos e Amaral et al. (1986) encontraram o maior valor $(2,79 \%)$ em méis de flores de laranjeira produzidos no Estado de São Paulo. 


\subsubsection{Viscosidade}

Segundo Campos (1998) o conhecimento das propriedades reológicas dos alimentos é importante para o controle da sua qualidade. Rao (1977) afirma que o comportamento reológico de um fluido depende da sua composição, temperatura e taxa de deformação.

De acordo com Abu-Jdayil et al. (2002) a viscosidade do mel é muito dependente do conteúdo de água e, geralmente, decresce com o aumento do conteúdo de água.

Campos (1998) verificou que a viscosidade em méis de melato é maior que em méis florais.

O menor valor (68 mPa.s) para viscosidade foi verificado por Soria et al. (2004) em méis de Madri, já o maior (19200mPa.s) foi constatado por Marchini e Moreti (2001) em méis de eucalipto do Estado de São Paulo.

\subsubsection{Análises polínicas}

O conhecimento da origem floral dos méis é importante para a caracterização do produto. Assim, a análise polínica do mel é um instrumento para o reconhecimento das plantas apícolas utilizadas pelas abelhas como suprimento de néctar e pólen (HOWER, 1953).

O pólen que aparece no mel é coletado involuntariamente pelas abelhas no momento da coleta do néctar e constitui importante indicador de sua origem botânica e, principalmente geográfica (BARTH, 1989). Por meio da análise quantitativa de grãos de pólen, é possível estabelecer a proporção com que cada planta nectarífera contribui para a constituição do mel (IWAMA; MELHEM, 1979).

A palinologia é ramo da botânica que estuda o pólen das plantas, contribuindo para o conhecimento das espécies procuradas pelas abelhas, por meio de um estudo detalhado dos grãos ocorrentes em amostras de mel. Com o seu uso pode-se identificar as plantas que contribuem para a produção do mel e, também, confirmar a utilização das plantas exóticas, as quais são, na grande maioria, usuais em nossos pomares (FERREIRA, 1981).

Segundo a Normativa $\mathrm{n}^{\circ}$ 03, de 19 de janeiro de 2001 (BRASIL, 2001), define-se pólen apícola como o resultado da aglutinação do pólen das flores, efetuada pelas abelhas, mediante néctar e substâncias salivares, o qual é recolhido no ingresso da colméia. 
O pólen apícola é coletado por uma tela de retenção, caindo num recipiente coletor, conjunto este denominado coletor de pólen. No final da coleta encontram-se reunidas as bolotas de grãos de variável coloração, que indicam as diversas espécies botânicas colecionadas pelas abelhas e formam uma mistura conhecida por "mix" polínico, sendo este material removido pelo apicultor para o beneficiamento, comercialização e consumo (animal e humano).

Com o aumento da procura de alimentos naturais, o pólen apícola vem se destacando, sendo necessários estudos a respeito de seu processamento e caracterização (SAMPAIO, 1994). Trabalhos desenvolvidos por Barth (1970 a,b,c, 1971, 1989, 1990); Bastos (1998); Bastos; Brandão e Silveira (1995); Bastos; Silveira e Soares (2003); Braga (1961); Carvalho e Marchini (1999); Cortopassi-Laurino e Gelli (1991); Costa et al. (1999); Durkee (1971); Feller-Demalsy; Parent e Strachan (1987); Freitas (1991); Herrero e Valencia (2001); Jato et al. (1991); Lazarova e Bozilova (2002); Magalhães; Sicupira e Terra (1996); Moreti; Marchini e Oliveira (2000); Santos (1964, 1974); Seijo et al. (1992, 2003); Terrab et al. (2003, 2004) e Von Der Ohe et al. (2004) e evidenciam a importância do pólen encontrado no mel, para o conhecimento da origem botânica e geográfica da planta fornecedora, aumentando assim, a utilização desses recursos tróficos.

\subsection{Material e métodos}

\subsubsection{Considerações sobre a área de estudos}

A Estação Experimental de Itirapina é uma das unidades da Divisão de Florestas e Estações Experimentais do Instituto Florestal, ocupa um total de 6580 ha e dista cerca de $226 \mathrm{~km}$ da capital do Estado. Está situada, em sua maior parte, no município de Itirapina, SP, sendo que há uma área de aproximadamente 1200 ha localizada no município de Brotas, SP.

Segundo Pinheiro; Lima e Moraes (1976) 1778,50ha estão cobertos com florestas implantadas, sendo 101,40ha com espécies do gênero Eucalyptus, 1677,10ha com espécies do gênero Pinus e 270 ha que constituem uma área de preservação em forma de aceiros. O restante é coberto por vegetação natural em sua maior parte representada por cerrado em todas as suas formas fisionômicas: campos limpos, campos sujos, campos cerrados, cerrados "sensu strictu" e cerradões (Figura 1). 
O estudo foi desenvolvido em um fragmento de cerrado (chamado Valério), no município de Itirapina $\left(22^{\circ} 14^{\prime} \mathrm{S}\right.$ e $\left.47^{\circ} 49^{\prime} \mathrm{W}\right)$, com altitude média de $760 \mathrm{~m}$ e solo do tipo Latossolo Vermelho Amarelo fase rasa (LVr) (GIANOTTI, 1988). A região apresenta clima úmido com inverno seco, precipitação anual média de $1425 \mathrm{~mm}$, temperatura média de $19,7^{\circ} \mathrm{C}$ e clima classificado como Cwa de Köeppen (1948).

Segundo a classificação de fitofisionomias de cerrado de Ribeiro e Walter (1998) a área do Valério pode ser classificado como cerradão, caracterizando-se por apresentar flora com elementos do cerrado "sensu strictu" e da mata, com cobertura arbórea de 50-60\%. O extrato arbório é composto por indivíduos tortuosos e eretos, contendo poucas espécies com caducifolia na estação da seca e alturas médias de 8 a $15 \mathrm{~m}$.

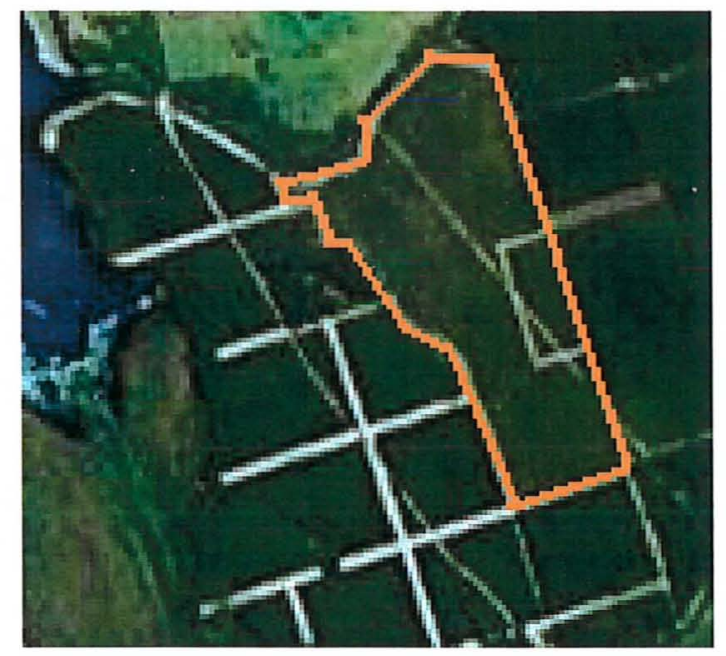

Figura 1 - Foto-satélite do fragmento de cerrado "Valério", município de Itirapina/SP

\subsubsection{Levantamento da flora apícola}

Foram realizados levantamentos quinzenais, durante o período de um ano, das plantas que estavam em floração (confecção do laminário de referência de pólen), com ênfase às que estavam sendo visitadas por A. mellifera, ao longo de uma trilha pré-determinada com cerca de $3000 \mathrm{~m}$ de extensão, seguindo o método baseado em Sakagami; Laroca e Moure (1967). Desta forma, sendo consideradas como componentes da flora apícola da área em estudo, as plantas cujo grão de pólen 
foi constatado nas amostras de mel e/ou do pólen proveniente dos coletores instalados nas colméias.

As plantas coletadas foram organizadas na forma de exsicata e direcionadas ao prof. Dr. Vinícius Castro Souza do Laboratório de Sistemática Vegetal (ESALQ/USP - Piracicaba/SP), para identificação deste material.

\subsubsection{As colônias de $A$. mellifera utilizadas no estudo}

Cinco colônias de $A$. mellifera $\mathrm{L}$. foram transferidas para caixas tipo Langstroth, mantidas dentro da respectiva área de estudo e avaliadas, mensalmente, durante o período de um ano, sendo determinada a composição físico-química e polínica do mel e identificação dos tipos de pólen proveniente dos coletores instalados nas colméias.

As análises físico-químicas e polínicas dos méis produzidos por $A$. mellifera e identificação

dos tipos polínicos foram realizadas no Laboratório de Insetos Úteis do Departamento de Entomologia, Fitopatologia e Zoologia Agrícola da Escola Superior de Agricultura "Luiz de Queiroz", Campus de Piracicaba, da Universidade de São Paulo.

\subsubsection{Coleta e análise do mel}

Para que não ocorresse mistura de mel produzido nos diferentes meses de coleta, foi adotado o critério de fornecimento de quadros vazios, marcados, colocados nas melgueiras. Ao final de cada mês foi feita a retirada dos mesmos com mel maduro.

Os favos foram centrifugados, o mel decantado e filtrado antes de se iniciarem as análises físico-químicas: cor, açúcares (açúcares redutores totais, açúcares redutores e sacarose), HMF, umidade, condutividade elétrica, $\mathrm{pH}$, acidez, índice de formol, teor de cinzas, proteínas, viscosidade e a análise polínica. Foi possível tipificar o mel produzido na área, possibilitando montar um banco de dados sobre o padrão de composição de méis produzidos na área de cerrado estudada.

Foram realizadas três repetições por amostra para cada parâmetro físico-químico analisado. Para a análise polínica foram realizadas duas contagens por amostra. 


\subsubsection{Cor $(\mathrm{nm})$}

A classificação da cor dos méis foi realizada em espectrofotômetro a $560 \mathrm{~nm}$ em célula de $1 \mathrm{~cm}$ e usando-se como branco a glicerina pura. Os valores encontrados foram transformados em cor pela escala de Pfund (VIDAL; FREGOSI, 1984).

\subsubsection{Açúcares redutores totais (AT), açúcares redutores (AR) e sacarose aparente (\%)}

A determinação dos açúcares redutores totais (\%), açúcares redutores (\%) e sacarose aparente $(\%)$ foram realizadas conforme o método Copersucar (1987) com modificações (Marchini; Sodré; Moreti, 2004).

\subsubsection{Hidroximetilfurfural $\left(\mathrm{mg} \cdot \mathrm{kg}^{-1}\right)$}

O hidroximetilfurfural foi determinado conforme o método A.O.A.C. (1990).

\subsubsection{Umidade (\%)}

A umidade das diferentes amostras de méis foi determinada pelo refratômetro manual marca ATAGO (luz natural, temperatura ambiente) específico para mel. O referido aparelho dispõe de uma escala, que expressa diretamente o valor da umidade (\%). Este aparelho foi adaptado a partir do refratômetro Abbe e possui um alto contraste no campo de visão (ATAGO CO. LTDA., 1988).

O método baseia-se no fenômeno da refração (relação entre as velocidades da luz no vácuo e numa substância) que um raio de luz incidente sofre ao incidir na solução de mel, que contém sólidos solúveis.

\subsubsection{Condutividade elétrica $\left(\mu \mathrm{S} . \mathrm{cm}^{-1}\right)$}

A condutividade elétrica foi medida em solução a $20 \%$ de matéria seca de mel a $20^{\circ} \mathrm{C}$ (B.O.E., 1986). Para tanto utilizou-se o condutivímetro, modelo HI8820, na obtenção dos dados. 


\subsubsection{0 pH e Acidez (meq. $\mathrm{kg}^{-1}$ )}

Os dois parâmetros foram determinados em seqüência, segundo o método adotado pelo Laboratório do Pólo Regional do Vale do Paraíba, da Agência Paulista de Tecnologia dos Agronegócios, em Pindamonhangaba, SP (MORAES; TEIXEIRA, 1998).

\subsubsection{1 Índice de formol ( $\left.\mathrm{mL} . \mathrm{kg}^{-1}\right)$}

O índice de formol foi determinado segundo o método adotado pelo Laboratório do Pólo Regional do Vale do Paraíba, da Agência Paulista de Tecnologia dos Agronegócios, em Pindamonhangaba, SP (MORAES; TEIXEIRA, 1998).

\subsubsection{Cinzas (\%)}

O teor de cinzas foi determinado por meio da calcinação em mufla a $550^{\circ} \mathrm{C}$ até um peso constante (PREGNOLATO; PREGNOLATO, 1985).

\subsubsection{Proteína $(\%)$}

A proteína do mel foi determinada seguindo-se o método de Silva e Queiroz (2002).

\subsubsection{Viscosidade (mPa.s)}

A viscosidade foi determinada com o auxílio do viscosímetro Brookfield, modelo $100 \mathrm{~S}$ digital, por meio da medição de torque originado pela resistência que o mel exerce ao movimento rotacional (CAMPOS, 1998).

\subsection{Análise polínica do mel e das cargas de pólen}

Adotou-se para esta análise o método da acetólise (ERDTMAN, 1952), que consiste no tratamento químico do grão de pólen, eliminando a intina, o citoplasma e as substâncias aderentes 
aos grãos, fossilizando-os artificialmente, ficando a exina mais transparente e mais própria para o estudo de seus detalhes.

Para preparação das lâminas (duas repetições para cada amostra) foram utilizadas amostras dos méis coletados durante o mês. Para o pólen, provenientes dos coletores, colocados nas colméias no decorrer de cada coleta de mel, foram colhidas amostras mensais. As amostras foram homogeneizadas e uma parcela de $1 \mathrm{~g}$ foi utilizada para a confecção das lâminas (duas repetições).

A identificação do pólen foi feita com base nos laminários de referência confeccionados com o pólen das plantas coletadas na área de estudo e, também, de laminários já existentes no laboratório de Insetos Úteis da ESALQ/USP.

Contou-se também para a identificação do material com o auxílio da Dra. Augusta Carolina de C. C. Moreti, do Instituto de Zootecnia de Nova Odessa,SP e da Dra. Ortrud Monika Barth da FIOCRUZ, no Rio de Janeiro, RJ.

Análise qualitativa - por meio dessa análise foram determinadas as espécies botânicas (ou tipos polínicos), levando-se em consideração aspectos morfológicos dos grãos de pólen quando comparados com laminário de referência.

Análise quantitativa - foi efetuada mediante contagem de 300 a 500 grãos de pólen por amostra e agrupados por espécies botânicas e/ou tipos polínicos. Essa contagem é caracterizada por agrupar os grãos de pólen em quatro classes de freqüência: pólen dominante com presença em mais de $45 \%$ do total de grãos, pólen acessório em 15 a 44\%, pólen isolado importante entre 3 e 15\% e pólen isolado ocasional em menos de 3\% (LOUVEAUX; MAURIZIO; VORWOHL, $1970,1978)$.

\subsection{Resultados e discussão}

\subsubsection{Composição da flora}

Foram coletadas no levantamento florístico 233 indivíduos, pertencentes a 79 espécies, 57 gêneros e 33 famílias (Tabela 1). 
Tabela 1 - Relação de espécies de plantas coletadas em área de cerrado no município de Itirapina/SP, de dezembro/2004 a novembro/2005

\begin{tabular}{|c|c|c|c|}
\hline Família & Espécie & Amostra & Período de coleta \\
\hline \multirow[t]{2}{*}{ Annonaceae } & Duguetia furfuraceae (St. Hil.) Benth \& Hook & 1 & $\mathrm{Jan} / \mathrm{Fev} / \mathrm{Mar} / \mathrm{Abr}$ \\
\hline & Xylopia aromatica (Lam.) Mart. & 2 & $\begin{array}{c}\mathrm{Fev} / \mathrm{Mar} / \mathrm{Jul} / \mathrm{Ago} / \mathrm{Set} / \mathrm{Out} / \mathrm{Nov} / \\
\mathrm{Dez}\end{array}$ \\
\hline Araliaceae & Didymopanax vinosum (Cham. \& Schltdl.) & 3 & $\mathrm{Ju} / \mathrm{Jul} / \mathrm{Ago}$ \\
\hline \multirow[t]{14}{*}{ Asteraceae } & Calea verticillata (Klatt) Pruski & 4 & Fev \\
\hline & Bidens gardneri Bak. & 5 & Fev/Mar \\
\hline & Emilia sonchifolia (L.) DC. & 6 & Out \\
\hline & Eupatorium conyzoides Vahl. & 7 & Mar/Abr/Jun \\
\hline & Eupatorium purpurascens Sch. & 8 & Jul \\
\hline & Eupatorium squalidum DC. & 9 & Mar/Abr/Mai/Jul \\
\hline & Eupatorium sp. & 10 & Ago \\
\hline & Gochnatia barrosi Cabrera & 11 & Ago \\
\hline & Gochnatia pulchra (Spreng.) Cabrera & 12 & Jul \\
\hline & Mikania hoffmaniana & 13 & Abr \\
\hline & Mikania sp. & 14 & Abril/Junho \\
\hline & Trichogonia salvifolia Gardner. & 15 & Set \\
\hline & Vernonia rubriramea Mart. ex DC. & 16 & $\mathrm{Abr} / \mathrm{Mai} / \mathrm{Jun} / \mathrm{Jul}$ \\
\hline & Vernonia sp. & 17 & Abr/Out/Nov \\
\hline \multirow[t]{6}{*}{ Bignoniaceae } & Amphilophium paniculatum (L.) H.B.K. & 18 & Jun/Nov \\
\hline & Arrabidaea sp. & 19 & Mar \\
\hline & Jacaranda caroba Vell. & 20 & Mai/Jul/Ago/Set/Out \\
\hline & Jacaranda decurrens Cham. & 21 & Out \\
\hline & Memora axillaris Burm. \& K. Schum. & 22 & Set \\
\hline & Pyrostegia venusta (Ker-Gawl.) Miers & 23 & $\mathrm{Abr} / \mathrm{Jun} / \mathrm{Jul} / \mathrm{Ago} / \mathrm{Set} / \mathrm{Out} / \mathrm{Nov}$ \\
\hline Bombacaceae & Eriotheca gracilipes (K. Schum) A. Robyns & 24 & $\mathrm{Jun} / \mathrm{Jul}$ \\
\hline Fabaceae: & Chamaecrista ramosa (Vogel) Irwin \& Barneby & 25 & Fev \\
\hline Caesalpinioideae & Senna rugosa (G.Don.) Irwin \& Barneby & 26 & $\mathrm{Mar} / \mathrm{Abr} / \mathrm{Nov}$ \\
\hline Caryocaraceae & Caryocar brasiliensis Camb. & 27 & Nov \\
\hline Commelinaceae & Commelina erecta $\mathrm{L}$. & 28 & Fev \\
\hline \multirow[t]{2}{*}{ Euphorbiaceae } & Sebastiania hispida (Mart.) Pax. & 29 & Junho \\
\hline & Croton glandulosus (L. em.) Muell. Arg. & 30 & Out/Nov \\
\hline Ebenaceae & Diospyros hispida A. DC. & 31 & Ago/Set \\
\hline \multirow[t]{2}{*}{ Fabaceaea } & Dalbergia miscolobium Benth. & 32 & Março \\
\hline & Stylosanthes gracilis H.B.K. & 33 & $\begin{array}{c}\mathrm{Jan} / \mathrm{Fev} / \mathrm{Mar} / \mathrm{Jun} / \mathrm{Jul} / \mathrm{Ago} / \mathrm{Out} / \\
\mathrm{Dez}\end{array}$ \\
\hline $\begin{array}{l}\text { Fabaceaea: } \\
\text { Faboideae }\end{array}$ & Crotalaria micans Link & 34 & Fev \\
\hline Hippocrateaceae & Peritassa campestris (Cambess.)A.C.Sm. & 35 & Out \\
\hline Lauraceae & Ocotea pulchella Nees et Mart. ex Ness & 36 & $\begin{array}{c}\text { Jan/Abr/Mai/Jun/Ago/Set/Nov } / \\
\operatorname{Dez}\end{array}$ \\
\hline
\end{tabular}


Tabela 1 - Relação de espécies de plantas coletadas em área de cerrado no município de Itirapina/SP, de dezembro/2004 a novembro/2005

\begin{tabular}{|c|c|c|c|}
\hline Família & Espécie & Amostra & Período de coleta \\
\hline \multirow[t]{2}{*}{ Lamiaceae } & Peltodon tomentosus Pohl. & 37 & Jul \\
\hline & Aegiphila lhotzkiana Cham. & 38 & Out \\
\hline Lythraceae & Cuphea mesostemon Koehne & 39 & Out/Nov \\
\hline Logamiaceae & Strychnos pseudoquina A. St-Hil. & 40 & Mar \\
\hline \multirow[t]{6}{*}{ Malpighiaceae } & Banisteriopsis variabilis B.Gates. & 41 & $\mathrm{Abr} / \mathrm{Set} / \mathrm{Out} / \mathrm{Nov}$ \\
\hline & Banisteriopsis sp. & 42 & $\mathrm{Jan} / \mathrm{Fev} / \mathrm{Mar} / \mathrm{Abr} / \mathrm{Ago} / \mathrm{Dez}$ \\
\hline & Byrsonima coccolobifolia & 43 & Out \\
\hline & Byrsonima crassa Nied. & 44 & Maio/Jun/Ago/Set \\
\hline & Byrsonima intermedia A. Juss & 45 & Out/Nov/Dez \\
\hline & Byrsonima sp. & 46 & Nov \\
\hline \multirow[t]{4}{*}{ Melastomataceae } & Miconia albicans (Sw.) Triana & 47 & Jun/Jul/Ago \\
\hline & Miconia fallax DC. & 48 & Jun/Set/Out \\
\hline & Miconia rubiginosa (Bonpl.) DC. & 49 & Abril/Jun/Jul/Ago/Dez \\
\hline & Miconia sp. & 50 & Abr/Mai/Jul/Ago/Set/Out/Nov \\
\hline Fabaceae: & Anadenanthera & 51 & $\mathrm{Jul} / \mathrm{Ago} / \mathrm{Set} / \mathrm{Out} / \mathrm{Nov}$ \\
\hline \multirow[t]{2}{*}{ Mimosoideae } & Stryphnodendron adstringens (Mart.) Coville & 52 & Set \\
\hline & Stryphnodendron obovatum Benth. & 53 & Nov/Dez \\
\hline \multirow[t]{6}{*}{ Myrtaceae } & Blepharocalyx salicifolius (HBK) O.Berg. & 54 & Nov \\
\hline & Campomanesia & 55 & Jul/Set/Out \\
\hline & Eugenia bimarginata DC. & 56 & Jul \\
\hline & Eugenia guianensis (Aubl.) DC. & 57 & Out \\
\hline & Myrcia guianensis (Aubl.) DC. & 58 & $\mathrm{Jul} / \mathrm{Ago} / \mathrm{Set}$ \\
\hline & Myrcia lingua $\mathrm{Berg}$. & 59 & Set \\
\hline Myrsinaceae & Rapanea sp. & 60 & Jan \\
\hline \multirow[t]{2}{*}{ Ochnaceae } & Ouratea spectabilis (Mart.) Engl. & 61 & Ago \\
\hline & Sauvagesia sp. & 62 & Nov \\
\hline Poaceae & Tipo Poaceae & 63 & Abr \\
\hline \multirow[t]{3}{*}{ Rubiaceae } & Barreria sp. & 64 & Mar \\
\hline & Palicourea croceoides Ham. & 65 & Nov \\
\hline & Palicourea rigida Kunth. & 66 & Dezembro \\
\hline Salicaceae: & Casearia sylvestris Sw. & 67 & Set/Out \\
\hline \multirow[t]{3}{*}{ Sapindaceae } & Serjania gracilis Radlk. & 68 & Set \\
\hline & Serjania paucidentata DC. & 69 & Ago/Set \\
\hline & Serjania sp. & 70 & $\mathrm{Jul} / \mathrm{Set} / \mathrm{Out}$ \\
\hline Solanaceae & Solanum lycocarpum A. St-Hil. & 73 & Jan/Fev/Mar/Jul/Out/Nov/Dez \\
\hline Styracaceae & Styrax camporum Pohl. & 74 & Jun/Jul \\
\hline
\end{tabular}


Tabela 1 - Relação de espécies de plantas coletadas em área de cerrado no município de Itirapina/SP, de dezembro/2004 a novembro/2005

\begin{tabular}{clccc} 
& \multicolumn{1}{c}{ Espécie } & Amostra & Período de coleta \\
\hline Familia & \multicolumn{1}{c}{ (conclũo) } \\
\hline Vochysiaceae & Qualea grandiflora Mart. & 75 & Dez \\
& Vochysia cinnamomea Pohl. & 77 & Abr/Jun \\
& Vochysia tucanorum Mart. & 78 & Jan/Mar \\
Verbenaceae & Aegiphila lhotzkiana Cham. & 79 & Jul \\
& Lippia velutina Sch. & & Jan/Fev/Mar \\
\hline
\end{tabular}

Das 33 famílias catalogadas neste trabalho, 17 foram representadas por apenas uma espécie, sete famílias por duas espécies, quatro famílias por três espécies, a família Melastomataceae por quatro espécies, Bignoniaceae, Malpighiaceae e Myrtaceae por seis espécies e a família Asteraceae por 14 espécies (Figura 2).

Gianotti (1988) em levantamento florístico da vegetação arbustiva e arbórea do fragmento de cerrado "Valério", município de Itirapina/SP, obteve 4822 indivíduos, correspondentes a 118 espécies, 87 gêneros e 46 famílias.

Almeida (2002) observou, em área de cerrado do município de Pirassununga/SP, que a família Asteraceae apresenta maior riqueza de espécies, encontrando 27 espécies na área.

Carvalho (1999) e Vieira (2005) em estudo de flora apícola, no município de Castro Alves/BA e em área de cerrado no município de Cassilândia/MS, respectivamente, encontraram as famílias Mimosaceae e Malpighiaceae com maior riqueza de espécies.

Segundo Barroso (1986) no Brasil são encontrados 300 espécies pertencentes a 32 gêneros da família Malpighiaceae. Apresentando importância apícola o gênero Byrsonima, cujas espécies são frequentes no cerrado (GOODLAND; FERRI, 1979). Campos (1989) observou que essa família ocupava o terceiro lugar em abundância de espécies apícolas em uma área de cerrado no município de Corumbataí/SP. Mateus (1998) observou essa famiília entre as com maior riqueza de espécies no município de Luiz Antônio/SP. 


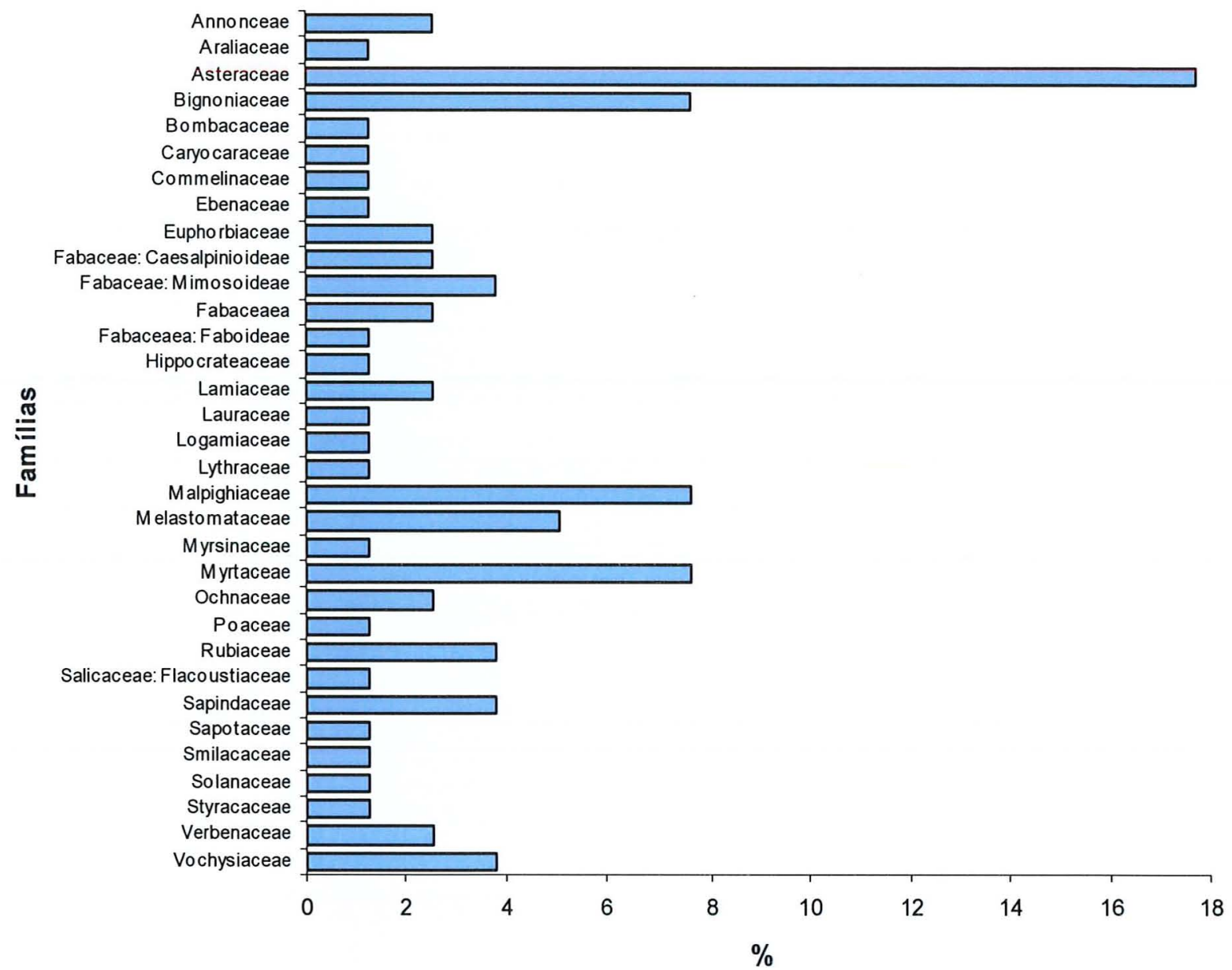

Figura 2 - Porcentagem de número de espécies de plantas, por família, coletadas em uma área de cerrado no município de Itirapina/SP, no período de dezembro de 2004 a novembro de 2005

Pedro (1992) analisando comunidade de abelhas em área de cerrado no município de Cajurú/SP, observou um grande número de Apis mellifera nas flores de espécies da família Malpighiaceae, concluindo que esta família era a única fonte de óleo no ecossistema.

Os gêneros com maior representatividade no estudo foram: Eupatorium, Byrsonima, Miconia (4 espécies cada) e Serjania (3 espécies).

Almeida (2002) e Vieira (2005) estudando flora apícola, em área de cerrado do município de Pirassununga/SP e Cassilândia/MS, respectivamente, encontraram cinco e três espécies, respectivamente, pertentecentes ao gênero Serjania. Dentre os gêneros de maior riqueza encontrados por Almeida (2002) encontra-se Eupatorium. 


\subsubsection{Composição físico-química do mel}

Os resultados dos parâmetros físico-químicos analisados para as amostras de méis de Apis mellifera, coletados durante o período de fevereiro a outubro de 2005, em Itirapina/SP, encontram-se nas Tabelas 2 e 3.

Tabela 2 - Cor e valores médios de açúcares (redutores, redutores totais e sacarose), hidroximetilfurfural (HMF) e umidade de méis produzidos por Apis mellifera de fevereiro/2005 a outubro/2005, em área de cerrado no município de Itirapina/SP

\begin{tabular}{|c|c|c|c|c|c|c|c|}
\hline Amostra & $\begin{array}{c}\text { Mês } \\
\text { coleta }\end{array}$ & $\begin{array}{l}\text { Cor } \\
(\mathrm{nm})\end{array}$ & $\begin{array}{l}\mathrm{AR}^{* *} \\
(\%)\end{array}$ & $\begin{array}{c}\text { ART** }^{* *} \\
(\%)\end{array}$ & $\begin{array}{c}\text { Sacarose } \\
(\%)\end{array}$ & $\begin{array}{c}\mathrm{HMF} \\
\left(\mathrm{mg} \cdot \mathrm{kg}^{-1}\right)\end{array}$ & $\begin{array}{c}\text { Umidade } \\
(\%)\end{array}$ \\
\hline 1 & Fev & Âmbar claro & 66,49 & 68,11 & 1,55 & 12,24 & 18,73 \\
\hline 2 & Mar & Âmbar claro & 68,16 & 69,58 & 1,34 & 19,12 & 17,17 \\
\hline 3 & $\mathrm{Abr}$ & Âmbar claro & 69,28 & 68,88 & 0,38 & 10,64 & 17,10 \\
\hline 4 & Mai & Âmbar claro & 67,22 & 67,70 & 0,45 & 4,15 & 16,97 \\
\hline 5 & Jun & Âmbar & 63,74 & 67,41 & 3,49 & 11,42 & 16,50 \\
\hline 6 & $\mathrm{Jul}$ & Âmbar & 60,86 & 64,20 & 3,17 & 7,60 & 19,53 \\
\hline 7 & Ago & Âmbar claro & 69,08 & 71,41 & 2,21 & 5,68 & 16,43 \\
\hline 8 & Set & Extra âmbar claro & 71,48 & 73,09 & 1,53 & 1,96 & 15,77 \\
\hline 9 & Out & Âmbar claro & 70,62 & 72,06 & 1,37 & 1,91 & 16,73 \\
\hline \multicolumn{3}{|c|}{ Média \pm desvio } & $67,39 \pm 3,35$ & $69,20 \pm 2,74$ & $1,72 \pm 1,07$ & $8,30 \pm 5,63$ & $17,21 \pm 1,18$ \\
\hline \multicolumn{3}{|l|}{ Mínimo } & 60,86 & 64,20 & 0,38 & 1,91 & 15,77 \\
\hline \multicolumn{3}{|l|}{ Máximo } & 71,48 & 73,09 & 3,49 & 19,12 & 19,53 \\
\hline \multicolumn{2}{|l|}{ Normas* } & $-\cdots$ & Mín. 65 & $\ldots$ & Máx. 6 & Máx. 60 & Máx. 20 \\
\hline
\end{tabular}


Tabela 3 - Valores médios de condutividade elétrica, $\mathrm{pH}$, acidez, índice de formol, cinzas, proteína e viscosidade de méis produzidos por Apis mellifera de fevereiro/2005 a outubro/2005, em área de cerrado no município de Itirapina/SP

\begin{tabular}{|c|c|c|c|c|c|c|c|c|}
\hline Amostra & $\begin{array}{c}\text { Mês } \\
\text { Coleta }\end{array}$ & $\begin{array}{l}\text { Cond. Elétrica } \\
(\mu \mathrm{S})\end{array}$ & $\mathrm{pH}$ & $\begin{array}{c}\text { Acidez } \\
(\text { meq.kg }\end{array}$ & $\begin{array}{c}\text { Ind. Formol } \\
\left(\mathrm{mL} \cdot \mathrm{kg}^{-1}\right)\end{array}$ & $\begin{array}{c}\text { Cinzas } \\
(\%)\end{array}$ & $\begin{array}{c}\text { Proteína } \\
(\%)\end{array}$ & $\begin{array}{l}\text { Viscosidade } \\
\text { (mPa.s) }\end{array}$ \\
\hline 1 & Fev & 1095,67 & 4,34 & 33,33 & 9,33 & 0,54 & 0,59 & 1070,00 \\
\hline 2 & Mar & 1428,33 & 4,64 & 28,33 & 9,33 & 0,72 & 0,57 & 2683,33 \\
\hline 3 & $\mathrm{Abr}$ & 1851,33 & 4,94 & 23,33 & 9,00 & 1,02 & 0,98 & 2636,67 \\
\hline 4 & Mai & 1744,33 & 4,90 & 24,67 & 11,67 & 0,85 & 0,66 & 3536,67 \\
\hline 5 & Jun & 1220,00 & 4,66 & 37,00 & 15,33 & 0,71 & 0,81 & 3550,00 \\
\hline 6 & Jul & 1334,67 & 4,30 & 47,00 & 16,67 & 0,57 & 0,74 & 1123,33 \\
\hline 7 & Ago & 547,00 & 4,29 & 24,33 & 7,00 & 0,20 & 0,58 & 2863,33 \\
\hline 8 & Set & 283,67 & 3,99 & 15,08 & 8,38 & 0,06 & 1,00 & 4546,67 \\
\hline 9 & Out & 227,33 & 3,77 & 17,78 & 6,04 & 0,04 & 0,13 & 2766,67 \\
\hline $\begin{array}{l}\text { Média } \\
\pm \text { desvio }\end{array}$ & & $1081,37 \pm 679,00$ & $4,43 \pm 0,39$ & $27,87 \pm 9,93$ & $10,31 \pm 3,61$ & $0,52 \pm 0,35$ & $0,67 \pm 0,25$ & $2752,96 \pm 1117,23$ \\
\hline Mínimo & & 227,33 & 3,77 & 15,08 & 6,04 & 0,04 & 0,13 & 1070,00 \\
\hline Máximo & & 1851,33 & 4,94 & 47,00 & 16,67 & 1,02 & 1,00 & 4546,67 \\
\hline Normas* & & $\ldots$ & $\ldots$ & Máx. 50 & --- & Máx. 0,6 & --- & $\ldots$ \\
\hline
\end{tabular}

\subsubsection{Cor}

As cores observadas nas amostras analisadas estão na Tabela $2 \mathrm{e}$ as porcentagens de amostras classificadas nas diferentes cores, na Figura 3. Observou-se uma predominância da cor âmbar claro $(66,7 \%)$, seguida das cores âmbar $(22,2 \%)$ e âmbar extra claro $(11,1 \%)$. As cores encontradas estão em conformidade com a legislação, que pode variar de branco d'água a âmbar escuro (BRASIL, 2000).

A cor do mel apresenta uma relação com a sua origem floral, condições climáticas durante o fluxo de néctar e a temperatura da colméia (SEEMANN; NEIRA, 1988). Segundo Smith (1967) essa propriedade também está relacionada com o tempo de estocagem, luz, calor e possíveis reações enzimáticas.

Resultados semelhantes, com predominância da cor âmbar claro, foram observados em outros trabalhos como de Baldi Coronel; Dall'Ogllio e Lezcano (1993) em méis argentinos; Carvalho et al. (2000) em méis produzidos no Estado da Bahia; Marchini e Moreti (2001) em méis do Estado de São Paulo; Marchini; Persano-Oddo et al. (1995) em méis italianos; Sodré (2000) em méis produzidos no mesmo Estado; Sodré et al. (2002) em méis produzidos no Estado da Bahia; Sodré (2005) em méis produzidos nos Estados do Ceará e do Piauí; Uñantes et al. 
(1999) em méis argentinos e Vieira (2005) em méis produzidos em área de cerrado do Estado do Mato Grosso do Sul.

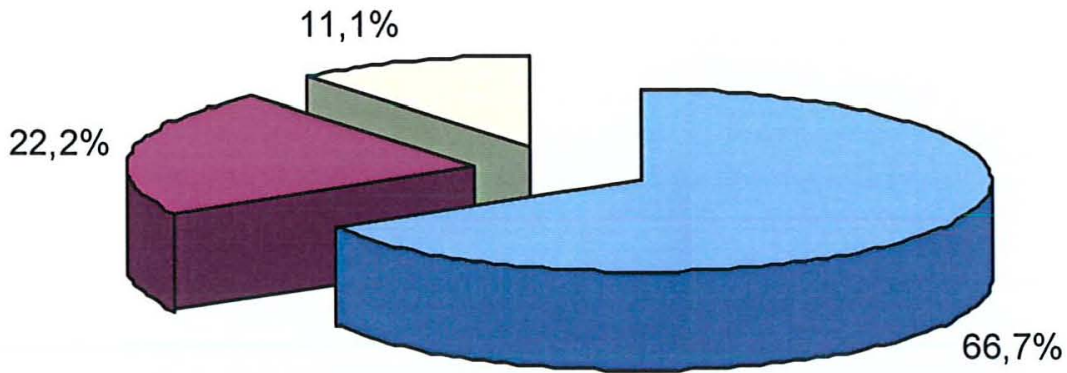

$\square$ Âmbar claro $\square$ Âmbar $\square$ Extra âmbar claro

Figura 3 - Porcentagem de classes de cor obtidas em amostras de méis produzidos por Apis mellifera, de fevereiro/2005 a outubro/2005, em área de cerrado no município de Itirapina/SP

\subsubsection{Açúcares redutores totais}

As porcentagens de açúcares redutores totais obtidos nas amostras analisadas variaram de 64,20 a 73,09\%, com valor médio de $69,20 \pm 2,74 \%$ (Tabela 2). Para este parâmetro não existe valor estabelecido na norma vigente.

Os resultados obtidos neste trabalho estão próximos aos encontrados por Campos (1998) em méis produzidos nos Estados de Minas Gerais e Santa Catarina; Marchini (2001) em méis do Estado de São Paulo; Sodré (2000) em méis do Estado de Sào Paulo; Sodré et al. (2002) em méis do Estado do Ceará que obtiveram uma variação de 58,36 a 81,93\% para açúcares redutores totais.

\subsubsection{Açúcares redutores}

Os teores de açúcares redutores obtidos nas amostras analisadas variaram de 60,86 a

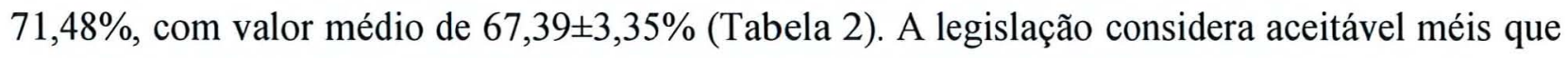
apresentem valores mínimos de $65 \%$ para açúcares redutores, portanto, nem todas as amostras 
estão em conformidade com os padrões estabelecidos para este parâmetro. De acordo com a norma vigente, $22,2 \%$ das amostras analisadas estão abaixo dos valores permitidos (Figura 4).

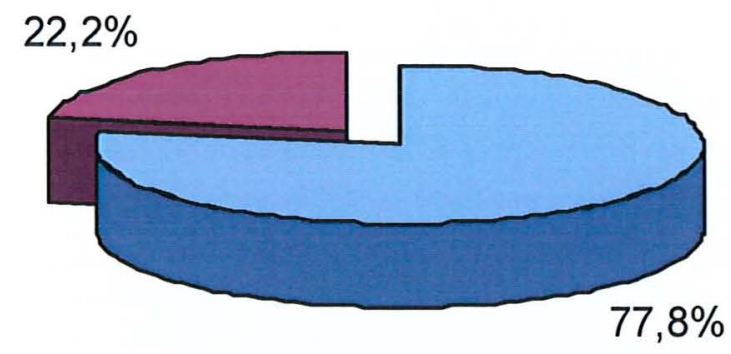

$\square$ Aceitável $\square$ Não aceitável

Figura 4 - Porcentagem de amostras de méis produzidos por Apis mellifera, de fevereiro/2005 a outubro/2005, em área de cerrado no município de Itirapina/SP, que apresentaram o parâmetro açúcares redutores aceitável segundo a legislação brasileira

Os resultados encontrados foram semelhantes aos obtidos por Campos (1998) em méis produzidos nos Estados de Minas Gerais e Santa Catarina, que obteve uma variação de 55,73 a $77,10 \%$.

Alguns trabalhos tiveram uma variação maior de açúcares redutores: Arruda (2003) em méis do Estado do Ceará; Baldi Coronel; Dall'Ogllio e Lezcano (1993) em méis argentinos; Komatsu; Marchini e Moreti (2002) méis de diferentes origens florais do Estado de São Paulo; Mendonça; Sodré e Marchini (2004) em méis do Estado do Mato Grosso; Sodré (2005) em méis produzidos nos Estados do Ceará e do Piauí e Vieira (2005) em méis produzidos no cerrado Estado do Mato Grosso do Sul que obtiveram uma variação de 53,2 a 87,3\% para açúcares redutores.

\subsubsection{Sacarose aparente}

As concentrações de sacarose encontradas nas amostras analisadas variaram de 0,38 a $3,49 \%$, com valor médio de $1,72 \pm 1,07 \%$ (Tabela 2 ). A norma vigente considera aceitável índices de até $6 \%$ para sacarose, com exceção para méis de melato cujo valor pode chegar a $15 \%$. Nenhuma das amostras analisadas está acima dos valores permitidos (Figura 5). 
O alto conteúdo de sacarose aparente nos méis pode indicar um mel "verde", ou seja, ainda não foi totalmente transformado em glicose e frutose pela ação da enzima invertase secretada pelas abelhas, além de indicar uma adulteração do produto (AZEREDO; AZEREDO; DAMASCENO, 1999).

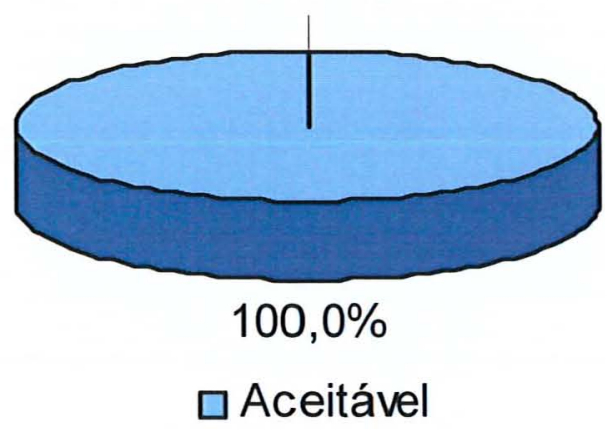

Figura 5 - Porcentagem de amostras de méis produzidos por Apis mellifera, de fevereiro/2005 a outubro/2005, em área de cerrado no município de Itirapina/SP, que apresentaram o parâmetro sacarose aceitável segundo a legislação brasileira

Resultados semelhantes foram obtidos por: Mendonça; Sodré e Marchini (2004) encontraram valor médio de 3,01\% méis do Estado do Mato Grosso; Rendón (1996) em amostras da Espanha obteve valores entre 0,5 e 4,2\% e Vit-Oliver; Martorelli e Palacios obtiveram variação de 0 a 4,73 para méis produzidos na Venezuela

Variações maiores foram observadas por alguns autores: Almeida (2002) obteve valores entre 0,2 e 11,4\% em méis produzidos em cerrado paulista; Arruda (2003) obteve valores entre 0,84 a 8,19 em méis do Estado do Ceará; Baldi Coronel; Dall'Ogllio e Lezcano (1993) obtiveram valores entre 1 e 13\% para méis produzidos na Argentina; Carneiro et al. (2002) obteve variação de 0,4 a 7,9 para méis produzidos no Estado do Piauí; Dozo (1980) em méis provenientes de Buenos Aires, obteve variação de 0,47 a 8,50\%; Komatsu; Marchini e Moreti (2002) encontraram valores entre 0,2 e $27,4 \%$ para méis silvestres, 0,1 a $15,2 \%$ para méis de eucalipto e 0,3 a $5,2 \%$ para méis de laranjeira do Estado de São Paulo; Marchini (2001) obteve variação de 0,1 a 15,2 e 0,2 a 27,4 para méis de eucalipto e silvestres, respectivamente, produzidos no Estado de São Paulo e Sodré (2005) encontrou uma variação de 0,16 a 7,63 e 0,15 a 11,44 em méis produzidos nos Estados do Ceará e do Piauí, respectivamente. 


\subsubsection{Hidroximetilfurfural (mg. $\left.\mathrm{kg}^{-1}\right)$}

As quantidades de hidroximetilfurfural (HMF) nas amostras analisadas variaram de 1,91 a

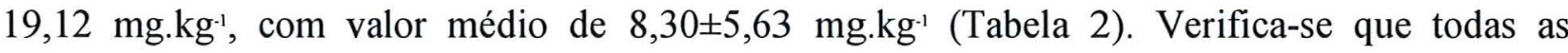
amostras estão em conformidade com a legislação, cujo valor máximo permitido é de $60 \mathrm{mg} \cdot \mathrm{kg}^{-1}$ (BRASIL, 2000) (Figura 6).

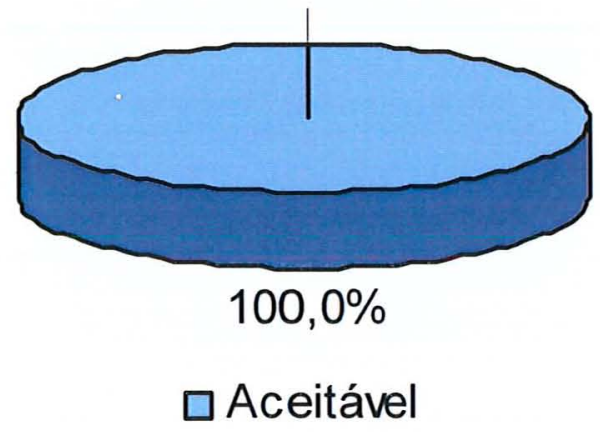

Figura 6 - Porcentagem de amostras de méis produzidos por Apis mellifera, de fevereiro/2005 a outubro/2005, em área de cerrado no município de Itirapina/SP, que apresentaram o parâmetro HMF aceitável segundo a legislação brasileira

Segundo Dayrell e Vital (1991) méis de países tropicais possuem alto teor de HMF, em função do clima quente, sendo a quantificação deste parâmetro fundamental para a verificação da qualidade do produto. Esses autores, analisando amostras de méis brasileiros, encontraram valores variando de 1,1 a 248,2 mg.kg-1.

Em estudos realizados com a determinação da quantidade de HMF, autores como: Almeida (2002); Arruda (2003); Gomez et al. (1993); Persano-Oddo et al. (1995); Pfau e Ruhle (1986); Serra-Bonvehí e Granados-Tarrés (1993) e Vieira (2005) apresentaram uma variação de 0 a 12,43 mg.kg-1 para HMF.

\subsubsection{Umidade (\%)}

As porcentagens de umidade obtidas nas amostras analisadas variaram de 15,77 a 19,53\%, com valor médio $17,21 \pm 1,18 \%$ (Tabela 2 ). 
As normas nacionais estabelecem o limite de $20 \%$ para a umidade, portanto, todas as amostras analisadas neste trabalho estão dentro dos níveis permitidos pela legislação (Figura 7).

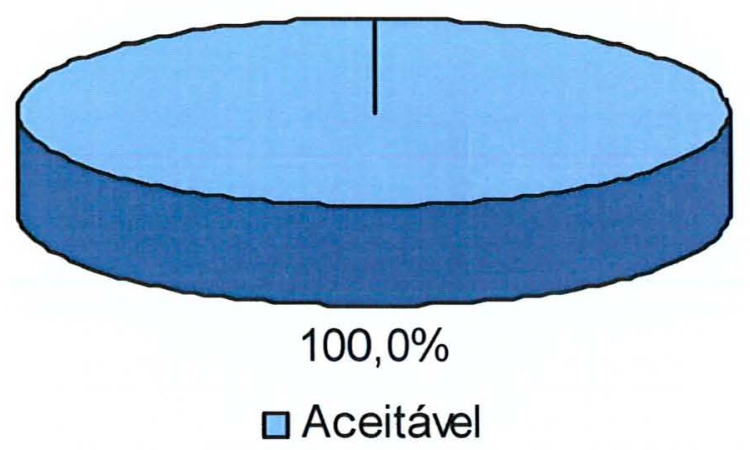

Figura 7 - Porcentagem de amostras de méis produzidos por Apis mellifera, de fevereiro/2005 a outubro/2005, em área de cerrado no município de Itirapina/SP, que apresentaram o parâmetro umidade aceitável segundo a legislação brasileira

Os resultados obtidos são semelhantes aos encontrados por: Almeida (2002) que obteve valores entre 16,6 a 20,8\% em méis do cerrado paulista; Arruda (2003) que encontrou valores entre 14,97 e 17,23 em méis do Estado do Ceará; Duran et al. (1996) obtiveram valor médio de 18,7\% para méis do Brasil; Marchini e Carvalho (2002) encontraram valores entre 17 e 22,9\% para més produzidos no litoral Norte do Estado da Bahia; Marchini; Sodré e Rodrigues (2001) obtiveram valor médio igual a $19,98 \%$ em méis produzidos no Mato Grosso do Sul; Sodré; Martínez-Gomez et al. (1993) obtiveram valores entre 16 a 19\% em méis de eucalipto; Mendonça; Sodré e Marchini (2004) encontraram valor médio de 17,24\% méis do Estado do Mato Grosso; Rendón (1996) obteve valores entre 15,00 a 18,80\% em méis produzidos na Espanha; Sodré (2005) verificou valores de 15,77 a 20,27\% para méis provenientes do Estado Ceará e 16,44 a 19\% para méis provenientes do Estado do Piauí e Vieira (2005) obteve valores de 15,7 a 26\% para méis do cerrado do Estado do Mato Grosso do Sul. 


\subsubsection{Condutividade elétrica $(\mu S)$}

Os valores obtidos para condutividade elétrica para as amostras analisadas variaram de 227,33 a $1851,33 \mu \mathrm{S}$, com valor médio de $1081,37 \pm 600,79 \mu \mathrm{S}$ (Tabela 3). A legislação não estabelece valores para este parâmetro.

Em estudos realizados com a determinação de valores de condutividade elétrica, autores como: Almeida (2002) que observou uma variação de 284 a $2200 \mu \mathrm{S}$ para méis produzidos no cerrado paulista; Durán et al. (1996) encontraram valores de 100 a $2103 \mu \mathrm{S}$ para méis de diferentes regiões brasileiras; Persano-Oddo et al. (1995) obtiveram uma variação de 90 a 2110 $\mu \mathrm{S}$ para méis produzidos na Itália e Sodré (2000) e obteve valores de 271,67 a $1634 \mu \mathrm{S}$ em méis provenientes do Estado da Bahia.

\section{$2.8 .8 \mathrm{pH}$}

Os valores encontrados para $\mathrm{pH}$ nas amostras analisadas variaram de 3,77 a 4,94 com um

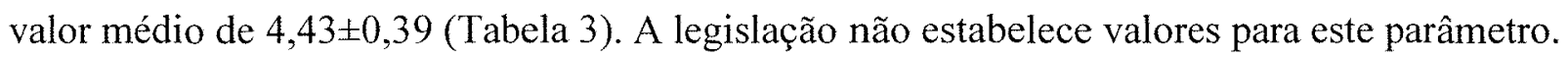

Valores semelhantes aos encontrados por: Almeida (2002) que obteve os índices de pH entre 3,27 a 4,45 para méis produzidos no cerrado paulista; Andrade et al. (1999) que analisaram amostras de méis de Portugal, obtendo valores entre 3,6 e 4,46; Arruda (2003) que obteve valores entre 3,58 a 3,83 em méis produzidos no Estado do Ceará; Marchini; Sodré e Rodrigues (2001) que obtiveram o valor médio de 4,13 para pH de méis provenientes do Estado de São Paulo; Mendonça; Sodré e Marchini (2004) encontraram valor médio de 3,57 em méis do Estado do Mato Grosso; Pamplona (1989) que obteve uma variação de 3,10 a 5,3 em diferentes méis brasileiros; Sodré (2002) que obteve valores de pH com uma variação de 3,37 a 4,46 em méis do Estado da Bahia e Vieira (2005) que obteve valores entre 3,4 e 4,9 em méis produzidos no cerrado do Mato Grosso do Sul.

\subsubsection{Acidez (meq. $\mathrm{kg}^{-1}$ )}

Os valores de acidez obtidos nas amostras analisadas variaram de 15,08 a 47,00 meq. $\mathrm{kg}^{-1}$, com valor médio de $27,87 \pm 9,93$ meq. $\mathrm{kg}^{-1}$ (Tabela .3). O valor máximo estabelecido pela 
legislação é de 50 meq. $\mathrm{kg}^{-1}$, portanto, todas as amostras encontram-se de acordo com a norma vigente (Figura 8).

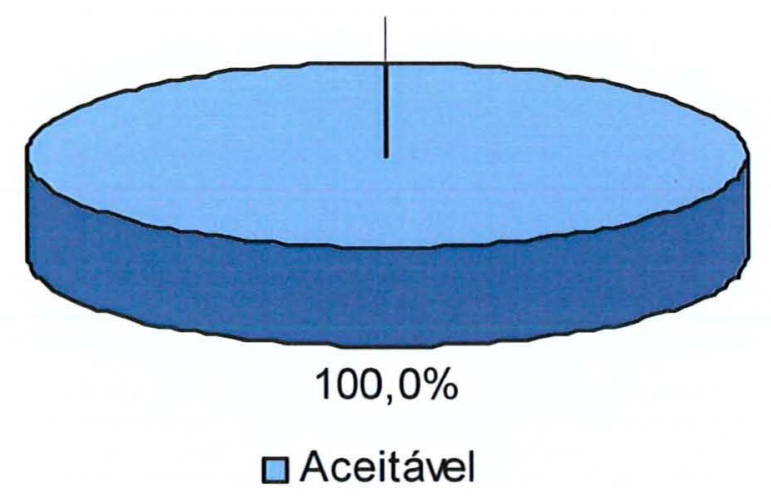

Figura 8 - Porcentagem de amostras de méis produzidos por Apis mellifera, de fevereiro/2005 a outubro/2005, em área de cerrado no município de Itirapina/SP, que apresentaram o parâmetro acidez aceitável segundo a legislação brasileira

Segundo Cornejo (1988) a acidez no mel permite detectar o processo de fermentação e as condições de armazenamento do mesmo. Pamplona (1989) relata que o ácido glucônico, formado pela ação da enzima glicose-oxidase sobre a glicose, tende a aumentar no mel mesmo durante o armazenamento, assim, a acidez do mel também aumenta durante o armazenamento.

Trabalhos como: Almeida (2002) em méis do cerrado paulista; Archenti (1984) em méis argentinos, Bendini; Faria Júnior e Barreto (2002) em méis do Estado de São Paulo; Campos (1998) analisando méis do cerrado paulista; Carvalho et al. (2000) em méis do Estado da Bahia; Marchini (2001) em méis do Estado de São Paulo; Marchini; Sodré e Rodrigues (2001) em méis do Mato Grosso do Sul; Mendonça; Sodré e Marchini (2004) em méis do Estado do Mato Grosso e Sodré (2005) em méis dos Estados do Ceará e Piauí obtiveram uma variação nos valores de acidez 8,0 de a $50 \mathrm{meq} \cdot \mathrm{kg}^{-1}$.

\subsubsection{0 Índice de formol $\left(\mathrm{mL} . \mathrm{kg}^{-1}\right)$}

Os valores obtidos para o índice de formol nas amostras analisadas variaram de 6,04 a $16,67 \mathrm{~mL} \cdot \mathrm{kg}^{-1}$ com valor médio de $10,31 \pm 3,61 \mathrm{~mL} \cdot \mathrm{kg}^{-1}$ (Tabela 3). A legislação não estabelece limites para este parâmetro (BRASIL, 2000). 
O índice de formol pode ser usado com um indicador da autenticidade do mel, podendo informar adulteração com produtos artificiais (FRIAS; HARDISSON, 1992).

Os valores obtidos são semelhantes aos encontrados por: Almeida (2002) que encontrou uma variação de 3,5 a $19,0 \mathrm{~mL} \cdot \mathrm{kg}^{-1}$ para méis produzidos no cerrado no Estado de São Paulo Carvalho et al. (1998) que obtiveram o valor médio de $16,49 \mathrm{~mL} \cdot \mathrm{kg}^{-1}$ em méis do Estado da Bahia; Komatsu (1996) que obteve o valor médio de $10,1 \mathrm{~mL} \mathrm{~kg}^{-1} \mathrm{em}$ méis de diferentes origens florais do Estado de São Paulo; Marchini (2001) que observou uma variação de 5,0 a 20,5mL. $\mathrm{kg}^{-1}$ e 5,0 a 12,5 mL.kg ${ }^{-1}$ para méis silvestres e de eucalipto, respectivamente, do Estado de São Paulo; Mendonça; Sodré e Sabadin (2004) obtiveram valores entre 6,33 e 14,33 para méis provenientes do Estado do Paraná; Mendonça; Sodré e Marchini (2004) encontraram valor médio de 5,63 ${\mathrm{mL} . \mathrm{kg}^{-1}}^{-1} \mathrm{em}$ méis do Estado do Mato Grosso; Sodré (2005) que encontrou valores de 4,0 a $13,0 \mathrm{~mL} \cdot \mathrm{kg}^{-1}$ em méis do Estado do Ceará e de 5 a $11 \mathrm{~mL} \cdot \mathrm{kg}^{-1}$ em méis do Estado do Piaú e Vieira (2005) obteve variação de 5,0 a 16,0 mL. $\mathrm{kg}^{-1}$ em méis do cerrado Estado do Mato Grosso do Sul.

\subsubsection{Cinzas $(\%)$}

As porcentagens de cinzas obtidas para as amostras analisadas variaram de 0,04 a $1,02 \%$, com valor médio de $0,52 \pm 0,35 \%$ (Tabela 3 ). A legislação considera aceitável méis com valores de cinzas de até $0,6 \%$ (BRASIL, 2000) Das amostras analisadas 44,4\% encontram-se acima desse valor (Figura 9).

O conteúdo de cinzas no mel é influenciado pela origem botânica, podendo ocorrer variações por fatores relacionados às abelhas, ao apicultor e ao clima da região onde $f$ oi produzido (LASCEVE; GONNET, 1974).

Trabalhos com determinação de teores de cinzas em méis: Almeida (2002) observou uma variação de 0,02 a 0,77\% em méis do cerrado paulista; Arruda (2003) encontrou uma variação de 0,127 a 0,246\% em méis provenientes do Estado do Ceará; Fletchtmann et al. (1963) obteve valores médios de 0,17 para méis do Estado de São Paulo; Marchini (2001) observou valores médios de $0,16 \%$ para méis do Estado de São Paulo; Marchini; Sodré e Rodrigues (2001) encontraram valor médio de $0,19 \%$ em méis produzidos no Mato Grosso do Sul; Sodré et al. (2002) obteve uma variação de 0,09 a 0,67\% em méis do Estado da Bahia; Mendonça; Sodré e Marchini (2004) encontraram valor médio de $0,15 \%$ em méis do Estado do Mato Grosso; Sodré 
(2005) obteve valores de 0,01 a 0,41 e 0,02 a 0,18 para méis do Estado do Ceará e do Piauí, respectivamente e Vieira (2005) observou uma variação de 0,1 a 0,68 para méis do cerrado do Estado do Mato Grosso do Sul.

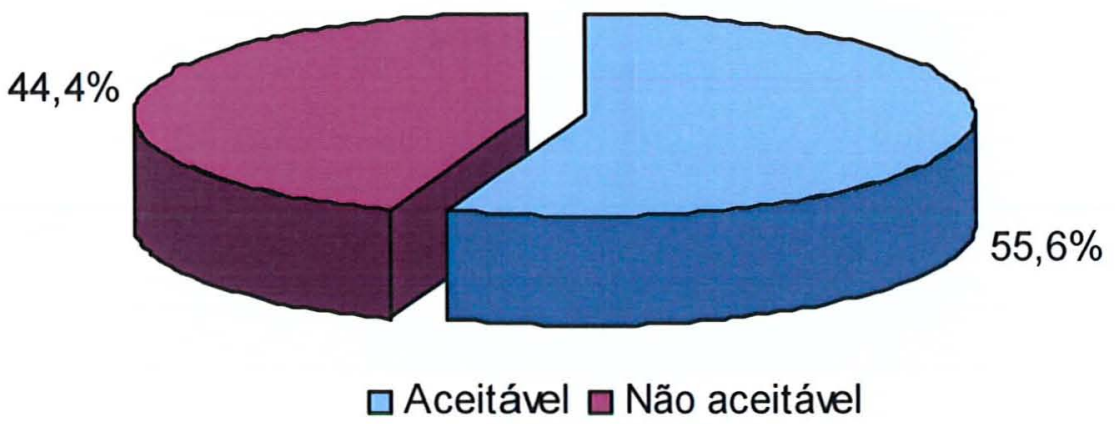

Figura 9 - Porcentagem de amostras de méis produzidos por Apis mellifera, de fevereiro/2005 a outubro/2005, em área de cerrado no município de Itirapina/SP, que apresentaram o parâmetro cinzas aceitável segundo a legislação brasileira

\subsubsection{Proteína (\%)}

As porcentagens de proteína obtidas para as amostras analisadas variaram de 0,13 a 1,00\%, com um valor médio de $0,67 . \pm 0,26 \%$ (Tabela 3 ). A legislação brasileira não estabelece valores para este parâmetro (BRASIL, 2000).

O material protéico do mel pode ser utilizado na detecção de adulteração do mesmo (CRANE, 1975).

Trabalhos com determinação de valores de proteína: Baldi Coronel; Dall’Ogllio e Lezcano (1993) encontraram valores entre 0,05 a $0,65 \%$ para méis argentinos; Carvalho et al. (1998) obtiveram valor médio de $0,44 \%$ para méis do Estado da Bahia; Sodré (2005) encontrou valores de 0,13 a $0,71 \%$ para méis do Estado do Ceará e Vieira (2005) obteve uma variação de 0,13 a 0,54\% em méis do cerrado do Estado do Mato Grosso do Sul. 


\subsubsection{Viscosidade (mPa.s)}

Os valores encontrados para viscosidade nas amostras analisadas variaram de 1070,00 a $4546,67 \mathrm{mPa} . \mathrm{s}$, com um valor médio de $2752,96 \pm 1117,23 \mathrm{mPa} . \mathrm{s}$, na temperatura de $25^{\circ} \mathrm{C}$ (Tabela 3). Para viscosidade não existe valor estabelecido pela legislação.

A viscosidade do mel pode ser influenciada por fatores como: composição, temperatura, conteúdo de água, densidade relativa e alto conteúdo de proteína (CRANE, 1983; ABU-JDAYIL et al., 2002).

Dentre trabalhos realizados na determinação de viscosidade, pode-se citar: Arruda (2003) encontrou valores de 1620 a 6770 mPa.s para méis provenientes do Estado do Ceará; Marchini; Sodré e Moreti (2002) encontraram valores de 98 a 5090 para méis do Estado de São Paulo; Mendonça; Sodré e Marchini (2004) encontraram valor médio de 2773,75 mPa.s, em méis do Estado do Mato Grosso; Sodré et al. (2002) obtiveram valor médio de $1607 \mathrm{mPa} . \mathrm{s}$, em méis dos Estados do Ceará, Piauí e Pernambuco.

\subsection{Análises polínicas}

Por meio com os resultados das análises quantitativas dos grãos de pólen das amostras analisadas foi possível demonstrar a importância das espécies vegetais na formação dos méis, classificando-os como pólen dominante $(>45,0 \%)$, pólen acessório $(16,0$ a 45,0\%), pólen isolado importante (3 a 15,0\%) e pólen isolado ocasional $(<3,0 \%)$ (LOUVEAUX; MAURIZIO; VORWOHL, 1978).

Barth (1970) relata a recorrência ao "tipo polínico", que engloba todas as espécies que possuem grãos de pólen iguais ou muito semelhantes, pertencendo ou não, ao mesmo gênero, devido às dificuldades na identificação das espécies devido ao pouco conhecimento da vegetação melifera estudada.

Segundo o mesmo autor, o pólen isolado importante e isolado ocasional tem pouca importância quanto a quantidade de néctar fornecido, entretanto fornece informação quanto à origem e procedência geográfica da amotra. 


\subsubsection{Tipos polínicos presentes no mel}

Os resultados das análises polínicas do mel, referentes a média de contagem de pólen de podem ser encontrados na Tabela 4. As amostras de méis analisadas apresentaram 13 tipos polínico, distribuídos em 11 famílias botânicas.

Com relação à porcentagem encontrada nas amostras, foram considerados dominantes: Eucalyptus sp. (Myrtaceae) e Citrus sp. (Rutaceae) (Tabela 4).

As espécies mais frequentes nas amostras analisadas foram Eucalyptus sp. (Myrtaceae) (100\%), Eupatorium sp. (Asteraceae) $(77,77 \%)$ e uma espécie não identificada $(44,44 \%)$. Excluindo-se Eucalyptus sp., por não se tratar de uma planta nativa de cerrado, a grande frequência de Eupatorium sp. demonstra o potencial apícola desta planta na área estudada.

Resultados semelhantes foram obtidos por Almeida (2002) e Vieira (2005) que encontraram maior frequência para Eucalyptus sp., em áreas de cerrado no município de Pirassununga/SP e Cassilândia/MS, respectivamente.

Quanto à distribuição dos tipos polínicos por família, Myrtaceae apresenta maior diversidade (15,38\%) (Figura 10). Almeida (2002) e Vieira (2005) também encontraram essa família dentre as com maior diversidade, em estudo em área de cerrado, no município de Pirassununga/SP e Cassilândia/MS, respectivamente. 


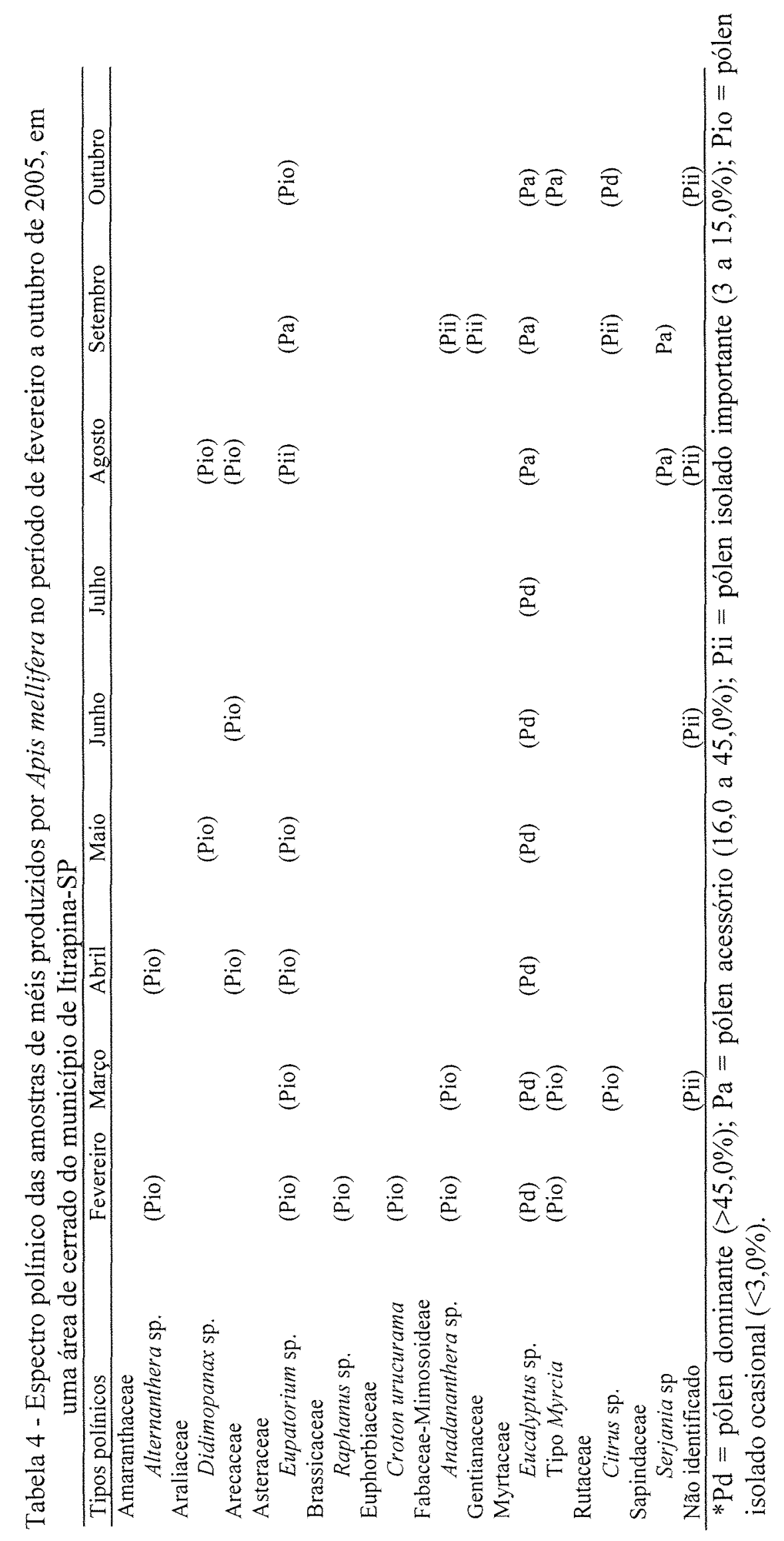




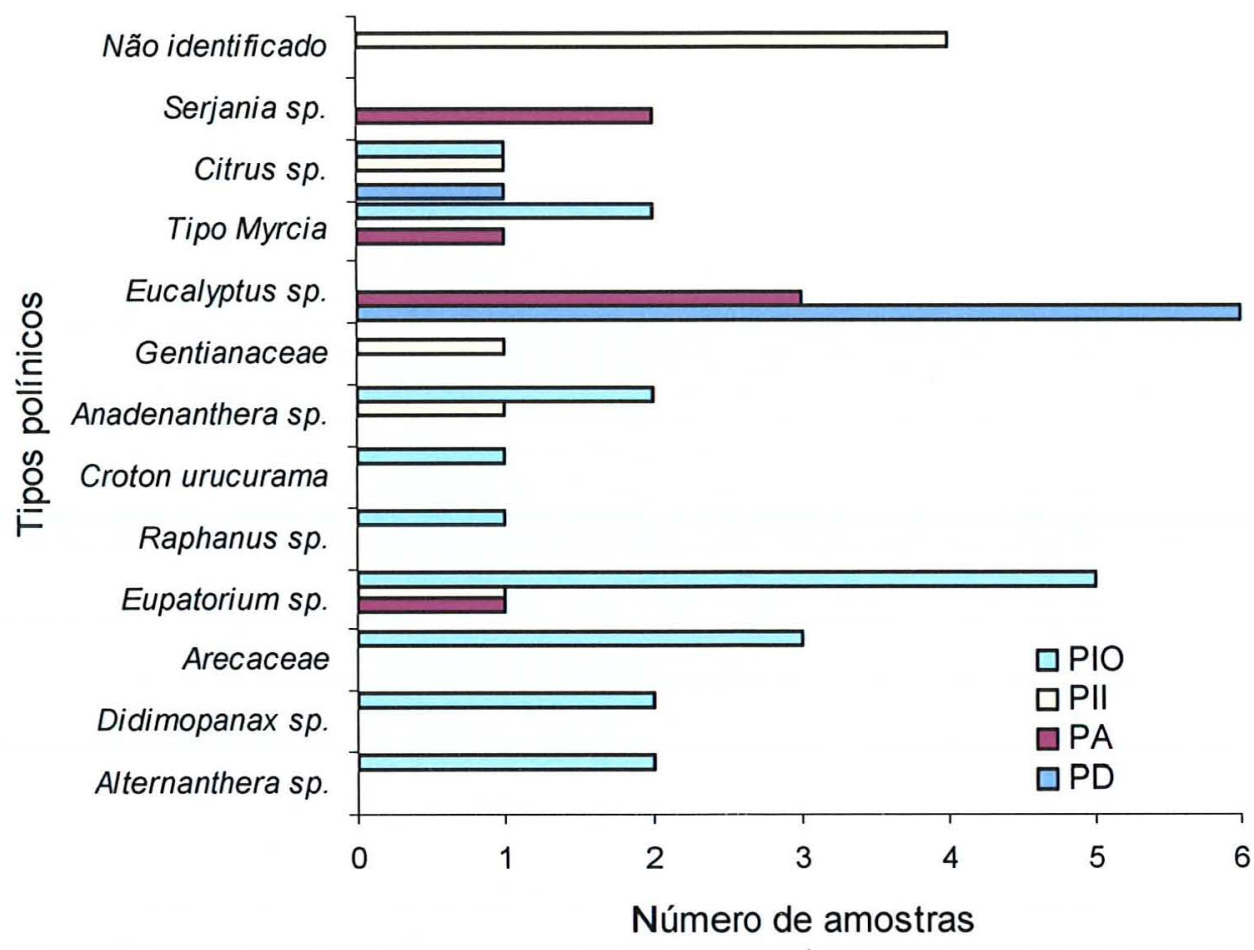

Figura 10 - Tipos polínicos e classes de frequência dos gãos de pólen presentes nas amostras de méis produzidos por Apis mellifera, de fevereiro/2005 a outubro/2005, em área de cerrado no município de Itirapina/SP

\subsubsection{Tipos polínicos presentes nas cargas de pólen}

Os resultados das análises polínicas de cargas de pólen encontradas nos coletores, referentes a média de contagem de pólen, podem ser encontrados na Tabela 5. As amostras de méis analisadas apresentaram 18 tipos polínicos, distribuídos em 11 famílias botânicas.

Com relação à porcentagem encontrada nas amostras, foram considerados dominantes: Eucalyptus sp. (Myrtaceae), Tipo Myrcia (Myrtaceae), uma espécie não identificada da família Poaceae e Citrus sp. (Rutaceae) (Tabela 5).

As espécies mais frequentes nas amostras analisadas foram Eucalyptus sp. (Myrtaceae) (100\%), uma espécie não identificada (70\%), Eupatorium sp. (Asteraceae), Tipo Myrcia (Myrtaceae) e Citrus sp. (Rutaceae) (30\%). 


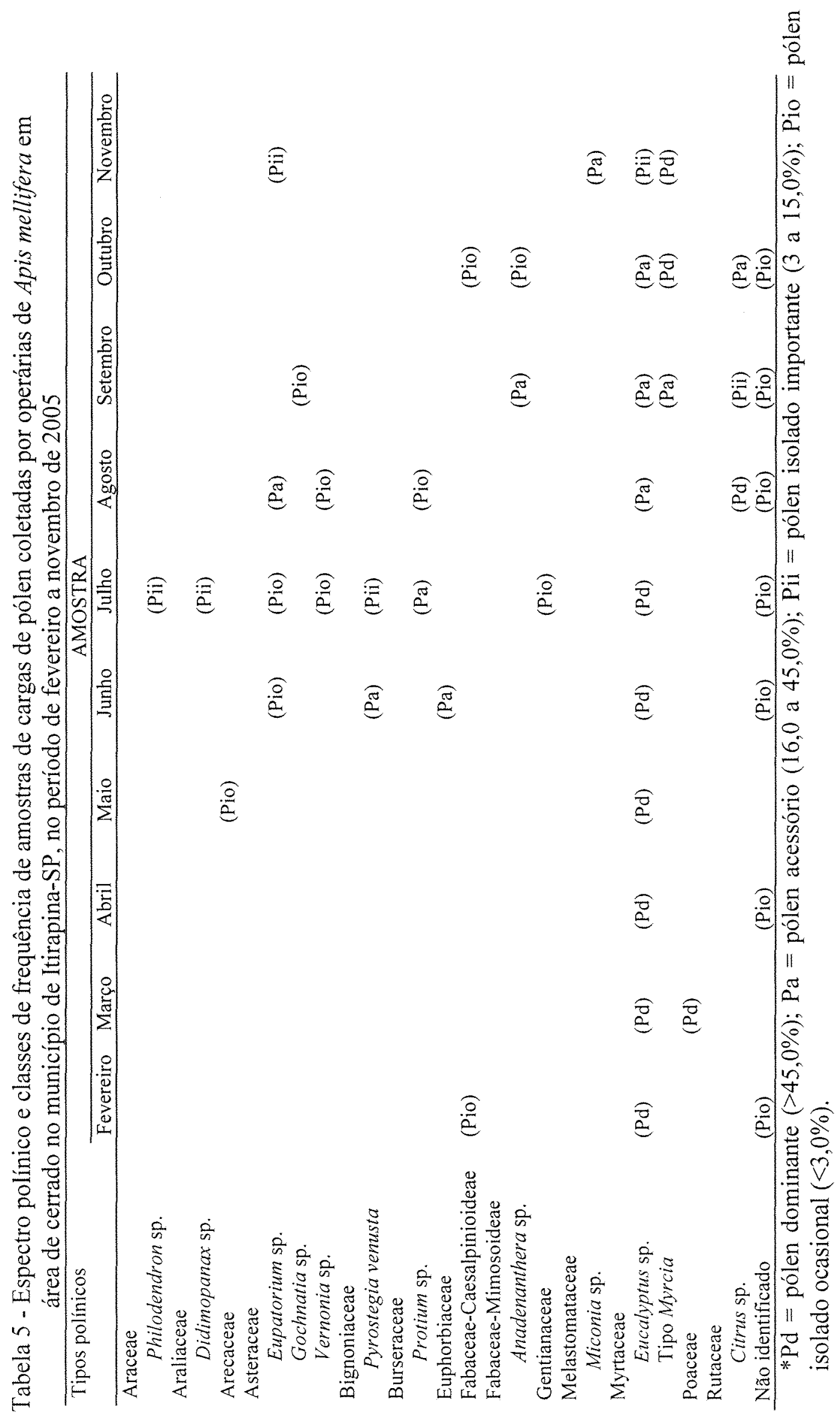


Quanto à distribuição dos tipos polínicos por família, Asteraceae apresenta maior diversidade (16,67\%), seguida por Myrtaceae (11,11\%) (Figura 11).

Os resultados obtidos são semelhantes ao observado por Vieira (2005) em área de cerrado no município de Cassilândia/MS, que dentre as famílias com maior diversidade, encontrou a família Asteraceae. Costa (2002) também observou maior diversidade de tipos polínicos para a família Asteraceae em estudos em Cruz das Almas/BA. Almeida (2002) também encontrou essa família dentre as com maiores valores, além de Myrtaceae e Mimosaceae em estudo em área de cerrado no município de Pirassununga/SP.

Barth e Luz (1998) relatam como mais frequentes nas amostras de mel e pólen as famílias Mimosaceae e Asteraceae. Esses autores, em análises de pólen coletados por Apis mellifera em uma área do Estado do Rio de Janeiro/RJ, observaram maior frequência para as famílias Asteraceae, Euphorbiaceae, Fabaceae, Myrtaceae e Arecaceae.

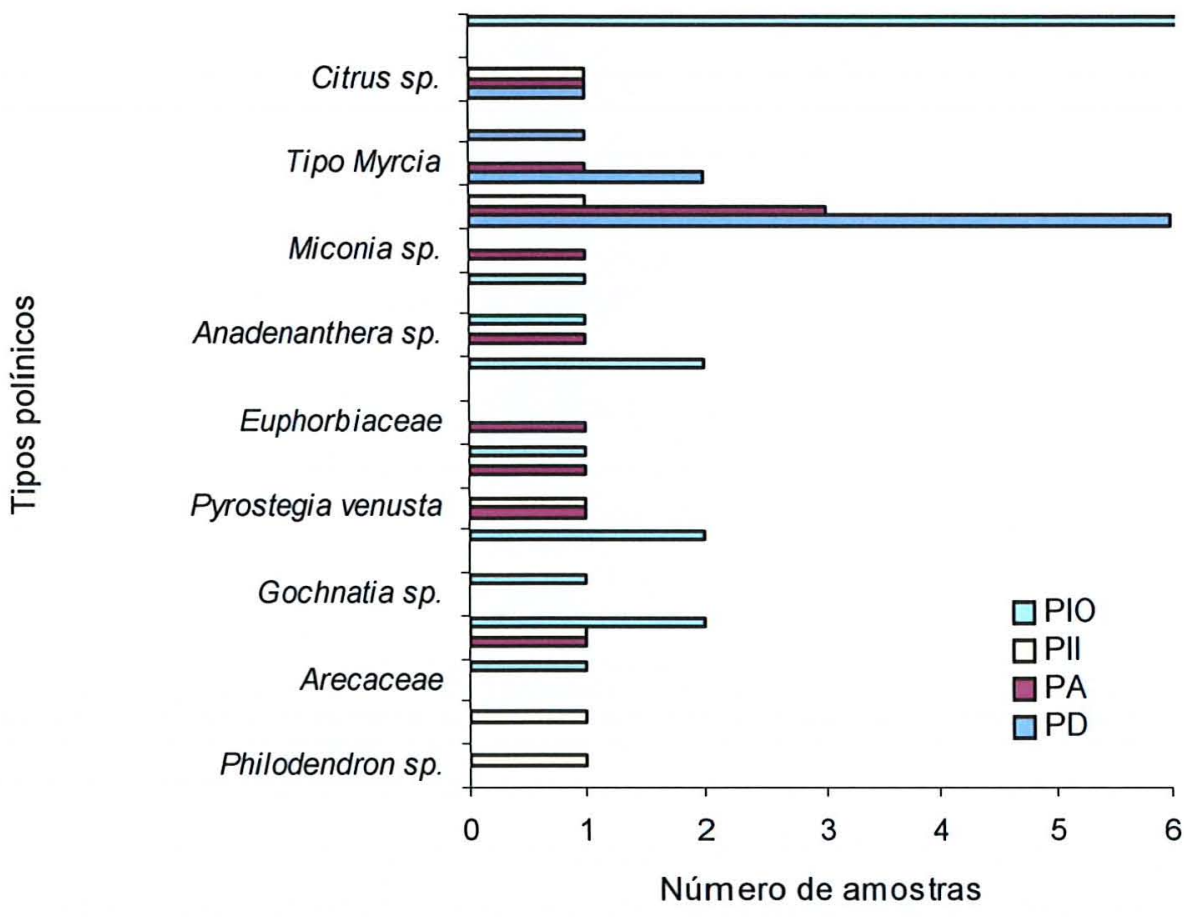

Figura 11 - Tipos polínicos e classes de frequência dos gãos de pólen presentes nas amostras de méis produzidos por Apis mellifera, de fevereiro/2005 a outubro/2005, em área de cerrado no município de Itirapina/SP 


\section{CONCLUSÕES}

As famílias botânicas Asteraceae, Bignoniaceae, Malpighiaceae e Myrtaceae apresentam maior representatividade dentre as espécies de flora estudada.

A flora do cerrado apresenta plantas com diferentes períodos de florescimento, proporcionando recursos florais para as abelhas durante todo o ano.

A maioria das amostras de méis obtidas na área estudada encontram-se em conformidade com a legislação sugerindo que a região apresentam condições favoráveis para a exploração apícola.

Dentre as espécies nativas do cerrado a Eupatorim sp. (Asteraceae) e Tipo Myrcia (Myrtaceae) apresentaram maior frequência, demonstrando o potencial apícola das mesmas.

Por meio das análises polínicas das amostras de méis e de polens coletados observou-se que as abelhas utilizam uma diversidade de recursos florais para a produção de mel, também visitaram áreas vizinhas aos locais onde se encontravam as colméias. 


\section{REFERÊNCIAS}

ABU-JDAYIL, B.; GHZAWI, A.A.M.; AL-MALAH, K.I.M. ZAITOUN, S. Heat effect on rheology of light and dark-colored honey. Journal of Food Engineering, Oxford, v.51, n.1, p.33-38, 2002.

AGANIN, A.F. Electrical condutivity of several unifloral honeys. Trudy Saratovskogo Zootekhnicheskogo Inatituta, Saratov, v. 21, p. 137-144, 1971. In: Apicultural Abstracts, Cardiff, v. 25, n. 1, p.144, 1973.

ALCOFORADO-FILHO, F.G. Levantamento e mapeamento da flora apícola do Meio-norte. Teresina: EMBRAPA MEIO-NORTE, 1993. 9p.

ALCOFORADO-FILHO, F.G. Flora apícola e seu aproveitamento. In: CONGRESSO BRASIlEIRO DE APICULTURA, 11., 1996, Piauí. Anais... Piauí: Confederação Brasileira de Apicultura, 1996. p. 131-134.

ALCOFORADO-FILHO, F.G. Sustentabilidade do Semi-árido através da apicultura. In: CONGRESSO BRASILEIRO DE APICULTURA, 12., 1998, Salvador. Anais... Salvador: Confederação Brasileira de Apicultura, 1998. p. 61.

ALMEIDA, D. Espécies de abelhas (Hymenoptera, Apoidea) e tipificação dos méis por elas produzidos em área de cerrado do município de Pirassununga, Estado de São Paulo. 2002. 103p. Dissertação (Mestrado em Entomologia) - Escola Superior de Agricultura "Luiz de Queiróz", Universidade de São Paulo, Piracicaba, 2002.

ALMEIDA, S.P. Potencial de flora apícola do cerrado. In: CONGRESSO BRASILEIRO DE APICULTURA, 11., 1996, Teresina. Anais... Teresina: Editora CBA, 1996. p. 187-191.

AMARAL, A.D.; IMPERATRIZ-FONSECA, V.L.; KLEINERT-GIOVANNINI, A. et al. Estudo comparativo entre amostras de méis com origem floral determinada; análise do teor de proteínas, lipídios e carboidratos totais. In: CONGRESSO BRASILEIRO DE APICULTURA, 7., Salvador, 1986. Anais... Salvador: Confederação Brasileira de Apicultura, 1986. p.60.

AMIM, W.A.; SAFWAT, M.; EL-IRAKI, S.M. Quality criteria of treacle (black honey). Food Chemistry, Valencia, v.67, n.1, p.17-20, 1999. 
ANDENA, S.R.; BEGO, L.R.; MECHI, M.R. Levantamento apifaunístico e utilização dos recursos florais no cerrado de Corumbataí (Corumbataí-SP). In: CONGRESSO BRASILEIRO DE ENTOMOLOGIA, 19., 2002, Manaus. Anais... Manaus: SEB, 2002. p. 1.

ANDRADE, P.B.; AMARAL, M.T; ISABEL, P.; CARVALHO, J.C.M.F.; SEABRA, R.M.; CUNHA, A.P. da. Physicochemical attributes and pollen spectrum of Portuguese heather honeys. Food Chemistry, Valência, v.66, n. 4, p. 503-510, 1999.

ARAÚJO, N. Ganhe muito dinheiro criando abelhas: a técnica do apiário ao alcance de todos. São Paulo: Nobel, 1984. 210 p.

ARCHENTI, A. Chemical composition of honeys from Chubut province (Argentina). Revista de Ciências Agrárias, Santa Maria, v. 5, n. 1/4, p. 12-28, 1984. Resumo em CAB Abstracts on CDROM, v. 2, 1987-89.

ARRUDA, C.M.F. Características físico-químicas e polínicas de amostras de méis de Apis mellifera L., 1758 (Hymenoptera, Apidae) da região da Chapada do Araripe, município de Santana do Cariri, Estado do Ceará. 2003. 86 p. Dissertação (Mestrado em Entomologia) Escola Superior de Agricultura "Luiz de Queiroz", Universidade de São Paulo, Piracicaba, 2003.

ASSOCIATION OF OFFICIAL ANALYTICAL COUNCIL. Official methods of analysis. 2 th ed. Washington, 1990. $1018 \mathrm{p}$.

ATAGO Co. Refratômetro para mel. Abelhas, Porto, v. 31, n. 362/363, p.9, 11-12, 41,44, 1988. In: CAB Abstracts on CD-ROM, 1987-89.

AUBERT, S.; GONNET, M. Measure de la couleur dês miels. Apidologie, Les Ulis, v.14, p.105$118,1983$.

AZEREDO, M.A.A.; AZEREDO, L.C.; DAMASCENO, J.G. Características físico-químicas dos méis do município de São Fidélis-RJ. Ciência e Tecnologia de Alimentos, Campinas, v. 19, n. 1, p. 3-7, 1999.

BALDI CORONEL, B.; DALL'OGLLIO, A.M.; LEZCANO, S. Caracterización físico químico de las mieles de la Provincia de Entre Rios. Alimentación Latinoamericana, Buenos Aires, n. 39, p. 39-44, 1993. 
BARROS, M.B. Apicultura. Rio de Janeiro: Serviço de Informação Agrícola, 1965. 251p. (Série Didática, 20).

BARROSO, O.M. Sistemática de angiospermas do Brasil. Viçosa: Imprensa Universitária. 1986. v. 3, 326 p.

BARTH, F.G. Insects and flowers: the biology of a partnership. Princeton: Princeton University Press, 1991. 408 p.

BARTH, O.M. Análise microscópicas de algumas amostras de mel. 1 - pólen dominante. Anais da Academia Brasileira de Ciência, São Paulo, v. 42, p.351-366. 1970a.

BARTH, O.M. Análise microscópicas de algumas amostras de mel. 2 - pólen acessório. Anais da Academia Brasileira de Ciência, São Paulo, v. 42, p.571-590. 1970 b.

BARTH, O.M. Análise microscópicas de algumas amostras de mel. 3 - pólen isolado. Anais da Academia Brasileira de Ciência, São Paulo, v. 42, p.747-772. 1970c.

BARTH, O.M. Análise microscópica de algumas amostras de mel; 6 Espectro polinico de algumas amostras de mel dos Estados da Bahia e do Ceará. Revista Brasileira de Biologia, Rio de Janeiro, v. 31, n. 4, p. 431-434, 1971.

BARTH, O.M. O pólen no mel brasileiro. Rio de Janeiro: Gráfica Luxor, 1989. 152p.

BARTH, O.M. Pollen in monofloral honeys from Brazil. Journal of Apicultural Research, Cardiff, v. 29, n. 2, p. 89-94, 1990.

BARTH, O.M.; LUZ, C.F.P. Melissopalynological data obtained from a mangrove area near to Rio de Janeiro, Brazil. Journal of Apicultural Research, Cardiff, v. 37, n. 3, p. 155-163, 1998.

BASTOS, E.M.A.F. Grão de pólen e estruturas secretoras de plantas como indicadores da origem botânica do mel e da própolis. In: CONGRESSO BRASILEIRO DE APICULTURA, 12., 1998, Salvador. Anais... Salvador: Confederação Brasileira de Apicultura, 1998. p.71-72.

BASTOS, E.M.A.F.; BRANDÃO, M.; SILVEIRA, F.R.C. Espectro polínico dos méis produzidos no parque da Serra do Caraça - MG. Daphne, Belo Horizonte, v. 5, n. 1, p. 40-45, 1995. 
BASTOS, E.M.A.F.; SILVEIRA, V.M.; SOARE, A.E.E. Pollen spectrum of honey produced in cerrado areas of Minas Gerais State (Brazil). Brazilian Journal of Biology, São Carlos, v. 63, n. 4, p. $1-14,2003$.

BATH, P.K.; SINGH, N.A. A comparison between Helianthus annuus and Eucalyptus lanceolatus honey. Food Chemistry, Valência, v. 67, n. 4, p. 389-397, 1999.

BAWA, K.S. Patterns of flowering in tropical plants. In.: JONES, G.E.; LITTLE, R.J. (Ed.). Handbook of experimental and pollination biology. New York: Van Nostrand Reinhold, 1983. p. 394-410.

BAWA, K.S. Plant-pollination interactions in tropical rain forests. Annual Review of Ecology and Systematics, Palo Alto, v. 21, p. 399-422, 1990.

BAWA, K.S.; BULlOCK, S.H.; PERRY, D.R.; COVILlE, R.E.; GRAYSON, M.H. Reproductive biology of tropical lowland rain forest trees. II. Pollination Systems. American Journal of Botany, St. Louis, v. 72, p. 346-351, 1985.

BEGON, M.; HARPER, J.L.; TOWNSEND, C.R. Ecology: individuals, populations and communities. 3th ed. Oxford: Blackwell Science, 1996. 1068p.

BENDINI, J.N.; FARIA JÚNIOR, L.R.R.; BARRETO, L.M.R.C. Análise físico-química dos méis produzidos em quinze municípios do Vale do Paraíba. In: CONGRESSO BRASILEIRO DE APICULTURA, 14., 2002, Campo Grande, Anais... Campo Grande: Confederação Brasileira de Paicultura, 2002. p. 63.

BERTIN, 1. R. Pollination biology. In: WARREN, G.A. (Ed.). Plant-animal interactions. New York: McGraw-Hill Book, 1989. p. 23-83.

BOGDANOV, S. Honey quality and international regulatory standards: review by the international honey commission. Bee World, Cardiff, v. 80, n. 2, p. 61-69, 1999.

BOGDANOV, S.; LÜLLMANN, C.; MARTIN, P.; Von DER OHE, W.; RUSSMANN, H.; VORWOHL, G.; PERSANO-ODDO, L.; SABATINI, A.G.; MARCAZZAN, A.L.; PIRO, R.; FLAMINI, C.; MORLOT, M.; LHÉRITIER, J.; BORNECK, R.; MARIOLEAS, P.; TSIGOURI, A.; KERKVLIET, J.; ORTIZ, A.; IVANOV, T.; D’ARCY, B.; MOSSEL, B.; VIT, P. Calidad de la mile de abejas y estándares de control: revisión realizada por la comisión internacional de la miel. 2001. Disponível em: http://www.beekeeping.com/articulos/calidad-miel >. Acesso em: 10 jul. 2005. 
BOLETIM OFICIAL ESPAÑOL. Orden de 12 de junio de 1986, de la Presidencia del Gobierno por la que se aprueban los métodos oficiales de anilisis para la miel. Madrid, 18 jun. 1986. n. 145.

BRAGA, R. Flora apícola de Curitiba. Boletim da Universidade do Paraná, Curitiba, v. 2, p. 1$11,1961$.

BRASIL. Ministério da Agricultura. Instrução normativa n. 11, de 20 de outubro/2000. Regulamento téenico de identidade e qualidade do mel. Disponível em: http://www.agricultura.gov.Br/das/dipoa/anexo. Acesso em: 30 jan 2001.

CAMPOS, M.J.O. Estudo das interações entre a comunidade de Apoidea, na procura de recursos alimentares, e a vegetação de cerrado da Reserva de Corumbataí, SP. 1989. 123 p. Tese (Doutorado em Ecologia) - Universidade Federal de São Carlos, São Carlos, 1989.

CAMPOS, G. Melato no mel e sua determinação através de diferentes metodologias. Belo Horizonte. 1998. 178 p. Tese (Doutorado em Ciência Animal) - Escola de Veterinária, Universidade Federal de Minas Gerais, Belo Horizonte, 1998.

CAMARGO, J.M.I. Manual de apicultura. São Paulo: Agronômica Ceres, 1972. 252p.

CARNEIRO, J.G.M.; SOUZA, D.C.; MURATORI, M.C.S; MOURA, S.G. de; MELO, R. de S.; SILVA, E. P. da; REGO, J. G. S. Características físico-químicas de 132 amostras de mel de abelhas da microrregião de Simplício Mendes, PI. In: CONGRESSO BRASILEIRO DE APICULTURA, 2002, Campo Grande. Anais... Campo Grande: Confederação Brasileira de Apicultura, 2002. p. 76.

CARVALHO, C.A.L. Diversidade de abelhas (Hymenoptera, Apoidea) no Vale do rio Paraguaçu, município de Castro Alves, Estado da Bahia. 1999. 83 p. Tese (Doutorado em Entomologia) - Escola Superior de Agricultura "Luiz de Queiroz", Universidade de São Paulo, Piracicaba, 1999.

CARVALHO, C.A.L.; MARCHINI, L.C. Tipos polínicos coletados por Nannotrigona testaceicorns e Tetragonistica angustula (Hymenoptera: Apidae: Meliponinae). Scientia Agricola, Piracicaba, v. 7, n. 3, p.17-20, 1999.

CARVALHO, C.A.L.; MARCHINI, L.C.; SODRÉ, G.S.; ALVES, M.O.; PASSOS, L.R.C. Análises de amostras de méis provenientes do Recôncavo da Bahia. In: ENCONTRO SOBRE ABELHAS, 2000, Ribeirão Preto. Anais... Ribeirão Preto: Faculdade de Filosofia Ciências e Letras, 2000. p. 352. 
CARVALHO, C.A.L.; MARCHINI, L.C.; TEIXEIRA, G.M.; OLIVEIRA, P.C.F.; RUBIA, V.R. Características físico-químicas de amostras de méis da Bahia. In: CONGRESSO BRASILEIRO DE APICULTURA, 1998, Salvador. Anais... Salvador: Confederação Brasileira de Apicultura, 1998. p. 200.

CASTRO, M.S. Plantas apícolas - identificação e caracterização. In.: BRANDÃO, A.L.S.; BOARETTO, M.A.C. (Coord.). Apicultura atual: diversificação de produtos. Vitória da Conquista: UEFS , DFZ, 1994. p.21-31.

COOPERATIVA DE PRODUTORES DE CANA, AÇÚCAR E ÁlCOOL DO ESTADO DE SÃO PAULO. Métodos analíticos. In: . Manual de controle químico da fabricação de açúcar. Piracicaba, 1987. p. 1-51.

CORBET, S.A.; WILLIAMS, I.H.; OSBORNE, J.L. Bees and the pollination of crops and wild flowers in the European Community. Bee World, Cardiff, v. 72, n. 2, p.47-59. 1991.

CORNEJO, L. G. Tecnologia de miel. In: SEEMANN, P.; NEIRA, M. (Ed.). Tecnologia de la produccion apicola. Valdivia: Universidad Austral de Chile, Facultad de Ciencias Agrarias, 1988. p.145-171.

CORTOPASSI-LAURINO, M. Divisão de recursos tróficos entre abelhas sociais principalmente em Apis mellifera Linné e Trigona (Trigona) spinipes Fabricius (Apidae, Hymenoptera). 1982. 180p. Tese (Doutorado em Ecologia) - Instituto de Biociências, Universidade de São Paulo, São Paulo, 1982.

CORTOPASSI-LAURINO, M.; GELLI, D.S. Analyse pollinique, propriétés physico-chimiques et action antibactérienne des miels d'abeilles africanisées Apis mellifera et de Méliponinés du Brésil. Apidologie, Les Ulis, v. 22, p. 61-73, 1991.

COSTA, J.B.A. Fontes de pólen utilizadas por operárias de Apis mellifera L. no município de Cruz das Almas, Bahia. 2002. 55p. Dissertação (Mestrado em Produção Animal) Universidade Federal da Bahia, Cruz das Almas, 2002.

COSTA, L.S M.; ALBUQUERQUE, M.L.; TRUGO, L.C.; QUINTEIRO, L.M.C; BARTH, O.M.; RIBEIRO, M; De MARIA, C.A.B. Determination of non-volatile compounds of different botanical origin brazilian honeys. Food Chemistry, Oxford, v. 65, p. 347-352, 1999.

COUTINHO, L.M. O Conceito de cerrado. Revista Brasileira de Botânica, São Paulo, v.1, p.1723,1978. 
CRANE, E. Honey: a comprehensive survey. London: Heinemann, 1975. 608 p.

CRANE, E. O livro do mel. 2.ed. São Paulo: Nobel, 1987. 226 p.

CRANE, E. Bees and beekeeping-science, practice and world resources. London: Neinemann Newnes, $1990.614 \mathrm{p}$.

CRECENTE, R. P.; LATORRE, C. H. Pattern recognition analysis applied to classification of honeys from two geographic origins. Journal of Agricultural and Food Chemistry, Easton, v. 41, p. 560-564, 1993.

CREPET, W. L. The role of pollination in the evolution of the angiosperms. In: REAL, L. (Ed.). Pollination biology. Orlando: Academic Press, 1983. p. 29-50.

DAYRELL, I.O.; VITAL, N.C. Comparação entre dois métodos oficiais para determinação de hidroximetilfurfural (HMF) em mel brasileiro. Ciência e Tecnologia de Alimentos, Campinas, v. 11, n. 1 , p. $137-141,1991$.

DE CICCO, L.H.S. Abelha. Disponível em: http://www.saudeanimal.com.br/abelha14htm. Acesso em: 10 jun. 2003.

DIAS, B.F.S. Cerrado: uma caracterização. In: Alternativas de desenvolvimento do cerrado: manejo e conservação dos recursos naturais renováveis. Brasília: FLT Natura; IBAMA. 1992. p. 11-25.

DOUROJEANNI, M.J. Entomology and biodiversity conservation in Latin America. American Entomologist, Lanham, v. 9, n.17, p.88-93, 1990.

DOZO, A.M.M. de. Determinacion de azucares em mieles producidas em la província de Buenos Aires - Republica Argentina. In: CONGRESSO BRASILEIRO DE APICULTURA, 5.; CONGRESSO LATINO-IBERO-AMERICANO DE APICULTURA, 1980, Viçosa. Anais... Viçosa: Universidade Federa de Viçosa, 1980. p. 312-316.

DURÁN, J.E.T.; CORTOPASSI-LAURINO, M.; ISSA, M.R.C.; TOLEDO, V.A.A. de; BASTOS, E.; SOARES, A.E.E. Méis brasileiros: resultados de análises físico-químicas e palinológicas. In: CONGRESSO BRASILEIRO DE APICULTURA, 1996, Teresina. Anais... Teresina: Confederação Brasileira de Apicultura. 1996. p. 403-429 
DURKEE, L.H. A Pollen profile from woden bog in North-Central Iowa. Ecology, Washington, V. 52, n. 5, p.837-844, 1971.

EMBRAPA. Centro de Pesquisa Agropecuária do Cerrado. Relatório técnico anual: 1982-1985. Brasília, 1987.

ENDRESS, P.K. Diversity and evolutionary biology of tropical flowers. Cambridge: Cambridge University Press, 1994. 236p. (Cambridge Tropical Biology Series).

ERDTMAN, G. Pollen morphology and plant taxonomy: angiosperms. Stockholm: Almqvist \& Wiksell, 1952. 539 p.

ESCOBAR-MARTÍNEZ, C.A.; GIMÉNEZ MEZA, G.G.; QUIÑONEZ MENDOZA, M.R. Mieles de abejas de flora paraguaya: composicion, tipificacion y normalizacion. San Lorenzo: Ministério de Agricultura y Ganaderia; Universidad Nacional de Asuncion; Asociacion Suiza para el Desarrollo y la Cooperacion, 1992. 31 p.

FAO. CODEX ALIMENTARIUS COMMISSION. Standard for honey (CAC/RS 121969 ). Rome, 1969. p. 59.

FELLER-DEMALSY, M.J.; PARENT, J.; STRACHAN, A.A. Microscopic analysis of honeys from Alberta, Canada. Journal of Apicultural Research, Cardiff, v. 23, n. 2, p. 123-132, 1987.

FERREIRA, N.B. Plantas apícolas no Estado de Minas Gerias. Informe Agropecuário, Belo Horizonte, v.7, p. 40-47, 1981.

FIORI, A. N.; FIORAVANTI, C. Os caminhos para salvar o cerrado paulista. FAPESP Pesquisa, São Paulo, n. 63, p. 38-43, abr/2001.

FLECHTMANN, C.H.W.; CALDAS FILHO, C.F.; AMARAL, E.; ARZOLLA, J.D.P. Análise de méis do Estado de São Paulo. Boletim de Indústria Animal, Nova Odessa, v. 21, p. 65-73, 1963.

FREE, J.B. Insect pollination of crops. London: Academic Press, 1993. 684 p.

FREITAS, B.M. Potencial de caatinga para a produção de pólen e néctar para a exploração apícola. 1991. 140 p. Dissertação (Mestrado em Zootecnia) - Universidade Federal do Ceará, Fortaleza, 1991. 
FREITAS, B.M. Caracterização e fluxo de néctar e pólen na caatinga do Nordeste. In: COMGRESSO BRASILEIRO DE APICULTURA, 11., Piauí, 1996. Anais... Piauí: Confederação Brasileira de Apicultura, 1996. p. 181-185.

FREITAS, B. M. A importância relativa de Apis mellifera e outras espécies de abelhas na polinização de culturas agrícolas. In: ENCONTRO SOBRE ABELHAS, 3., Ribeirão Preto, 1998. Anais... Ribeirão Preto: Faculdade de Filosofia Ciências e Letras, 1998. p.10-20.

FRÍAS, I.; HARDISSON, A. Estudio de los parámetros analíticos de interés em la miel. II. Azúcares, cenizas y contenido mineral y color. Alimentaria, Catalunya, v. 28, n. 235, p. 41-43, 1992.

GIANOTTI, E. Composição florística e estrutura fitossociológica da vegetação de cerrado e de transição entre cerrado e mata ciliar da Estação Experimental de Itirapina (SP). 1988. 222 p. Dissertação (Mestrado) - Instituto de Biologia, Universidade Estadual de Campinas, Campinas, 1988.

GIL, J.M.S. Apicultura. 2.ed. Barcelona: Aedos, 1986. 418 p.

GODOY, R.A.; BAWA, K.S. The economic value and sustainable harvest of plants and animals from the tropical forest: assuptions, hypotheses, and methods. Economic Botany, New York, v. 47, n. 3, p. 215-219, 1993.

GODOY, R.A.; LUBOWSKI, R.; MARKANDAYA, A. A method for the economic valuation of non-timber tropical forest products. Economic Botany, New York, v. 47, n. 3, p. 220-233, 1993.

GOMEZ, M.E.M.; HERNANDEZ, E.G.; GOMEZ, J.Y.M.; MARIN, J.L.M. Physicochemical analysis of Spanish commercial Eucalyptus honeys. Journal of Apicultural Research, Cardiff, v. 32, n. $3 / 4$, p. $121-126,1993$.

GOODLAND, R.; FERRI, M.G. Ecologia do cerrado. São Paulo: Ed. Itatiaia, 1979. 193p. (Coleção Reconquista do Brasil, 52).

HALFFTER, G.; EZCURRA, E. La diversidad biológica de Iberoamérica. Disponível em: http://www.wri.org/wri/biodiv/sp01.gbs.html\#que . Acesso em: 1 jun. 1996.

HEIN, Y.K.F.; LAURINO, M.C.; FONSECA, V.L.I.; GIOVANNINI, A.K. Como conhecer plantas apícolas. Apicultura no Brasil, São Paulo, v. 2, n.12, p.34-38, 1986.

HERRERO, B.; VALENCIA, B.R.M. Palynological analysis of honeys from Palencia Province (Spain). Acta Botanica Croatica, Zagreb, v. 60, n. 1, p. 11-24, 2001. 
HOWER, F.N. Plantas melíferas. Barcelona: Reverté, 1953. 35 p.

INTERNATIONAL TRADE FORUM Upswing in the honey market. International Trade Forum, Geneva, v.13, n.3, p.21-31, 1977. In: Apicultural Abstracts, Cardiff, v.30, n.3, p.214, $1979 /$.

ITC UNCTAD/GATT. Major markets for honey: openings for quality supplies from developing countries. Geneva, 1977. $120 \mathrm{p}$.

IWAMA, S.; MELHEM, T.S. The pollen spectrum of the honey of Tretagonisca angustula Latrelle (Apidae, Meliponinae), Apidologie, Les Ulis, v. 10, n. 3, p. 275-295, 1979.

JATO, M.V.; SALA-LLINARES, A.; IGLESIAS, M.I.; SIAREZ-CERVERA, M. Pollens of honeys from north-western Spain. Journal of Apicultural Research, Cardiff, v. 30, n. 2, p. 69-73, 1991.

KEVAN, P.G.; BAKER, H.G. Insects as flower visitors and pollinators. Annual Review of Entomology, Standford, v. 28, p. 407-53, 1983.

KOEPPEN, W. Climatologia. México: Fundo de Cultura Econômica, 1948. 389 p.

KOMATSU, S.S. Caracterização físico-química de méis de Apis mellifera L. 1758 (Hymenoptera: Apidae) de diferentes municípios do estado de São Paulo. 1996. 90 p. Tese (Doutorado em Entomologia) - Escola Superior de Agricultura "Luiz de Queiroz", Universidade de São Paulo, Piracicaba, 1996.

KOMATSU, S.S.; MARCHINI, L.C.; MORETI, A.C.C.C. Análises físico-químicas de amostras de méis de flores silvestres, de eucalipto e de laranjeira, produzidos por Apis mellifera L., 1758 (Hymenoptera: Apidae) no estado de São Paulo. 2. conteúdo de açúcares e de proteína. Ciência e Tecnologia de Alimentos, Campinas, v. 22, n. 2, p. 143-146, 2002.

LAROCA, S.; ALMEIDA, M.C. O relicto de cerrado de Jaguariaíva, (Paraná, Brasil): padrões biogeográficos, melissocenosses e flora melissófila. Acta Biologica Paranaense, Curitiba, v. 23, n. $1 / 4$, p. $89-122,1994$.

LASCEVE, G.; GONNET, M. Analyse par radioactivation du contenu mineral d'un mile. Possibilité de préciser son origine géofraphique. Apidologie, Les Ulis, v. 5, n. 3, p. 201-223, 1974.

LAZAROVA, M.; BOZILOVA, E. Pollen and chemical analysis of honey from different floristic regions of South Bulgaria. Phytologia Balcanica, Bulgaria, v. 8, n. 2, p. 145-164, 2002. 
LORENZON, M. C. A. Competição entre abelhas Africanizadas (Apis mellifera) e Jandaíras (Melipona subnitida) na região Semi-Árida. In: CONGRESSO BRASILEIRO DE APICULTURA, 11., Teresina, 1996. Anais... Teresina: Confederação Brasileira de Apicultores, 1996. p.362.

LOUVEAUX, J.; MAURIZIO, A.; VORWOHL, G. Methods of melissopalynology. Bee World, Cardiff, v. 51, p. 125-138, 1970.

LOUVEAUX, J.; MAURIZIO, A.; VORWOHL, G. Methods of melissopalynology. Bee World, Cardiff, v. 59, p. 139-157, 1978.

MAGALHÃES, E.O.; SICUPIRA, P.R.; TERRA, P.S. Levantamento preliminar da flora apícola no sul da Bahia. In: CONGRESSO BRASILEIRO DE APICULTURA, 11., Teresina, 1996. Anais.... Teresina: Confederação Brasileira de Apicultores, 1996. p.326.

MAIA, A.R.; OLIVEIRA, M.G.; ITAGIBA,R. O planejamento da flora apícola no apiário. A Lavoura, Rio de Janeiro, v. 97, n. 607, p.41-43, 1994.

MARCHINI, L.C. Caracterização de amostras de méis de Apis mellifera L. 1758 (Hymenoptera: Apidae) do Estado de São Paulo, baseada em aspectos físico-químicos e biológicos. Piracicaba-SP, 2001. 83p. Tese (Livre Docência) - Escola Superior de Agricultura "Luíz de Queiroz", Universidade de São Paulo, Piracicaba, 2001.

MARCHINI, L.C.; MORETI, A.C.C.C. Características físico-químicas de amostras de mel de cinco diferentes espécies de eucaliptos. In: SIMPÓSIO LATINO AMERICANO DE CIENCIA DE ALIMENTOS, 4., 2001, Campinas. Resumos... Campinas: R. Vieira Gráfica, 2001a. p. 42.

MARCHINI, L.C.; CARVALHO, C.A.L. de; ROSS, P.B. Tipos polínicos coletados por Partamona cupira (HYMENOPTERA, APIDAE, MELIPONINAE ) In: ENCONTRO ANUAL DE ETOLOGIA, 15., 1997, São Carlos. Anais... São Carlos: UFSCar, 1997. p.290.

MARCHINI, L.C.; RODRIGUES, A.C.L.; MORETI, A.C.C.C. Características qualitativas de méis que passaram por diferentes tipos de descristalização. In: CONGRESSO BRASILEIRO DE APICUlTURA, 12., 1996, Piauí. Anais... Piauí: Confederação Brasileira de Apicultura. 1996. $348 \mathrm{p}$.

MARCHINI, L.C.; SODRÉ; G.S.; RODRIGUES, S.R. Características físico-químicas de amostras de méis de Apis mellifera (Hymenoptera: Apidae) provenientes do Mato Grosso do Sul. 
In: SIMPÓSIO LATINO AMERICANO DE CIÊNCIA DE ALIMENTOS, 4., 2001, Campinas. Resumos... Campinas: R. Vieira Gráfica, 2001b. p. 160.

MARCHINI, L.C.; SODRÉ, G.S.; MORETI, A.C.C.C. Condutividade elétrica, teor de proteína, viscosidade e teor de água de amostras de mel de flores de laranjeira produzidos por Apis mellifera L no Estado de São Paulo. In: SIMPÓSIO INTERNACIONAL DE INCIAÇÃOO CIENTÍFICA DA UNIVERSIDADE DE SÃO PAULO, 10., Piracicaba, 2002. Piracicaba: Universidade de São Paulo, 2002. 1 CD-ROM.

MARCHINI, L.C; SODRÉ, G.S.; MORETI, A.C.C.C. Mel brasileiro: composição e normas. Ribeirão Preto: A.S.P., 2004. 131 p.

MARTINEZ-GOMEZ, M.E; GUERRA HERNANDEZ, E.; MONTILLA GOMEZ, J.Y.; MOLINS MARIN, J.L. Physicochemical analysis of Spanish commercial Eucalyptus honeys. Journal of Apicultural Research, Cardiff, v. 32, n. 3/4, p. 121-126, 1993.

MARTINHO, M.R. Apicultura. Viçosa: UFV, 1990. 26 p. (Informe Técnico).

MATEUS, S. Abundância relativa, fenologia e visita as flores pelos Apoidea do cerrado da estação ecológica de Jataí- Luiz Antônio - SP. 1998. 160 p. Dissertação (Mestrado em Entomologia) - Faculdade de Filosofia, Ciências e Letras, Universidade de São Paulo, Ribeirão Preto, 1998.

MENDES, E.; PROENÇA, E.B.; FERREIRA, I.M.P.L.V.O.; FERREIRA, M.A. Quality evaluation of portuguese honey. Carbohydrate Polymers, Valência, v.37, n.3, p. 219-223, 1998.

MENDONÇA, K.; SODRE, G.S.; MARCHINI, L.C. Parâmetros físicos-químicos de méis de Apis mellifera provenientes do município de Casseres- Mato Grosso. In: CONGRESSO BRASILEIRO DE APICULTURA, 15., Natal, 2004. Natal: CONBRAPI, 2004. 1 CD-ROM.

MENDONÇA, K.; SODRE, G.S.; SABADIN, J. Viscosidade de amostras de méis de Apis mellifera provenientes do Estado da Bahia. In: SIMPÓSIO INTERNACIONAL DE INICIAÇÃO CIENTÍFICA DA UNIVERSIDAD DE SÃO PAULO, 11., REUNIÂO PAULISTA DE INICIAÇÃO CIENTÍFICA EM CIÊNCIAS AGRÁRIAS, 14, CONGRESSO DE INICIAÇÃO CIENTÍfICA DA ESALQ, 17, 2003, Piracicaba. Anais... Piracicaba: ESALQ, 2003. Sessão: Ciência e Tecnologia Agroindustrial, n.6.64. 1 CD-ROM. 
MENESES-PEDRO, S.R.; CAMARGO, J.M.F. Interactions on floral resourses between the africanized honey bee Apis mellifera and the native bee community (Hymenoptera, Apoidea) in a natural cerrado ecossystem in southeast Brazil. Apidologie, Les Ulis, v. 22, p. 397-415, 1991.

MESALLAN, A.S.; EL-SHAARAWY, M.I. Quality attributes of honey in Saudi Arabia. Food Chemistry, Valência, v. 25, n. 1, p.1-11, 1987.

MORAES, R.M. de. Análise de mel. Pindamonhangaba: IZ, Centro de Apicultura Tropical, 1994. 1v. (Manual Técnico):

MORAES, R.M. de; MANTOVANI, D.M.B Composição química de méis de diferentes fontes florais. In: CONGRESSO BRASILEIRO DE APICULTURA, 7., 1996, Salvador. Programa e resumo... Salvador: Confederação Brasileira de Apicultura, 1986. p.58.

MORAES, R.M. de; TEIXEIRA, E.W. Análise do mel. Pindamonhangaba: SN, 1998. 4lp. (Manual técnico).

MORAES, R.M. de; BENEVIDES, L.H.T.S.; MENEZES, A. de; PRATA, M.B.; BARBOSA, L.H. A desumidificação do mel no Brasil. Apicultura \& Polinização, São Paulo, n. 31, p.27-29, 1989.

MORETI, A.C.C.C. Pasto apícola e flora apícola: conceitos. In: apícola. Pindamonhangaba: Convênio SAA/AMA, 1998. cap.1, p.1-7. Manejo da pastagem

MORETI, A.C.C.C.; MARCHINI, L.C.; OLIVEIRA, P.C.F. Principais tipos polínicos observados em amostras de mel silvestre, produzido por abelhas (Apis mellifera L) no Estado de São Paulo. In: ENCONTRO SOBRE ABELHAS, 14., 2000, Ribeirão Preto. Anais... Ribeirão Preto: USP, Faculdade de Filosofia, Ciências e Letras, 2000. p. 345.

MORETI, A.C.C.C.; CARVALHO, C.A.L.; MARCHINI, L.C.; OLIVEIRA, P.C.F. Espectro polínico de amostras de méis de Apis mellifera. Coletados na Bahia. In: CONGRESSO BRASILEIRO DE APICULTURA, 12., 1998, Salvador. Anais... Salvador: Confederação Brasileira de Apicultura, 1998. p.189.

MORGADO, L.N. Fauna de abelhas (Hymenoptera: Apoidea) nas flores de girassol, Helianthus annus Linnaeus, 1753, em Lavras-MG. 2000. 41 p. Dissertação (Mestrado em Entomologia) - Universidade Federal de Lavras, Lavras, 2000. 
MUSTAFA, T.; MUSTAFA, D. Physicochemical analysis of Tokat region (Turkey) honeys. Advances in Food Sciences, Washington, v.24, n. 3, p. 125-127, 2002.

NAUTA, V.S. di. Alcume caratteristiche merceologuche e commerciali del miele. Industrie Alimentari, Pinerolo, v.22, n. 208, p. 624-629, 1983.

NEFF, J.L.; SIMPSON, B.B. Bees, pollination systems and plant diversity. In: LASALLE, J., GAULD, I.D. (Ed.). Hymenoptera and biodiversity. Wallingford: CAB International, 1993. p. 143-167.

NILSSON, T.T. Flores do cerrado. Apicultura no Brasil, São Paulo, v.1, n.5, p.29, 1984.

NOGUEIRA, R.H.F. Polinização. In: SIMPÓSIO SOBRE APICULTURA, 1984, Jaboticabal. Anais... Jaboticabal: FUNEP, 1984. p. 231.

NOGUEIRA-COUTO, R.H. As abelhas na manutenção da biodiversidade e geração de renda. In: CONGRESSO BRASILEIRO DE APICULTURA, 7., 1998. Salvador. Programa e resumos... Salvador: Confederação Brasileira de Apicultura, 1998. p. 101-105.

NOGUEIRA-COUTO, R.H.; COUTO, L.A. Apicultura: manejo e produtos. Jaboticabal: FUNEP, 1996. 154 p.

NOGUEIRA-COUTO, R.H.; COUTO, L.A. Apicultura: manejo e produtos. 2.ed. Jaboticabal: FUNEP, 2002. 191 p.

NOGUEIRA-NETO, P. A criação de abelhas indígenas sem ferrão. São Paulo: Nogueriapis, 1997. $445 \mathrm{p}$.

OLEK, A.; STEINKRAUS, K.H.; MATTICHK, L.R.; MUEGO, K.; UNDERWOOD, B.A.; MORSE, R.A. Carbohydrate composition of two Nepalese honeys produced by Apis laboriosa and Apis cerana. Journal of Apicultural Research, Cardiff, v. 26, n.3, p. 203-204, 1987.

ORTIZ, V.A. The ash content of 69 honey samples from La Alcarria and neighbouring areas, collected in the period 1985-87. Cuadernos de Apicultura, Guadalajara, n. 5, p.8-9, 1988. In: Apicultural Abstracts, Cardiff, v. 40, n. 4, p.360, 1989. 
PAMPLONA, B.C. Exame dos elementos químicos inorgânicos encontrados em méis brasileiros de Apis mellifera e suas relações físico-biológicas. 1989. 131 p. Dissertação (Mestrado em Entomologia) - Instituto de Biociências, Universidade de São Paulo, São Paulo, 1989.

PAPOFF, C.M.; CAMPUS, R.L.; CICU, M.F.I.; FARRIS, G.A.; FLORIS, I; RICCIARDELLI D'ALBORE, G. Physical, chemical, microbiological and palinological characteristics of Somalian honeys. Apicoltura, Sassari, n. 4, p. 147-72, 1988. In: CAB Abstractes on CD-ROM, v. 3A, 1990-91.

PARKER, R.L. The collection and utilization of pollen by the honeybee. Memoirs Cornell Agricultural Experiment Station, Cornell, n. 98.p. 1-55. 1926.

PEDRO, S.R.M. Sobre as abelhas (Hymenoptera: Apoidea) em um ecossistema de cerrado (Cajuru, NE do estado de São Paulo): composição, fenologia e visita às flores. 1992. $164 \mathrm{p}$. Dissertação (Mestrado em Entomologia) - Faculdade de Filosofia, Ciências e Letras, Universidade de São Paulo, Ribeirão Preto, 1992.

PENG, Z. F.; PAN, J. G. Protein content in honey and its effects on precipitation of beverage. Journal of Food Science, Wooster, v. 12, p. 6-8, 1994.

PERCIVAL, M.S. Floral biology. Oxford: Pergamon Press, 1965. 243 p.

PEREIRA, B.A.S. Espécies apícolas da flora da Área de Proteção Ambiental (APA) da bacia do rio São Bartolomeu, DF. Cadernos de Geociências, Rio de Janeiro, n. 5, p. 7-19, 1990.

PEREIRA, B.A.S. Flora apícola do cerrado. In: CONGRESSO BRASILEIRO DE APICUlturA, 10., 1994, Pousada do Rio Quente. Anais... Pousada do Rio Quente: CBA, 1994. p.142-146.

PEREIRA, J.G.; DENADAI, J.M.; HIANE, P.A.; ARÃO, A.; RAMOS FILHO, M.M.; RAMOS, M.I.L. DENADAI, S.M.S. Mel de abelhas - análises de amostras comercializadas no município de Campo Grande-MS. Higiene Alimentar, São Paulo, v. 2, n. 4, p. 213-216, 1983.

PEREZ-ARQUILlUÉ, C.; CONCHELLO, P.; ARIÑO, A.; JUAN, T. Estudio de algunos parametros fisico-quimicos en mieles monoflorales de Zaragoza. Alimentaria, Catalunia, v. $27, \mathrm{n}$. 213 , p. 59-61, 1990.

PERSANO-ODDO, L.P.; PIAZZA, M.G.; SABATINI, A.G.; ACCORTI, M. Characterization of uniflora honeys. Apidologie, Les Ulis, v. 26, p. 453-465, 1995. 
PERSANO-ODDO, L.P.; PIRO, R.; BRUNEAU, E.; BRUNEAU, E.; GUYOT-DECLERCK, C.; TZEKO IVANOV, T.; PISKULOVÁ, J.; FLAMINI, C.; LHERITIER, J.; MORLOT, M.; RUSSMANN, H.; VON DER OHE, W.; VON DER OHE, K.; GOTSIOU, P.; KARABOURNIOTI, S.; KEFALAS, P.; PASSALOGLOU-KATRALI, M.; THRASYVOULOU, A.; TSIGOURI, A.; MARCAZZAN, G.L.; PIANA, M.L.; PIAZZA, M.G.; SABATINI; A.G.; KERKVLIET, J.; GODINHO, J.; BENTABOL, A.; VALBUENA, A.O.; BOGDANOV, S.; RUOFF, K. Main European unifloral honeys: descriptive sheets. Apidologie, Les Ulis, v.35, p.S38-S81, 2004.

PETROV, V. Mineral constituents of some Australian honeys as determined by atomic absorption spectrophotometry. Journal of Apicultural Research, Cardiff, v.9, n.2, p. 95-101, 1970.

PFAU, L.A.; RUHLE, E.R. Concurso de mel: método de avaliar a qualidade do mel. In: CONGRESSO BRASILEIRO DE APICULTURA, 7., 1986, Salvador. Programa e resumos ... Salvador: Confederação Brasileira de Apicultura, 1986. p. 58-59.

PIAZZA, M.G.; ACCORTI, M. HMF of domestic and foreign and honey sold in Italy. Apitalia, Rome, v. 10, p. 8-10, 1983. In: CAB Abstractes on CD-ROM, v. 1, 1984-86.

PINHERO, G.S.; LIMA, O.S.; MORAES, J.L. Inventário florestal das Estações Experimentais do Instituto Florestal - Fase I: Cadastramento dos plantios. Boletim Técnico do Instituto Florestal, São Paulo, n. 23, p. 1-80, 1976.

PONCINI, L.; WIMMER, F.L. The composition of some Fijian honeys. Fiji Agricultural Journal, Suva, v. 45, n. 1, p. 25-29, 1983. In: CAB Abstracts on CD-ROM, v.1, 1984-86.

PONCINI, L.; PRASAD, B.; SINGH, S.K. WIMMER, F.L. A survey of some Fijian honeys. New Zealand Journal of Science, Suva, v. 27, n.2, p. 141-144, 1984. Resumo em CAB Abstracts on CD-ROM, v.1, 1984-86.

PREGNOLATO, W.; PREGNOLATO, N.P. (Coord.). Normas analíticas do Instituto Adolfo Lutz. 3.ed. São Paulo: Instituto Adolfo Lutz, 1985. v. 1: Métodos químicos e físicos para análise de alimentos, 533p.

PROCTOR, M.; YEO, P.; LACK, A. The natural history of pollination. London: Harper Collins, 1996. 479p.

RAO, M.A. Rheology of liquid foods - a review. Journal of Texture Studies, Les Ulis, v. 8,n. 2, p. 135-168, 1977.

REIO, L.; ENGLUND, L. Honey and its composition. Var Föda, Uppsala, v. 37, n. 2, p. 42-62, 1985. In: CAB Abstracts on CD-ROM, 1987-89. 
REIS, M.S.; MARIOT, A. Diversidade natural e aspectos agronômicos de plantas medicinais. In: SIMÕES, C.M.O.; SCHENKEL, E.P.; GOSMAN, G.; MELLO, J.C.P.; MENTZ, L.A.; PETROVICK, P.R. (Org.). Farmagnosia: da planta ao medicamento. Porto Alegre: Ed. UFSC; Ed. UFRGS, 1999. p. 39-60.

REIS, V.D.A. Fatores que influenciam na coleta de pólen por Apis mellifera L. e análises físico-químicas do pólen coletado. 76 p. 2000. Dissertação (Mestrado em Entomologia) - Escola Superior de Agricultura "Luiz de Queiroz", Universidade de São Paulo, Piracicaba, 2000.

RENDÓN, S.R. Estudio de la composicion fisico-química de las mieles extremenas y extranjeras. In: CONGRESSO IBERO LATINO AMERICANO DE APICULTURA, 5., 1996, Uruguai. Anais... Mercedes: Intendência Municipal de Soriano, 1996. p. 174-183.

RIBEIRO, J.F.; WALTER, B.M.T. Fitofisionomias do bioma cerrado. In: SANO, S.M.; ALMEIDA, S.P. (Ed.). Cerrado: ambiente e flora. Planaltina: Emprapa, 1998. p. 89-166.

ROCHA, I.R.D.; CAVALCANTI, R.B.; MARINHO-FILHO, J.S.; ARAUJO, A.B.; KITAYAMA, K. Faúna do distrito Federal. In: PINTO, M.N. (Org.). Cerrado: caracterização, ocupação e perspectivas. Brasilia: UnB, 1990. p. 185-191.

RODRIGUEZ-OTERO, J.L.; PASEIRO, P.; SIMAL, J.; TERRADILlOS, L.; CEPEDA, A. Determination of $\mathrm{Na}, \mathrm{K}, \mathrm{Ca}, \mathrm{Mg}, \mathrm{Cu}, \mathrm{Fe}, \mathrm{Mn}$ and total cationic milliequivalents in Spanish comercial honeys. Journal of Apicultural Research, Cardiff, v. 31, n. 2, p. 65-69, 1992.

ROUBIK, D.W. Competitive interaction between neotropical pollinators and Africanized honey bees. Science, Washington, v. 210, n.15, p.1030-1032, 1978.

ROUBIK, D.W. Experimental community studies: Time-series tests competition between African and Neotropical bees. Ecology, Cambridge, n. 64, v.5, p.971-978, 1983.

ROUBIK, D.W. Ecology and natural history of tropical bees. Cambridge: Cambridge University Press, 1989. 514 p.

SAKAGAMI, S.F.; LAROCA, S.; MOURE, J.S. Wild bees biocenotics in São José dos Pinhais (PR), South Brazil - preliminary report. Journal of the Faculty of Science, Hokkaido University, Hokkaido, Series VI, Zoology, v.6, p.253-291, 1967.

SALASHINSKII, N. A.; BARANOVA, Z. A.; KIBENKO, G. V. Comparison of characteristics of honey. Tovarovedenie, v. 13, p. 15-16, 1980. In: Apicultural Abstracts, Cardiff, v. 33, n. 4, p. $295,1982$. 
SALINAS, F; ESOINOSA-MANSILLA, A. BERZAS-VEVADO, J.J. Flow-injection determination of HMF in honey by Winkler method. Fresenius, Journal of Analytical Chemistry, Fresenius, v. 340, n. 4, p. 250-252. 1991.

SAMPAIO, E.A.B. Pólen apícola - caracterização e processamento. In: CONGRESSO BRASILEIRO DE APICULTURA, 10., 1994, Pousada do Rio Quente. Anais... Pousada do Rio Quente: CBA, 1994.p. 96-102

SANTOS, C.F.O. Morfologia e valor taxonômico do pólen das principais plantas apícolas. 1961. 92 p. Tese (Livre Docência). Escola Superior de Agricultura "Luiz de Queiroz", Universidade de São Paulo, Piracicaba, 1961a..

SANTOS, C.F.O. Principais tipos de pólen encontrados em algumas amostras de mel. Nota Prévia. Revista de Agricultura, Piracicaba, v. 36, p. 93-96, 1961 b.

SANTOS, C.F.O. Avaliação do período de florescimento das plantas apícolas no ano de 1960, através do pólen contido nos méis e dos coletados pelas abelhas (Apis mellifera). Anais da Escola Superior de Agricultura "Luiz de Queiroz", Piracicaba, v. 21, p.253-264, 1964.

SANTOS, C.F.O. Análise polínica de alguns méis do Estado de São Paulo. In: CONGRESSO BRASILEIRO DE APICULTURA, 3., 1974, Piracicaba. Anais... Piracicaba: ESALQ, 1974. p. 273-278.

SCHEREN, O.J. Apicultura racional. 3. ed. São Paulo: Nobel, 1977. 110 p.

SCHEREN, O. J. Apicultura racional. 17. ed. São Paulo: Nobel, 1983. 110 p.

SEEMANN, P.; NEIRA, M. Tecnologia de la producción apícola. Valdivia: Universidad Austral de Chile Facultad de Ciencias Agrarias Empaste, 1988. 202 p.

SEIJO, M.C.; AIRA, M.J.; MENDEZ, J. Palynological differences in the pollen content of Eucalyptus honey from Australia, Portugal and Spain. Grana, Stockholm, v.42, n.3, p.183-190, 2003.

SEIJO, M.C.; AIRA, M.J.; IGLESIAS, I.; JATO, M.V. Palynological characterization of honey from La Coruña province (NW Spain). Journal of Apicultural Research, Cardiff, v. 31, n. 3/4, p.149-155, 1992. 
SERRA-BONVEHI, J.; GRANADOS-TARRÉS, E. Physicochemical properties composition and pollen spectrum of ling heather (Calluna vulgaris (L) Hull) honey produced in Spain. Apidologie, Les Ulis, v. 24, p. 586-596, 1993.

SILBERBAUER-GOTTSBERGER, I.; GOTTSBERGER, G. A polinização de plantas do cerrado. Revista Brasileira de Biologia, São Paulo, v. 48, n. 4, p. 651-663, 1988.

SILVA, R. M.B. Curso de apicultura. Nova Odessa: Instituto de Zootecnia, 1985. 115 p.

SILVA, D.J.; QUEIROZ, A.C.de. Determinação do nitrogennio total e da proteína bruta. In: SILVA, D.J. QUEIROZ, A.C.de. Análise de alimentos: métodos químicos e biológicos. 3.ed. Viçosa: UFV, 2002. p.57-75.

SILVEIRA, F.A. da. A flora apícola: um desafio à apicultura brasileira. Informe Agropecuário, Belo Horizonte, v.9, n.106, p.26-55, 1983.

SILVEIRA, F.A. da. Abelhas silvestres (Hymenoptera: Apoidea) e suas fontes de alimento no cerrado da estação florestal de experimentação de Paraopeba - Minas Gerais. 1989. 50 p. Dissertação (Mestrado em Entomologia) - Universidade Federal de Viçosa, Viçosa, 1989.

SILVEIRA, F.A. da.; MELO, G.A.R.; ALMEIDA, A.B. Abelhas brasileiras: sistemática e identificação. Belo Horizonte: IDM, 2002. 253p.

SIMAL, J.; HUIDOBRO, J. Parâmetros de calidde de la miel III. Acidez, (pH libre, lactónica \& total) e índice de formol. Offarm, Barcelona, v. 3, n. 9, p. 532, 1984.

SIMPSON, B.B.; NEFF, J.L. Foral rewards: alternatives to pollen and nectar. Annals of the Missouri Botanical Garden, Missouri, v.68, p.301-322, 1981.

SMITH, F.G. Deterioration of the colour of honey. Journal of Apicultural Research, Cardiff, v. 6, n. 2, p. $95-98,1967$.

SODRÉ, G.S. Características físico-químicas e análises polínicas de amostras de méis de Apis mellifera L., 1758 (HYMENOPTERA: APIDAE) da região litoral norte do Estado da Bahia. 2000. 83p. Dissertação (Mestrado em Entomologia) - Escola Superior de Agricultura "Luíz de Queiroz", Universidade de São Paulo, Piracicaba, 2000. 
SODRÉ, G.S. Características físico-químicas, microbiológicas e polínicas de amostras de méis de Apis mellifera L., 1758 (Hymenoptera:Apidae) dos estados do Ceará e Piauí. 2005. 127p. Tese (Doutorado em Entomologia) - Escola Superior de Agricultura "Luiz de Queiroz", Universidade de São Paulo, Piracicaba, 2005.

SODRÉ, G.S.; MARCHINI, L. C. ; ARRUDA, C.M. F.; LEVY, P.S. Viscosidade e umidade de amostras de méis de Apis mellifera provenientes de estados da região Nordeste do Brasil. In: SIMPÓSIO INTERNACIONAL DE INICIAÇÃO CIENTÍFICA DA UNIVERSIDADE DE SÃO PAULO, 10., 2002, Piracicaba. Anais... Piracicaba: Universidade de São Paulo, 2002. 1 CDROM.

SORIA, A.C.; GONZALEZ, M.; LORENZO, C.D.E. MARTINEZ-CASTRO, I; SANZ, J. Characterization of artisanal honeys from Madrid (Central Spain) on the basis of their melissopalinological, physicochemical and volatile composition data. Food Chemistry, Valência, v.85, n.1, p. 121-130, 2004.

SOUZA, V.C.; CORTOPASI-LAURINO, M.; SIMÃO-BIANCHINI, R.; PIRANI, J.R.; AZOUBEL, M.L.; GUIBU, L.S.; GIANNINI, T.C. Plantas apícolas de São Paulo e arredores. São Paulo: USP, Instituto de Biociências, 1993. p. 143-178.

SPETTOLI, P.; CECCHINI, A.; MATCOVICH, P. Indigene sulle caratteristiche fisico-chimiche di mieli del Frluli Orientale. Industrie Alimentari, Pinerolo, v.22, n. 210, p. 849-858, 1983.

STANLEY, R.G.; LINSKENS, H.F. Pollen: biology, biochemistry, and management. New York: Springer-Verlag, 1974. p. 230-235.

STEFANINI, R. Variability and cluster analysis of Italian honeys. Apiacta, Romania, v. 19, n. 4, p.109-114. 1984.

STONOGA, V.I.; FREITAS, R.J.S. Conteúdo de água e açúcares em mel de abelha. Boletim do Centro de Pesquisa e Processamento de Alimentos, Campinas, v. 9, n. 1, p. 13-16, 1991.

TABIO, C.; ALVAREZ, J.D.; BERISIARTU, M. Preliminary characterization of some physicochemical and organoleptic characteristics of Citrus honeys from Jaguey Grande, Matanzas. Ciencia y Tecnica en la Agricultura - Apicultura, Havana, v.3., p.29-39, 1987. In: CAB Abstracts on CD-ROM, v.3A, 1990-91.

TEMIZ, A.I. Composition and characteristics of honeys from the Izmir region, and effects of different storage methods. Ege Bolge Zirai Arastirma Enstitusu Yayinlari, Berlin, v. 31, n. 11, p.113, 1983. In: CAB Abstracts on CD-ROM, 1984-86. 
TERRAB, A.; GONZALEZ, A.G.; DIEZ, M.J.; HEREDIA, F.J. Mineral content and electrical conductivity of the honeys produced in Northwest Morocco and their contribution to the caracterisation of unifloral honeys. Journal of the Science of Food and Agriculture, Chichester, v. 83, n.7, p. 637-643, 2003.

TERRAB, A.; ESCUDERO, M.L.; GONZALEZ, M.M.L.; HEREDIA, F.J. Colour characteristics of honeys as influenced by pollen grain content: a multivariate study. Journal of the Science of Food and Agriculture, Chichester, v.84, n.4, p.380-386, 2004.

THRASYVOULOU, A.T. The use of HMF and diastase as criteria of quality of greek honey. Journal of Apicultural Research, Cardiff, v. 25, n. 3, 186-195, 1986.

THRASYVOULOU, A.; MANIKIS, J.; TSELIOS, D. Liquefying crystallized honey with ultrasonic waves. Apidologie, Les Ulis, v. 25, n. 3, p. 297-302, 1994.

THRASYVOULOU, A.; MANIKIS, J. Some physiochemical and microscopic characteristics of Greek unifloral honeys. Apidologie, Les Ulis, v. 26, n. 4, p. 441-452, 1995.

TILMAN, D. Biodiversity: population versus ecosystem stability. Ecology, Washington, v.77, n.2, p.350-363, 1996.

TUVERI, F.; PROSPERI, S. Contributo alla conoscenza del miele prodotto in Sardegna. Industrie Alimentari, Pinerolo, v. 24, n. 3, p.259-262, Mar. 1985.

UNATES, M.A.; AGUILAR, A.B.; PIOLA, H.D.; STURNIOLO, H.L.; AGUILAR, G.; PEDERNERA, M.M. Estudio físico-químico de mieles de la provincia de San Luis-República Argentina. Archivos Latinoamericanos de Nutrición, Caracas, v. 49, n. 2, p. 193-196, 1999.

VANSELL, G.H.; GRIGGS, W.H. Honeybees as agents of polination. Yearbook of Agriculture USDA, Washington, p. 88-107, 1952.

VERÍSSIMO, M.T.L. Saiba o que é o HMF. Apicultura no Brasil, São Paulo, v. 4, n. 24, p.31, 1988.

VERMEULEN, L.; PELERENTS, C. Suiker, fosfor en ijzerghalte van Belgische Honing. Medeldelingen-Rijksfakulteit-Landbouwwetenschappen-Gent., Ghent., v. 30, n. 2, p. 527$541,1965$. 
VIDAL, R.; FREGOSI, E.V. Mel: características, análises físico-químicas, adulterações e transformações. Barretos: Instituto Tecnológico Científico "Roberto Rios", 1984. 95p.

VIEIRA, G.H.C. Análise faunística de abelhas (hymenoptera: apoidea) e tipificação dos méis produzidos por Apis mellifera l., em área de cerrado no município de Cassilândia/MS. 2005. 97 p. Tese (Doutorado em Entomologia) - Escola Superior de Agricultura "Luiz de Queiróz", Piracicaba, Universidade de São Paulo, Piracicaba, 2005.

VILLAMIEL, M.; DEL CASTILHO, M.D.; CORZO, N.; OLANO, A. Presence of furosine in honeys. Journal of the Science of Food and Agriculture, Chichester, v. 81, n. 8, p. 790-793, 2001 .

VIT, P. Physical-chemical characteristics of commercial honeys from Venezuela. In: AUSTRALIAN AND INTERNATIONAL BEEKEEPING CONGRESS, 2., 1988. Beekeeping, 2000. Proceedings ... Queensland: International Colour, 1988, p.227-228. In: Apicultural Abstracts, Cardiff, v.42, n.2, p.168, 1991.

VIT-OLIVER, P.; MARTORELLI, I.G.; PALACIOS, S.L. Clasificación de mieles comerciales venezolanas. Archivos Latinoamericanos de Nutrición, Caracas, v. 44, n. 1, p. 39-44, 1994.

VIVINO, A.E; PALMER, L.S. The chemical composition and nutritional value of polens collected by bees. Archives of Insect Biochemistry and Physiology, New York, v.4: 129-136. 1944.

VON DER OHE, W.; PERSANO-ODDO, L.; PIANA, L.M; MORLOT, M.; MARTIN, P. Harmonized methods of melissopalynology. Apidologie, Les Ulis, v.35, p.S18-S35, 2004.

WHITE, J.W. Jr. A survey of American honeys. 7. Relation of color to composition. Bee Culture, Medina, v. 89, p. 292-293, 1961.

WHITE, J. R. Jr. Honey. In: . The hive and honeybee. Hamilton: Dadant, 1976. p.491530.

WHITE, J.W. Jr. Honey. Advances in Food Research, Davis, v. 22. p. 287-374, 1978.

WHITE, J.W. Jr. Methods for determinung carbohydrates, hydroxymetilhyfurfural and proline in honey; Collaborative study. Journal of the Association of Official Analytical Chemists, Bethesda,. v. 62, n. 3, p.515-526, 1979. 
WHITE, J.W. Jr. Hydroxymethylfurfural content of honey as na indicator of its adulteratino wiht invert sugars. Bee World, Cardiff, v.61, n. 1, p. 29-37, 1980.

WHITE, J.W. Jr. Quality evaluation of honey: role of HMF and diastase assays. American Bee Journal, Navasota, v.13, n.11-12 p.737-742, 1992.

WHITE, J.W. Jr. Quality evaluation of honey: role of HMF and diastase assays. Part II. American Bee Journal, Hamilton, v. 132, n. 12, p. 792-794, 1992.

WHITE, J.W. Jr.; RUDYJ, O.N. The protein content of honey. Journal of Apicultural Research, Cardiff, v. 17 n. 4, p. 234-244, 1978.

WIESE, H. (Coord.). Nova apicultura. 3.ed. Porto Alegre: Agropecuária, 1982. 485 p.

WIESE, H. (Coord.) Nova apicultura. 6.ed. Porto Alegre: Agropecuária, 1985. 491 p.

WINSTON, M.L. The biology of the honey bee. Cambridge: Harvard University Press, 1987. $281 \mathrm{p}$.

WINSTON, M.L. A biologia da abelha. Tradução de C.A. Osowski. Porto Alegre: Magister, 2003. $276 \mathrm{p}$.

WOOTON, M.; RYALL, L. A comparison of Codex Alimentarius Commission and HPLC methods for 5-hidroxymethyl-2-furaldehyde determination in honey. Journal of Apicultural Research, Cardiff, v. 24, n. 2, p.120-124, 1975.

YEBOAH-GYAN, K.; MARFO, E.K. The colour and mineral composition of honeys produced in major vegetation áreas of Ghana. Journal of Apicultural Research, Cardiff, v. 37, n. 2, p. 7984. 1998. 
ANEXOS 
Anexo A - Imagens dos tipos polínicos e/ou espécies botânicas dos pólens (aumento de 40x), classificados como dominantes e/ou acessórios, encontrados nas lâminas das amostras de mel coletadas nas colmeias instaladas em área de cerrado do município de Itirapina, Estado de São Paulo, entre os meses de dezembro/2004 a novembro/2005

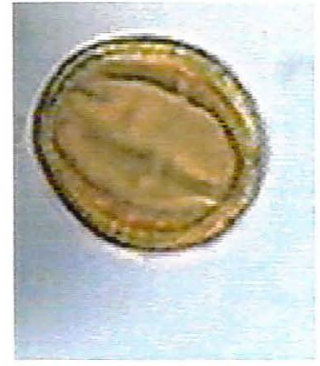

Rutaceae

Citrus sp.

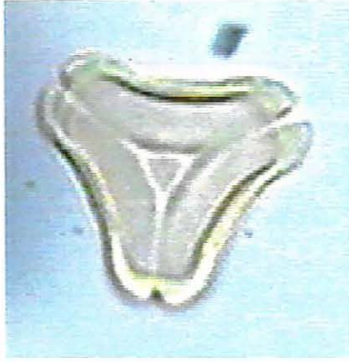

Myrtaceae

Eucalyptus sp.

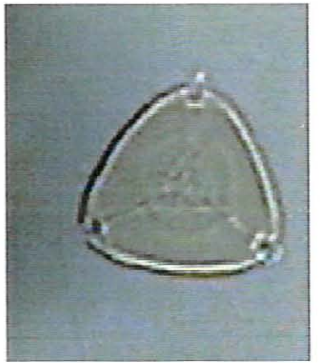

Myrtaceae

Tipo Myrcia

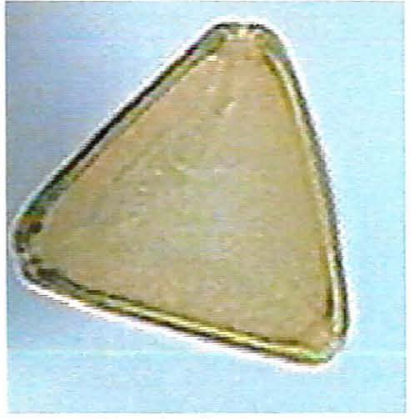

Sapindaceae

Serjania sp.

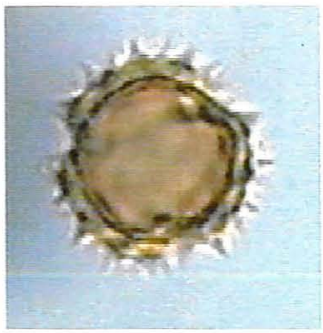

Asteraceae Tipo Asteraceae 
Anexo B - Imagens dos tipos polínicos e/ou espécies botânicas dos pólens (aumento 40x), classificados como dominantes e/ou acessórios, encontrados nas lâminas das amostras de pólen provenientes dos coletores instalados nas colmeias, em área de cerrado do município de Itirapina, Estado de São Paulo, entre os meses de dezembro/2004 a novembro/2005

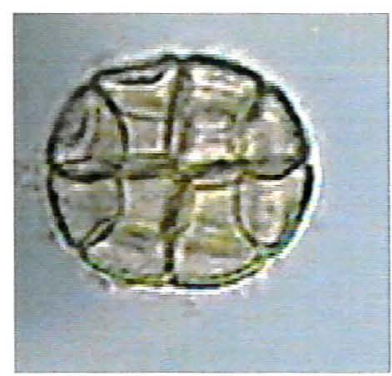

Mimosaceae Anadenanthera sp.

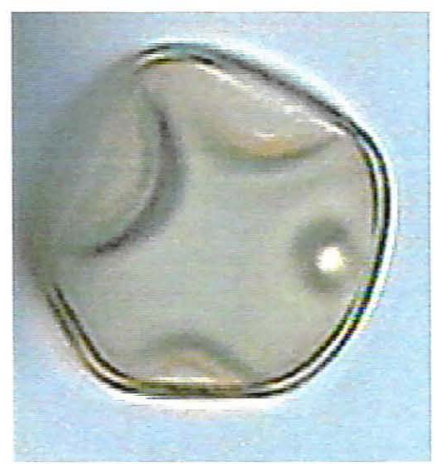

Poaceae

Tipo Poaceae

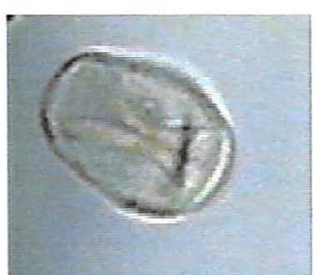

Araceae

Philodendron sp.

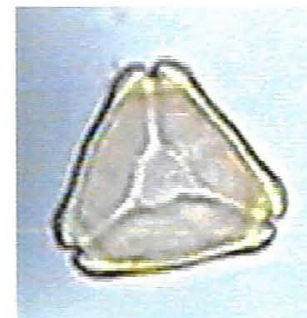

Myrtaceae

Eucalyptus sp.

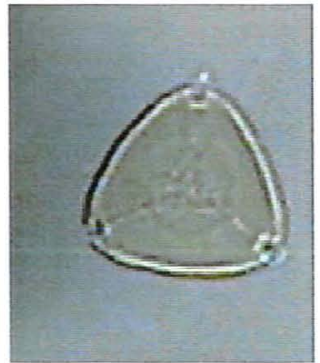

Myrtaceae

Tipo Myrcia

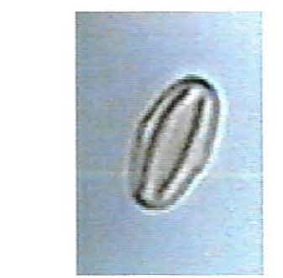

Melastomataceae Miconia sp.

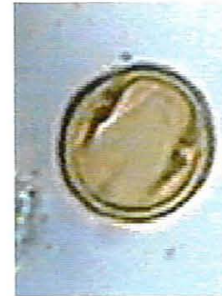

Euphorbiaceae

Tipo Euphorbiaceae

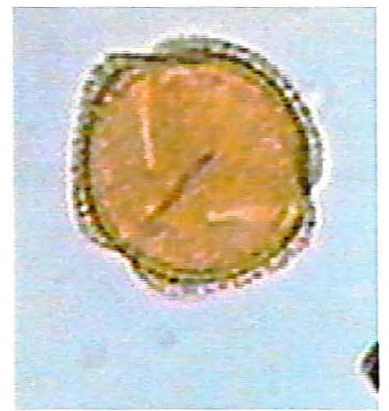

Araliaceae

Didymopanax sp.

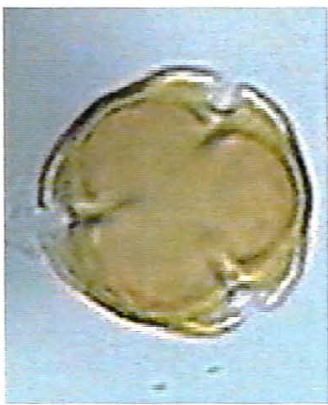

Fabaceae

Tipo Fabacea

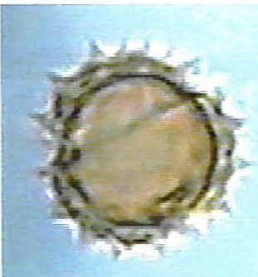

Asteraceae

Eupatorium sp.

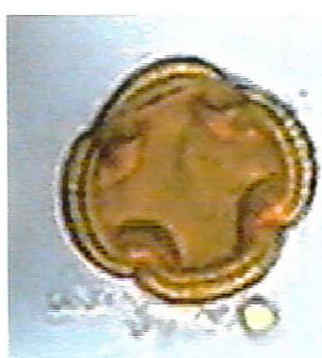

Rutaceae

Citrus sp. 